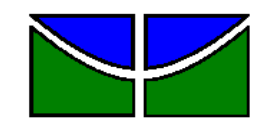

\author{
Universidade de Brasília \\ Faculdade de Medicina \\ Núcleo de Medicina Tropical
}

Programa de Pós-Graduação em Medicina Tropical

Camile de Moraes

Doença meningocócica no Brasil: descrição de casos, evidência da efetividade e do impacto da vacina anti-meningocócica conjugada sorogrupo C, $2001-2013$

Brasília

2016 


\section{CAMILE DE MORAES}

Doença meningocócica no Brasil: descrição de casos, evidência da efetividade e do impacto da vacina anti-meningocócica conjugada sorogrupo C, $2001-2013$

Tese apresentada ao Programa de PósGraduação em Medicinal Tropical, Faculdade de Medicina, Universidade de Brasília, para obtenção do título de Doutor em Medicina Tropical.

Área de concentração: Epidemiologia e Controle das Doenças Infecciosas e Parasitárias.

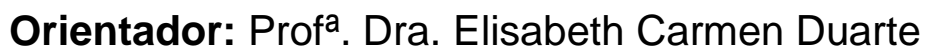

Co-orientador: Profó. Dr. José Cassio de Moraes

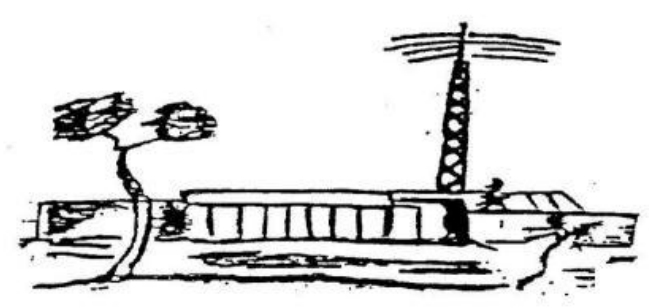

Brasília 
Ficha catalográfica elaborada automaticamente, com os dados fornecidos pelo(a) autor(a)

Noraes, Camile de

Doença meningoc6cica no Brasil: descrição de casos, evidencia da efetividade e do impacto da vacina anti meningoc6cica conjugada sorogrupo C, 2001 - 2013 / Camile de Moraes; orientador Blisabeth Carmen Duarte; co-orientador José Cásaio de Moraea. -Brasilia, 2016.

$146 \mathrm{p}$.

Tese (Doutorado - Doutorado em Medicina Tropical) -- Universidade de Brasilia, 2016.

1. Neisseria meningitidis. 2. Doença meningoc6cica 3. Vacina meningoc6cica C conjugada. 4. Impacto. 5. Efetividade. I. Duarte, Bliaabeth Carmen, orient. II. Moraes, José Cássio de, co-orient. III. Título. 


\section{BANCA EXAMINADORA}

Prof. Dra. Elisabeth Carmen Duarte

Faculdade de Medicina - Universidade de Brasília

Presidente

Prof. Dr. Eduardo Hage Carmo

Secretaria de Vigilância em Saúde - Ministério da Saúde

Membro

Prof. Dr. Marco Aurélio Palazzi Sáfadi

Faculdade de Ciências Médicas da Santa Casa de São Paulo

Membro

Prof. Dra. Marilia Miranda Forte Gomes

Faculdade do Gama - Universidade de Brasília

Membro

Prof. Dr. Wildo Navegantes de Araújo

Faculdade de Ceilândia - Universidade de Brasília

Membro

Prof. Dra. Maria Regina Fernandes de Oliveira

Faculdade de Medicina - Universidade de Brasília

Suplente

Data de defesa: 04 de outubro de 2016 . 


\section{DEDICATÓRIA}

Aos meus amados pais Guido e Miriam que sempre me apoiaram e permitiram que eu alçasse asas rumo aos meus sonhos. 


\section{AGRADECIMENTOS}

Ao meu companheiro de vida Alessandro, pelo amor, força e apoio para levar a vida adiante e não desistir.

A Julia, minha filha amada, por fazer parte da minha vida e me fazer uma pessoa melhor a cada dia.

Aos meus pais Guido e Miriam por sempre acreditarem que é possível.

As minhas irmãs, Carina e Giovana, por sempre me apoiarem e cuidarem de $\operatorname{mim}$.

Aos coordenadores da Coordenação Geral de Doenças Transmissíveis/SVS/MS pela autorização e liberação para realizar este estudo.

Aos colegas de trabalho, em especial a Camila Portela e a Indianara Grando.

Aos profs. da Pós-Graduação em Medicina Tropical pelos ensinamentos, em especial ao prof. Dr. Gustavo Romero.

A Lucia, secretaria do PPG em Medicina Tropical, pela ajuda na resolução dos problemas.

Ao prof. Dr. José Cassio por compartilhar seus conhecimentos e aceitar a co-orientação neste trabalho.

A prof $^{\mathrm{a}}$ Elisabeth Carmen Duarte que me acolheu e orientou com toda paciência e humanidade. Para você Beth, meu eterno agradecimento! 


\section{LISTA DE ABREVIAÇÕES}

DM

DMC

DMB

MM

MCC

MenC

PNI

MS

SNVEM

Sinan

Sinasc

IBGE

Lacen
Doença menigocócica

Doença meningocócica sorogrupo C

Doença meningocócica sorogrupo B

Meningite meningocócica

Meningococcemia

Vacina meningocócica $\mathrm{C}$ conjugada

Programa Nacional de Imunizações

Ministério da Saúde

Sistema nacional de vigilância epidemiológica das meningites

Sistema de Informação de Agravos de Notificação

Sistema de Informação de Nascidos Vivos

Instituto Brasileiro de Geografia e Estatística

Laboratório estadual de saúde pública 


\section{LISTA DE TABELAS}

Artigo 1: Distribuição geográfica e temporal da doença meningocócica com ênfase na Neisseria meningitidis sorogrupo C. Brasil, 2001-2013.

Tabela 1 Número de casos e óbitos, taxas de incidência, mortalidade 36

e letalidade de doença meningocócica total, a as causadas pelo sorogrupo C e sorogrupo B. Brasil, 2001 a 2013.

Tabela 2 Taxa de incidência e de letalidade da doença 42 meningocócica sorogrupo C por faixa etária. Brasil, 2001 a 2013.

Artigo 2: Avaliação do impacto do programa de vacinação contra a doença meningocócica do sorogrupo C no Brasil e Regiões: estudo de base populacional - 2001-2013.

Tabela 1 Taxa de incidência da doença meningocócica sorogrupo C 68 por grupo etário e região de residência. Brasil, 2001-2013.

Tabela 2 Associação entre taxa de incidência de doença 70 meningocócica sorogrupo $\mathrm{C}$ e variáveis por grupo de idade. Brasil e Regiões, 2001-1013.

Tabela 3 Percentual de redução de casos estimado pelo modelo de 76 regressão para os menores de um ano e para o grupo de um a quatro anos de idade no Brasil e regiões nos três anos seguintes a introdução da vacina MenC. 
Artigo 3: Efetividade da vacina meningocócica conjugada C contra doença meningocócica do sorogrupo $\mathrm{C}$ em menores de cinco anos de idade no Brasil, 2011-2015.

Tabela 1 Características demográficas e clinicas da população de 100 estudo. Brasil, 2011 a 2015.

Tabela 2 Efetividade da vacina meningocócica C conjugada por 103 grupo de idade. Brasil, 2011 a 2015.

Tabela 3 Efetividade da vacina meningocócica C conjugada em 104 menores de cinco anos de idade por ano. Brasil, 2011 a 2015.

\section{LISTA DE FIGURAS}

Artigo 1: Distribuição geográfica e temporal da doença meningocócica com ênfase na Neisseria meningitidis sorogrupo C. Brasil, 2001-2013.

Figura 1 Taxa de incidência de doença meningocócica por sorogrupo. 38 Brasil, 2001 a 2103.

Figura 2 Taxa de incidência de doença meningocócica sorogrupo C por 39 região. Brasil, 2001 a 2103.

Figura 3 Taxa de incidência de doença meningocócica sorogrupo B por 40 região. Brasil, 2001 a 2103.

Figura 4 Distribuição proporcional dos casos de doença meningocócica 43 do sorogrupo C nos períodos anterior (2001-2010) e posterior (20112013) a vacinação, segundo idade (0-11 meses). Brasil, 2001 a 2103. 
Artigo 2: Avaliação do impacto do programa de vacinação contra a doença meningocócica do sorogrupo C no Brasil e Regiões: estudo de base populacional - 2001-2013.

Figura 1 Descrição dos casos confirmados de doença meningocócica 64 por sorogrupo. Brasil, 2001-2013.

Figura 2 Taxas de incidência de doença meningocócica com e sem 66 redistribuição de casos por trimestre e ano de inicio de sintomas. Brasil, 2001-2013.

Figura 3 Reduções médias das taxas de incidência de doença 72 meningocócica sorogrupo $C^{*}$ por faixa etária após a introdução da vacina. Brasil, 2010 a 2013.

Artigo 3: Efetividade da vacina meningocócica conjugada C contra doença meningocócica do sorogrupo $\mathrm{C}$ em menores de cinco anos de idade no Brasil, 2011-2015.

Figura 1 Fluxograma de seleção dos casos de Doença 98 Meningocócica (DM) para o estudo (casos=casos confirmados do sorogrupo C; controles=casos confirmados de outros sorogrupos). 


\section{ÍNDICE}

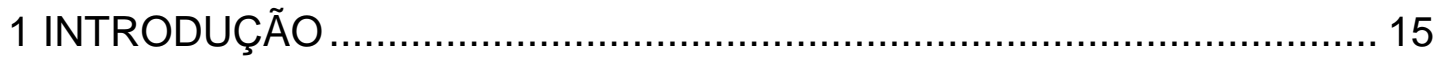

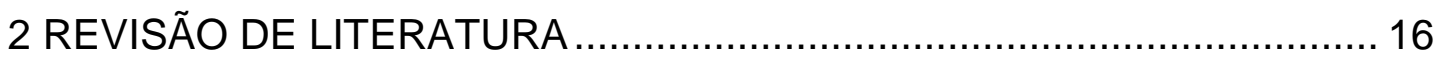

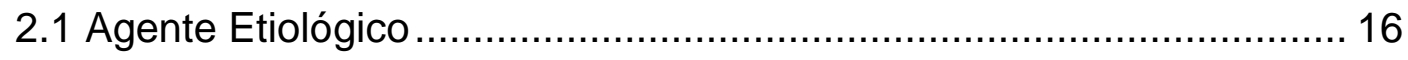

2.2 Transmissão e estado de portador ................................................. 18

2.3 Patogenia e manifestações clínicas .................................................... 19

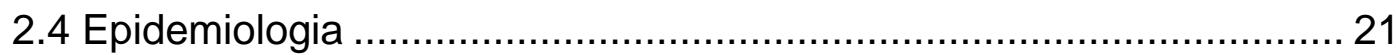

2.5 A vacina como forma de prevenção e controle .................................. 26

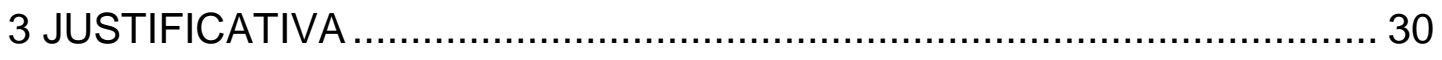

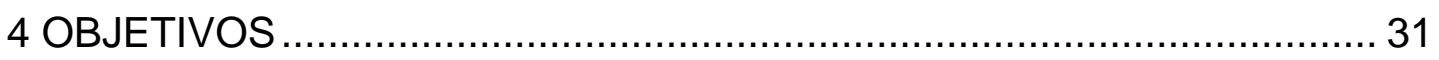

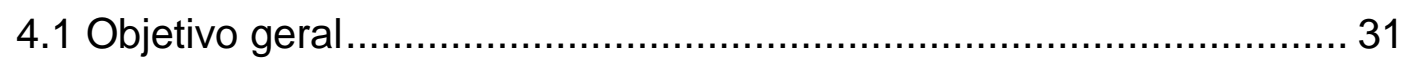

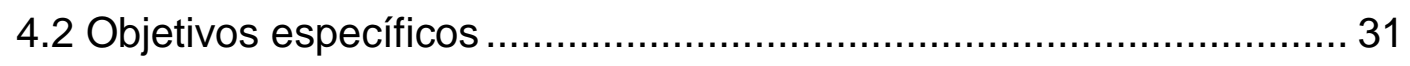

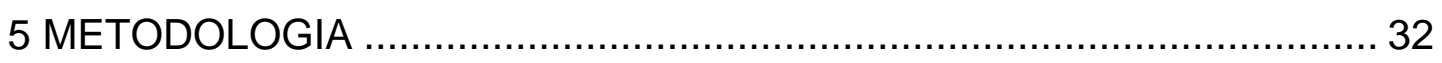

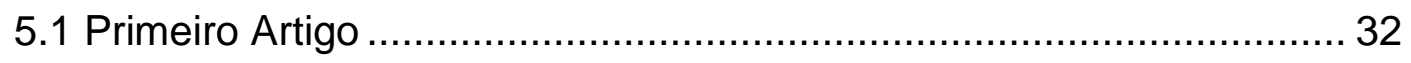

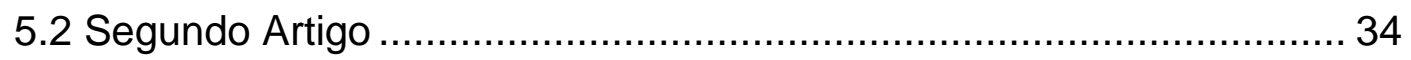

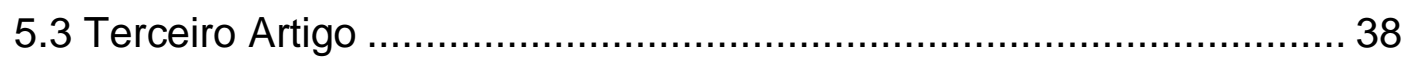

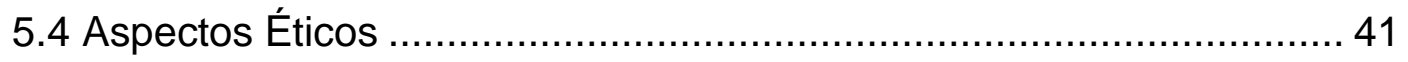

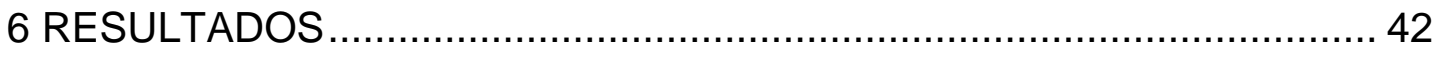

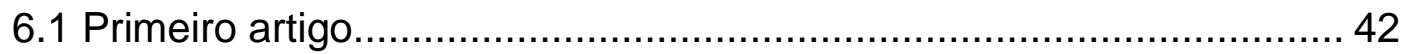

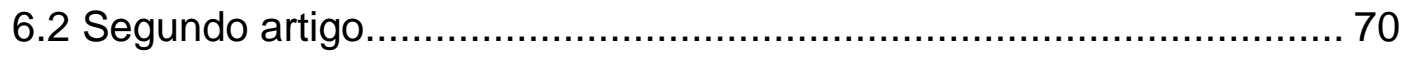

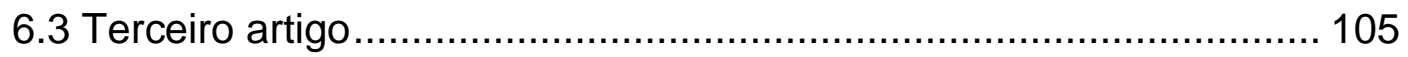

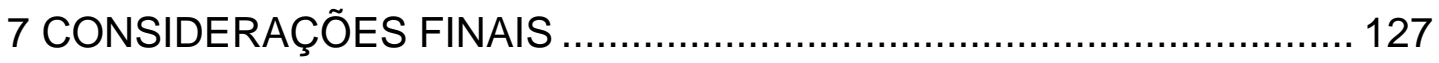

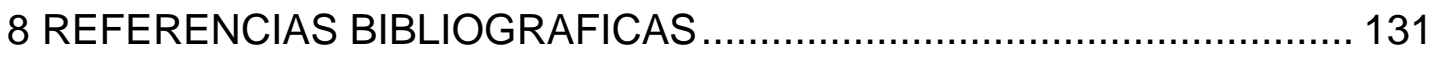




\section{Resumo}

Introdução: A doença meningocócica (DM) é importante causa de morbidade e mortalidade em todo mundo. No Brasil, a doença tem caráter endêmico com ocorrência eventual de períodos epidêmicos. A vacina meningocócica $\mathrm{C}$ conjugada (MenC) foi incluída no calendário de vacinação da criança do Programa Nacional de Imunizações em 2010. Objetivos: Descrever a ocorrência da DM no Brasil e avaliar o impacto e a efetividade da vacina MenC, no período de 2001 a 2013. Métodos: Foram realizados três estudos: i) estudo descritivo utilizando os casos confirmados de DM registrados no sistema de informação de agravos de notificação (Sinan) entre 2001-2013; ii) estudo observacional ecológico misto, analítico, com análise de séries temporais baseada em dados de painéis utilizando os casos confirmados de DM registrados no Sinan entre 2001-2013; iii) estudo caso-controle não pareado para estimar a efetividade da vacina em crianças menores de cinco anos registradas como casos confirmados de DM no Sinan entre 2011-2015. Resultados: Ocorreu uma importante elevação das taxas de incidência (de 0,19 para 0,62 casos/100.000 habitantes), de mortalidade $(0,02$ para 0,13 óbitos/100.000 habitantes) e de letalidade $(10,6$ para $21,8 \%$ ) da DM sorogrupo C entre 2001 e 2010, respectivamente. Nos três anos seguintes à introdução da vacina foi observada redução nas taxas de incidência da DM sorogrupo $C$ para as crianças menores de um ano (65,2\%; IC95\%: 20,5\%, $84,7 \%)$ e de um a quatro anos de idade $(46,9 \%$; IC95\%: 14,6\%, 79,1\%). O impacto estimado da vacinação variou de $83,7 \%$ 
(IC95\%: 51,1\%, 100,0\%) na região Centro-Oeste a 56,7\% (IC95\%: 37,4\%, $76,0 \%)$ na região Nordeste. A efetividade da vacina MenC para os menores de cinco anos foi de $89,3 \%$ (IC95\%: 83,3 a 93,1; $p<0,001$ ), e para os menores de um ano de idade foi de 93,0\% (IC95\%: 85,4 a 96,6; $\mathrm{p}<0,001$ ). Conclusão: Ocorreu aumento expressivo da DM sorogrupo C no período de estudo, em especial até o ano de 2010. A vacina MenC demonstrou ter impacto na redução das taxas de incidência para as crianças menores de um ano de idade, em todas as regiões analisadas, bem como no grupo etário de um a quatro anos de idade. A vacina MenC apresentou ainda alta efetividade no contexto brasileiro entre crianças menores de cinco anos. Mesmo assim, acreditamos que há espaço para melhorar a estratégia de vacinação adotada no Brasil. Ações voltadas para melhoria do diagnóstico laboratorial, assistência aos pacientes, e avaliações das ações de imunização são de fundamental importância para o aprimoramento do controle da doença no país.

Palavras chaves: doença meningocócica, vacina conjugada sorogrupo C, impacto, efetividade, Brasil. 


\section{Abstract}

Introduction: Meningococcal disease (MD) is important cause of morbidity and mortality worldwide. In Brazil, MD is endemic with occurrence of epidemic periods. Meningococcal C conjugate (MenC) vaccine was included in the routine vaccination schedule for infants and children of the National Immunizations Program in 2010. Objectives: Describe MD in Brazil, evaluate the MenC vaccine impact and effectiveness, from 2001 to 2013. Methods: Three studies were performed: i) descriptive study of MD confirmed cases using the Notifiable Diseases Information System (Sinan) from 2001-2013; ii) observational, mixed ecological, analytical study with time series analysis based on panel data, using MD confirmed cases registered in Sinan from 2001-2013; iii) unmatched case-control study to estimate MenC vaccine effectiveness in children under five years recorded as confirmed cases in Sinan from 2011 - 2015. Results: During the study period, until 2010, there was an increase in MD serogroup C incidence (0.19 to 0.62 cases/100,000), mortality $(0.02$ to 0.13 death/100,000) and case-fatality rates (CFR) (10.6 to $21.8 \%$ ). For the three years following the vaccine implementation, a reduction was observed in MD incidence rate in children aged $<1$ year $(65.2 \% ; 95 \% \mathrm{Cl}: 20.5 \%, 84.7 \%)$ and $1-4$ years old $(46.9 \%$; $95 \% \mathrm{Cl}: 14.6 \%, 79.1 \%)$. The estimated impact of the vaccine on MDC incidence reduction ranged from $83.7 \%(95 \% \mathrm{Cl}: 51.1,100.0)$ in the Midwest region to $56.7 \%(95 \% \mathrm{Cl}: 37.4,76.0)$ in the Northeast region. MenC vaccine effectiveness was $89.3 \%(95 \% \mathrm{Cl}: 83.3,93.1 ; P<0,001)$ for children under five 
years and $93.0 \%(95 \% \mathrm{Cl}: 85.4,96,6 ; P<0,001)$ for children under one year. Conclusions: There was a significant increase in MD serogroup $C$ rates during the study period, especially until 2010. MenC vaccine had impact on the population of children aged $<1$ year old in all the regions and also had a relevant effect on children 1-4 years old. MenC also presented high effectiveness in the Brazilian context in children $<5$ years old. Even so, we believe there is still room for improving the vaccination strategy adopted in Brazil. Actions targeting the improvement of laboratory diagnosis, patient care and immunization campaigns assessment are crucial for the improvement of meningococcal disease control.

Key words: meningococcal disease, serogroup $C$ conjugate vaccine, impact and effectiveness vaccine evaluation, Brazil. 


\section{INTRODUÇÃo}

A doença meningocócica (DM) é uma importante causa de morbidade e mortalidade, ocorre de forma endêmica em praticamente todo o mundo e assume com certa frequência caráter epidêmico. Existem diferenças geográficas marcantes na sua incidência e na distribuição de sorogrupos causadores de doença (Harrison et al. 2009; Halperin et al. 2012).

No Brasil, a DM é endêmica, com ocorrência esporádica de surtos. O meningococo é a principal causa de meningite bacteriana. Os coeficientes de incidência da DM têm reduzido, permanecendo em torno de 1,0 a 1,5 casos/100.000 habitantes, nos últimos cinco anos. Acomete indivíduos de todas as faixas etárias, porém aproximadamente $40 \%$ dos casos notificados no período pré-vacina ocorriam em crianças menores de cinco anos de idade. Entretanto, os maiores coeficientes de incidência da doença ainda são observados no primeiro ano de vida. A letalidade da doença no Brasil é bastante elevada, situando-se em torno de 20\% (Secretaria de Vigilância em Saúde/MS, 2015). Desde a década de 1990 os sorogrupos causadores de DM prevalentes no Brasil são o B e C. A partir de 2006/2007 o principal sorogrupo causador de doença é o C (Guia de Vigilância em Saúde, 2014).

Algumas das características da DM, como sua rápida evolução, gravidade e letalidade, assim como seu potencial caráter epidêmico, fazem com que a possibilidade de prevenção dessa infecção por meio de vacinas assuma fundamental importância (Safadi et al., 2012). 
A implantação da vacina MenC em diferentes países do mundo foi um marco para o controle da DM e muitos estudos que estimaram o impacto e a efetividade foram conduzidos, particularmente, em Países Europeus e da América do Norte (Larrauri et al. 2005; Trotter \& Ramsay 2007; Bettinger et al. 2009).

No Brasil, a redução das taxas de incidência e mortalidade foi observada logo após sua introdução no Programa Nacional de Imunização (PNI/MS), que ocorreu em meados de 2010 (Ministério da Saúde, 2013). No entanto, poucos estudos que avaliassem o impacto e efetividade desta intervenção foram realizados até o momento (Cardoso et al. 2012, 2015; Tauil et al. 2014).

\section{REVISÃO DE LITERATURA}

\subsection{Agente Etiológico}

A Neisseria meningitidis, conhecida como meningococo, é uma bactéria Gram-negativa, caracterizada morfologicamente como diplococo, membro da família Neisseriaceae (Caugant DA. 2008). O primeiro isolamento em cultura foi em 1887, por Weichselbaum, oitenta anos depois da primeira descrição da doença, que data do ano de 1805, pelo médico suíço Vieusseux (Rosenstein et al. 2001). 
A N. meningitidis é classificada em 12 diferentes sorogrupos: A, B, C, E, H, I, K, L, W, X, Y e Z, de acordo com a estrutura da cápsula polissacarídica (Harrison et al. 2013). Entretanto, somente os sorogrupos A, B, C, W e Y geralmente causam infecções invasivas (Harrison et al. 2009). Além disso, os meningococos são classificados em sorotipo, sorosubtipo e imunotipos, de acordo com as proteínas de membrana externa de classe 1 (PorA), de classe 2 ou 3 (PorB) e de lipo-oligossacarídeos, respectivamente (Rosenstein et al. 2001; Stephens et al. 2007).

Os meningococos também são caracterizados em linhagens hipervirulentas, por meio da tipagem molecular baseada em polimorfismos de genes constitutivos usando a técnica de Multilocus Sequence Typing MLST (Maiden et al. 1998). Para caracterização de cepas em situações de surtos outros métodos podem ser utilizados em conjunto com o MLST, como o sequenciamento de genes que codificam as proteínas da membrana externa, e a eletroforese de campo pulsado em gel (PFGE) (Harrison et al. 2009). Mais recentemente o sequenciamento do genoma total (wholegenome sequencing - WGS) vem sendo mais amplamente utilizado para a tipagem microbiana. Esta abordagem permite a identificação da bactéria de forma rápida, dos fatores de virulência, a caracterização de surtos, bem como o reconhecimento de genótipos de resistência antimicrobiana (Maiden \& Harrison 2016).

Os meningococos têm a capacidade de trocar o material genético responsável pela produção da cápsula e assim mudar de sorogrupo, como 
por exemplo, de B para C ou vice-versa (Rosenstein et al. 2001). A mudança de capsula é o mecanismo no qual $N$. meningitidis pode mudar seu fenótipo. Este fenômeno ocorre por transferência horizontal de genes, que é detectado por meio da identificação de cepas geneticamente relacionadas, mas que expressam cápsulas polissacarídicas diferentes (Harrison et al. 2009).

\subsection{Transmissão e estado de portador}

A transmissão da $N$. meningitidis ocorre por contato direto pessoa-apessoa ou por dispersão de gotículas respiratórias de uma pessoa infectada. Requer que o contato entre as pessoas seja próximo, pois os meningococos são particularmente sensíveis à desidratação, e sobrevivem muito pouco tempo no meio ambiente (Caugant DA. 2008).

É uma bactéria comensal obrigatoriamente humana, sendo a mucosa da orofaringe seu habitat. A colonização do trato respiratório pelo meningococo é um fenômeno referido como estado de portador. Quando representa um relacionamento comensal bem sucedido entre a bactéria e 0 hospedeiro, sem causar doença, é denominado estado de portador assintomático. Por outro lado, a doença ocorre quando há um desequilíbrio neste relacionamento (Caugant \& Maiden 2009). Por isso, a doença invasiva é considerada um resultado relativamente raro da infecção por $N$. 
meningitidis (Christensen et al. 2010). O período de tempo em que os indivíduos podem permanecer como portadores pode variar desde alguns dias a anos e finaliza naturalmente. Após este processo, o portador permanece suscetível a outro meningococo (Maiden \& Frosch 2012).

O estudo recente de Christensen e colaboradores demonstrou que 0 estado de portador não é linear, e a idade é o fator mais importante no estabelecimento da prevalência de portadores. O modelo estimou baixa prevalência em lactentes (4,5\%) que aumentou ao longo da infância, 7,7\% aos 10 anos, atingindo o pico de $23,7 \%$ aos 19 anos de idade. Nos adultos mais velhos a prevalência começa a diminuir $(13,1 \%$ aos 30 anos e $7,8 \%$ em menores de 50 anos). A alta taxa de prevalência de portadores em adolescentes pode ser atribuída a uma série de fatores, que incluem padrões de contato e comportamento social (Christensen et al. 2010).

\subsection{Patogenia e manifestações clínicas}

Ocasionalmente, logo após o início da colonização, a N. meningitidis pode atravessar a membrana da mucosa e acessar a corrente sanguínea. As bactérias que forem capazes de sobreviver e se multiplicar podem, então, cruzar as meninges e ter acesso ao fluido cérebro-espinhal (Caugant DA. 2008). A infecção invasiva pela N. meningitidis resulta em amplo espectro clínico de doença, que inclui principalmente a meningite e a meningococcemia, ou ambas as formas associadas. A meningite é a 
apresentação clínica mais comum da DM invasiva, ocorre em aproximadamente $60 \%$ dos casos, enquanto que a meningococcemia ocorre entre 5 e 20\%. A pneumonia meningocócica ocorre em cerca de 5 a $15 \%$ dos pacientes com doença invasiva. Muito menos frequente, outras síndromes são associadas com a doença meningocócica, incluindo conjuntivite, otite média, epiglotite, artrite, entre outras (Rosenstein et al. 2001).

A capacidade de causar DM invasiva depende de um conjunto de fatores, como falta de uma resposta imunológica adequada do hospedeiro, de fatores ambientais e da virulência da cepa (Stephens DS. 2009). Entre os fatores do hospedeiro destaca-se a ausência de anticorpos bactericidas contra a cepa infectante que é considerado o fator de predisposição mais importante para o desenvolvimento da doença (Caugant DA. 2008). Outros fatores genéticos, como os defeitos do sistema de complemento e polimorfismos em genes que codificam moléculas envolvidas em diferentes vias do sistema imunitário, foram associados com 0 aumento da susceptibilidade às infecções meningocócicas, e com a gravidade da doença (Rosenstein et al. 2001; Caugant DA. 2008). Além disso, alguns fatores ambientais podem prejudicar a integridade da mucosa da nasofaringe humana e aumentar o risco de ocorrência da DM invasiva, como exposição ao tabaco, a baixa umidade do ar e poeira, e coinfecções respiratórias (Stephens DS. 2009). Os principais fatores de virulência do microrganismo, que contribuem para a doença invasiva, são: o polissacarídeo capsular; as 
estruturas de superfície - como o pili; as proteínas de membrana externa (PorA, PorB, Opa, Opc) e o lipo-oligossacarideo (LOS); e o genótipo da cepa (Stephens DS. 2009).

\subsection{Epidemiologia}

A DM ocorre em todo o mundo, entretanto há diferenças regionais nas taxas de incidência e na distribuição dos sorogrupos. Uma característica marcante da $N$. meningitidis é a flutuação cíclica da doença e a ocorrência de surtos e epidemias (Harrison et al. 2009). Seis sorogrupos (A, B, C, W, X, Y) são responsáveis por virtualmente todos os casos de doença invasiva (Halperin et al. 2012), sendo o sorogrupos A, B e C, responsáveis pela maioria dos casos. O sorogrupo A ocorre na África e Ásia, os sorogrupos B e C predominam na Europa, Américas e Oceania.

Importante ressaltar que a natureza e a qualidade da vigilância realizada em determinado país ou região tem impacto direto na incidência reportada. Nem todos os países contam com vigilância ativa baseada na população, com casos clínicos confirmados por testes laboratoriais e caracterização de cepas. Em vez disso, são utilizadas combinações de vigilância sindrômica, vigilância ativa e passiva, vigilância sentinela e vigilância laboratorial, tornando difícil a comparação entre os diferentes 
locais, e impossível o cálculo da verdadeira incidência da doença (Halperin et al. 2012).

Nos Estados Unidos da América (EUA) a incidência da DM nas últimas décadas oscilou entre 0,5 e 1,5 casos por 100 mil habitantes, em ciclos de aproximadamente 10 anos. A incidência anual da DM tem diminuído de forma constante, chegando em 2009, a 0,28 casos por 100 mil habitantes - casos confirmados por cultura (Harrison et al. 2009; Halperin et al. 2012). No Canadá a epidemiologia da DM é bastante similar à observada nos EUA, com média anual de aproximadamente 1,0 caso por 100 mil habitantes (Harrison et al. 2009). As taxas de incidência mais elevadas são observadas em crianças menores de um ano, seguidas das de um a quatro anos, e dos adolescentes entre 15-19 anos de idade (Halperin et al. 2012).

$\mathrm{Na}$ maioria dos países europeus, a epidemiologia da DM é bem caracterizada (Harrison et al. 2009). A grande maioria dos casos é causada por cepas dos sorogrupos B e C. Em 2009, a incidência média de DM invasiva foi de 0,92 casos por 100 mil habitantes, com a Irlanda (3,4/100 mil) e Reino Unido (2,0/100 mil) relatando as taxas mais elevadas (Halperin et al. 2012). A taxa de letalidade em toda a Europa situa-se entre $6 \%$ e $8 \%$. A distribuição etária dos casos foi consistente em todos os países, com a incidência mais elevada em menores de um ano de idade. Alguns países relatam taxa de incidência mais elevada em adolescentes mais velhos (15 a 19 anos de idade). Os casos ocorrem durante todo o ano, com aumento nos meses de inverno (Harrison et al. 2009). A incidência global da doença 
diminuiu a partir de 1999, período onde vários países introduziram a vacinação de rotina contra DM do sorogrupo C, entre eles: Reino Unido (com introdução no ano de 1999), Irlanda (2000), Espanha (2000), Holanda (2002), Bélgica (2002), Islândia (2002), Portugal (2006), Grécia (2006) e Alemanha (2006) (Harrison et al. 2009; Halperin et al. 2012). Nos últimos anos, a proporção de casos de DM invasiva causada pelo sorogrupo $Y$ aumentou em vários países europeus, em particular nos países Escandinavos (com exceção da Dinamarca) e na Suécia (Pelton SI. 2016). A incidência do sorogrupo W também aumentou no Reino Unido desde 2009, sendo associado a $15 \%$ dos casos de DM em 2013/2014. Em resposta a este aumento foi recomendada a vacinação de adolescentes de 14 a 18 anos com a vacina quadrivalente conjugada sorogrupos ACWY (Pelton SI. 2016).

Na Austrália e Nova Zelândia, a epidemiologia da DM, em geral, segue o padrão observado em outras nações mais desenvolvidas. Entretanto, observam-se diferenças marcantes na circulação de sorogrupos entre estes países. Na Austrália, em 2000, a incidência de DM era de 3,0 casos por 100 mil. A partir de 2003, ano de introdução da vacina, a incidência diminuiu chegando a 1,3 casos por 100 mil em 2006. Neste país, a letalidade está em torno de 7\% (Harrison et al. 2009). Na Nova Zelândia, entre 1996 e 2003 ocorreu uma epidemia causada pelo sorogrupo B, que atingiu altas taxas de incidência (>13 casos por 100 mil), com mais da metade dos casos ocorrendo em crianças menores de cinco anos. Diante 
deste cenário, em 2004, foi desenvolvida uma vacina contra o sorogrupo B especifica para as cepas daquele país (MeNZB ${ }^{\mathrm{TM}}$ ) (Harrison et al. 2009; Halperin et al. 2012). O sorogrupo C é relativamente constante, com incidência de aproximadamente 0,5 casos por 100 mil habitantes em 2010 (Halperin et al. 2012).

A carga da doença meningocócica na Ásia é bem menos estudada. Mesmo assim, os dados disponíveis sugerem baixos níveis de endemia, e um padrão de surtos e epidemias pouco frequentes (Harrison et al. 2009; Halperin et al. 2012). A maioria das publicações é relacionada aos surtos, cuja principal causa é o sorogrupo A, como os registrados na Índia e nas Filipinas, em 2005. No Japão, Tailândia e Taiwan o sorogrupo B é a causa mais comum de doença (Harrison et al. 2009). Na China, no século XX, mais de $95 \%$ da DM eram devido ao sorogrupo A, com os sorogrupos B e C causando casos esporádicos. Na década de 1980, a taxa de incidência situava-se em torno de 0,2 a 1,0 por 100 mil. Em 2003, o número de casos de doença do sorogrupo $\mathrm{C}$ aumentou devido ao surgimento de uma nova linhagem hiperinvasiva (Harrison et al. 2009).

Os dados mais consistentes sobre a DM na África dizem respeito ao cinturão de meningite, que se estende do Senegal, no oeste do continente, até a Etiópia, no leste. Esta região apresenta as maiores incidências já observadas em qualquer outro lugar do mundo, com taxas anuais durante as epidemias excedendo 1.000 casos por 100 mil habitantes, predominantemente relacionadas ao sorogrupo A. As epidemias iniciam na 
estação seca e finalizam subitamente com o início da estação chuvosa. A taxa de letalidade varia entre 10\% e 15\% (Greenwood B. 2006; Harrison et al. 2009). Em 2013, o número de casos foram os mais baixos registrados durante a temporada de epidemia nos últimos 10 anos. A redução do número de casos foi relacionada com a vacinação contra o sorogrupo $A$ (MenAfriVac ${ }^{\mathrm{TM}}$ ) a partir de 2010 (OMS 2013). Mais recentemente, outros sorogrupos emergiram como importante causa de epidemia, a exemplo do sorogrupo W no Niger (Collard et al. 2013) e em Burkina Faso (MacNeil et al. 2014). Em 2015, o sorogrupo C foi responsável por um surto no Niger de características sem precedentes (OMS 2015).

Na América Latina, a incidência da DM varia entre $<0,1$ a 2 casos por 100 mil habitantes, no México e Brasil, respectivamente. As crianças menores de um ano apresentam as taxas mais elevadas. A letalidade varia de 10 a 20\%. A maioria dos casos é esporádica, com ocorrência de surtos sazonais, que ocorrem em intervalos irregulares. Os sorogrupos B e C são responsáveis pela maioria dos casos. No Uruguai e em países da América Central e do Caribe a maioria dos casos é causada pelo sorogrupo B. $\mathrm{Na}$ Argentina e Chile o sorogrupo mais prevalente é o W. Além disso, o sorogrupo Y foi observado na Colômbia e Venezuela (Safadi e Cintra 2010; Safadi et al. 2013).

No Brasil, a DM é endêmica com ocorrência esporádica de surtos em vários municípios. Os primeiros relatos da DM datam do início do século XX, nas cidades de São Paulo e Rio de Janeiro, onde em 1920 ocorrem as 
primeiras epidemias registradas no país (Barroso D. 2000; Moraes e Barata 2005). Em São Paulo, a incidência aumentou 8,5 vezes e atingiu o pico em 1923 com taxa 12 vezes maior do que a média no período endêmico. Metade dos casos foi causada pelo sorogrupo A e $25 \%$ pelo sorogrupo C (Moraes e Barata, 2005). A segunda onda epidêmica em São Paulo ocorreu entre 1945 e 1952, esta epidemia foi causada por cepas do sorogrupo A (Barroso D. 2000; Moraes e Barata 2005). A terceira e maior epidemia registrada no Brasil iniciou em abril de 1971 com predomínio do sorogrupo C. A incidência no município de São Paulo foi de mais de 100 casos por 100 mil habitantes. Em 1974, sem que as taxas de incidência do sorogrupo C tivessem retornado aos valores endêmicos, teve inicio outra epidemia, agora causada pelo sorogrupo A (Moraes e Barata 2005). Durante a década de 1980, a incidência da doença permaneceu baixa, com o sorogrupo B mais prevalente do que o C. Contudo, a partir de 1987, houve aumento constante no número de casos, que atingiu o seu pico em 1996, com epidemias atribuídas ao sorogrupo B em vários locais do país (Sáfadi e Cintra 2010). Desde a década de 1990 os sorogrupos prevalentes no Brasil são o B e o C.

\subsection{A vacina como forma de prevenção e controle}

A vacinação é considerada a forma mais efetiva na prevenção da DM. As vacinas meningocócicas são sorogrupo ou sorosubtipo específicas. 
Com relação ao sorogrupo $B$, as vacinas baseadas em proteínas de membrana externa, são sorosubtipos específicas, o que faz com que sejam usadas especificamente em situações de surtos. Já foram desenvolvidas em Cuba, Noruega e Nova Zelandia (Sáfadi e Barros 2006; WHO 2011). Mais recentemente duas vacinas contra o sorogrupo B tem sido utilizadas em diversos países, MenB-FHbp (Trumenba) e MenB-4C (Bexsero) (American Academy of Pediatrics. 2016). No Brasil, somente a ultima está licenciada para uso desde 2015.

Para os outros sorogrupos, existem as vacinas polissacarídicas e as polissacaridicas conjugadas a proteínas. Embora os antígenos capsulares purificados estimulem resposta de anticorpos, as vacinas de polissacarideos conjugados são mais imunogênicas e induzem memória imunológica. Ambas as vacinas estão disponíveis contra o meningococo dos sorogrupos $\mathrm{A}, \mathrm{C}, \mathrm{W}$ e Y (WHO 2011).

As vacinas polissacarídicas não conjugadas podem ser bivalentes ( $A$, $C)$, trivalentes $(A, C, W)$ ou quadrivalentes $(A, C, W, Y)$. Estas vacinas não geram resposta imune adequada em crianças menores de dois de idade em função da ausência de resposta consistente a antígenos $T$ independentes nesta faixa etária. Além disso, mesmo em adultos, a proteção conferida tem curta duração, pois não são capazes de induzir resposta imunologica adequada (Tan et al. 2010; WHO 2011). Adicionalmente, podem induzir hiporresponsividade em doses subsequentes (dose requerida a cada 3 a 5 anos) (Tan et al. 2010). Isso faz com que essas vacinas não sejam usadas 
na rotina, e sim indicadas apenas para grupos de alto risco ou em presença de surtos ou epidemias (Safadi et al. 2012).

As vacinas polissacarídicas conjugadas a proteínas podem ser monovalentes (sorogrupos $A$ ou C), ou quadrivalentes (A, C, W, Y). Também há uma combinação entre Haemophilus influenzae sorotipo b e $N$. meningitidis sorogrupo C (HibMenC) (WHO 2011). A conjugação dos polissacarídeos às proteínas carreadoras (toxina diftérica mutante atóxica CRM197 - ou toxóide tetânico) leva para uma resposta T dependente, propiciando uma excelente resposta imunológica de duração prolongada, inclusive em lactentes (Tan et al. 2010; Safadi et al. 2012). Além disso, foi observado que a vacina meningocócica $C$ conjugada (MenC) era capaz de reduzir a colonização do meningococo em nasofaringe, diminuindo dessa maneira o numero de portadores entre os vacinados, e consequentemente a transmissão da doença na população, resultando em imunidade indireta ou proteção de rebanho (Mainden et al. 2008; Kinlin et al. 2009).

O Reino Unido foi o primeiro país a introduzir a vacina MenC no seu programa de vacinação, em 1999. Resultados favoráveis foram observados já nos primeiros meses após o inicio da vacinação (Ramsay et al. 2001). A exemplo dos bons resultados observados naquele país, vários outros incluíram a vacina em seus programas de imunização, tais como, Espanha, Holanda, Bélgica, Portugal e Canadá (Larrauri et al. 2005; Trotter \& Ramsay 2007; Bettinger et al. 2009). 
Após alguns anos do uso da vacina, foi constatado declínio da efetividade, principalmente no grupo de crianças vacinadas em esquemas de rotina (Trotter et al. 2004; Larrauri et al. 2005). Também foi verificado que nos casos de falha vacinal, a DM sorogrupo $\mathrm{C}$ ocorreu mesmo na presença de memória imunológica, em consequência da doença estar associada a curtos períodos de incubação, destacando a importância da persistência de títulos de anticorpos protetores para a manutenção de proteção individual (Aukland et al. 2006). A partir destas e outras observações, foi incorporada uma dose de reforço após um ano de idade, a fim de garantir proteção a longo prazo aos lactentes imunizados no primeiro ano de vida (Campbell et al., 2010).

Estudos mais recentes avaliaram a persistência de títulos de anticorpos protetores (anticorpos bactericidas séricos) entre crianças e adolescentes que foram vacinados em diferentes idades e esquemas. Os resultados demonstraram que crianças que receberam a vacina em idades mais avançadas, por ex. entre 6-15 anos, mantiveram mais altas taxas de persistência de títulos de anticorpos protetores do que aquelas vacinadas em idades mais precoces (entre dois meses e seis anos) (Snape et al. 2008; Perrett et al. 2010). Ou seja, as vacinas MenC têm relação direta com a idade em que é aplicada. Essas evidências, de rápida perda de títulos de anticorpos protetores para as crianças imunizadas mais precocemente, sugerem que parte dessas crianças estará suscetível ao risco de estado de portador e doença ao entrar na adolescência (Safadi et al. 2012). 


\section{JUSTIFICATIVA}

Devido aos elevados coeficientes de incidência da DM sorogrupo C observados principalmente em lactentes e a ocorrência de vários surtos em diferentes regiões brasileiras, foi incluída no calendário de vacinação da criança do Programa Nacional de Imunizações (PNI/MS) a vacina MenC, a partir de meados de 2010 até início de 2011. O esquema preconizado foi de duas doses ( 3 e 5 meses) + um reforço (12-15 meses). As crianças entre 12 e 23 meses de idade receberam uma dose da vacina dentro do primeiro ano do inicio da vacinação (Ministério da Saúde 2010). Para um país das dimensões populacionais do Brasil, esta estratégia envolveu grande mobilização do setor saúde, incluindo custos operacionais de implantação e manutenção elevados.

Estudos de efetividade em outros países (Reino Unido, Canadá e Espanha) demonstraram os benefícios advindos dessa estratégia. Nesses países, além dos esquemas de rotina para os menores de um ano, foram usualmente incluídas campanhas catch-up para crianças maiores e adolescentes (Larrauri et al. 2005; Trotter \& Ramsay 2007; Bettinger et al. 2009).

Estudos no Brasil sobre a efetividade desta vacina são escassos e nenhum estudo nacional foi realizado com esse objetivo até o momento. Diante disso, observa-se a importância e a necessidade da avaliação formal da efetividade e impacto desta intervenção no Brasil. Este estudo foi 
realizado com o objetivo de caracterizar o perfil epidemiológico da doença, descrever sorogrupos circulantes, conhecer os efeitos da vacina sobre a faixa etária alvo, bem como na população em geral.

\section{OBJETIVOS}

\subsection{Objetivo geral}

- Descrever a ocorrência da doença meningocócica no Brasil e avaliar o impacto e a efetividade da vacina meningocócica C conjugada, no período de 2001 a 2013.

\subsection{Objetivos específicos}

- Descrever a distribuição geográfica e temporal da doença meningocócica com ênfase no sorogrupo C [Artigo 1];

- Avaliar o impacto da vacina sobre a incidência da DM sorogrupo C segundo regiões geográficas e grupos etários ajustando por tendências históricas e sazonais [Artigo 2];

- Estimar a efetividade da vacina sobre a DM sorogrupo C em menores de cinco anos [Artigo 3]. 


\section{METODOLOGIA}

\subsection{Primeiro Artigo}

Tipo de estudo, população e período

Foi realizado um estudo descritivo, considerando a série temporal e a distribuição nas regiões dos casos confirmados de DM que ocorreram e foram notificadas ao Sistema de Informação de Agravos de Notificação (Sinan), no Brasil, entre 2001 e 2013.

Fonte de dados

As bases populacionais utilizadas foram: Sistema de Informação de Nascidos Vivos (Sinasc) e as estimativas populacionais do Instituto Brasileiro de Geografia e Estatística (IBGE).

Os casos de DM incluídos no estudo foram os registrados no Sinan, oriundos do Sistema nacional de vigilância epidemiológica das meningites (SNVEM). No Brasil, todo caso de DM (suspeito ou confirmado) é de notificação compulsória e universal (oriundos de serviços públicos ou privados) e deve ser notificado às vigilâncias epidemiológicas municipais dentro de 24 horas, onde são incluídos no Sinan.

Definição de caso de DM confirmado adotada pelo SNVEM

Os casos confirmados são classificados como meningite meningocócica, meningococcemia, ou meningococcemia com meningite meningocócica (Brasil MS. 2014). 
Os critérios de diagnóstico considerados para confirmação de casos de DM são: cultura, detecção de DNA bacteriano por meio da reação em cadeia da polimerase - PCR, detecção de antígeno (aglutinação por látex e contra-imunoeletroforese), critério clínico-epidemiológico (quando é identificado contato próximo com caso confirmado por teste laboratorial), coloração de Gram, ou critério clínico (com presença de petéquias). O sorogrupo é determinado apenas para os casos de DM confirmados por cultura, PCR, deteç̧ão de antígeno e por critério clínico-epidemiológico. Quando o caso de DM é confirmado por coloração de Gram e por critério clínico, o sorogrupo não pode ser identificado (Brasil MS. 2014).

\section{Variáveis de estudo}

As variáveis utilizadas foram: idade, sexo, Unidade Federada de residência, data de primeiros sintomas, evolução do caso, exames realizados e sorogrupo. Para este estudo foi criada uma variável denominada como "outros" sorogrupos, que agregou os casos causados pelos sorogrupos $A, X, 29 E$ e NG.

\section{Análise de dados}

Para o cálculo das taxas de incidência e das taxas específicas de mortalidade foram utilizados como numerador os casos e os óbitos (respectivamente), todos confirmados de DM por qualquer sorogrupo e de DM por sorogrupo especifico. Como denominador, foi considerada a população do ano de referência. A taxa de letalidade foi calculada utilizando 
como numerador os óbitos de DM por qualquer sorogrupo e de DM por sorogrupo especifico e como denominador os casos de DM por qualquer sorogrupo e de DM por sorogrupo especifico. Esses indicadores foram analisados segundo ano de notificação, região de residência e idade do paciente.

A análise foi feita com auxilio dos softwares Microsoft Office Excel 2010 e Epilnfo versão 7.

\subsection{Segundo Artigo}

Tipo de estudo

Foi realizado um estudo observacional, ecológico misto (agregados no tempo e espaço) (Morgenstern H. 1995), analítico, com análise de séries temporais baseada em dados de painéis, ou seja, observações transversais em diferentes pontos no tempo (Hsiao C. 2007).

Fonte de dados

O banco de dados utilizado foi o Sistema de Informação de Agravos de Notificação (Sinan), no qual são registrados os casos de DM notificados ao sistema nacional de vigilância epidemiológica. No Brasil, a notificação dos casos de DM é compulsória (Brasil MS. 2014). 
As bases populacionais utilizadas foram: Sistema de Informação de Nascidos Vivos (Sinasc) e as estimativas populacionais do Instituto Brasileiro de Geografia e Estatística (IBGE).

População e período do estudo

Foram incluídos no estudo os casos confirmados de DM que ocorreram no Brasil entre 2001 e 2013 e foram notificados no Sinan. De acordo com o Guia de Vigilância em Saúde (Brasil MS. 2014), os casos notificados no Sinan são classificados como meningite meningocócica, meningococcemia, ou meningococcemia com meningite meningocócica.

Os critérios de diagnóstico considerados para confirmação de casos de DM são: cultura; detecção de DNA bacteriano por meio da reação em cadeia da polimerase - PCR; detecção de antígeno; critério clínicoepidemiológico (para caso com contato próximo com caso confirmado por teste laboratorial); coloração de Gram; ou critério clínico (com presença de petéquias). O sorogrupo é determinado apenas para os casos de DM confirmados por cultura, PCR, detecção de antígeno e por critério clínicoepidemiológico. Quando o caso de DM é confirmado por coloração de Gram e por critério clínico, o sorogrupo não é identificado (Brasil MS. 2014).

Os casos de DM sem identificação de sorogrupo foram redistribuídos de acordo com a proporção de casos com sorogrupo identificado na região de residência, faixa etária e o trimestre de início dos sintomas. 
A população do estudo foi composta por casos confirmados de doença meningocócica do sorogrupo $\mathrm{C}$, somados a fração de casos sem sorogrupo identificados que após a redistribuição proporcional foram atribuídos ao sorogrupo $\mathrm{C}$. Todas as análises foram realizadas utilizando as taxas de incidência de DMC com e sem a redistribuição dos casos com sorogrupo não identificado.

\section{Variáveis de estudo}

Variáveis dependentes: taxas de incidência trimestrais de DMC foram calculadas para cada ano, por grupo etário $(<1 ; 1-4 ; 5-9 ; \geq 10$ anos) e por região de residência.

Variáveis independentes: i) Ano (tendência histórica): variável "ano" para o período 2001-2013; ii) Trimestre (sazonalidade): variável "mês" foi agregada em trimestres: janeiro-março (categoria $=0$, referência), abril-junho (categoria=1), julho-setembro (categoria=2) e outubro-dezembro (categoria=3); iii) Vacina (impacto da vacinação): a série temporal foi dividida em períodos de acordo com as etapas de implantação da vacinação, como se segue: 2001-2009 - sem rotina de vacinação (pré-implantação, período de referência=0); 2010 - ano de implantação (categoria=1); 2011-2013 período pós implantação da vacina (categoria=2), sendo também classificado como categoria=2 (2011), 3 (2012) e 4 (2013); iv) Região de residência: Nordeste, Centro Oeste, Sudeste, Sul e Norte; v) Idade: $<1$ ano; 1-4 anos; 5-9 anos; $\geq 10$ anos de idade. 
Análise de dados

Para a análise das séries temporais foi utilizado o modelo generalizado de mínimos quadrados ("Generalized Least Square" - GLS) com componente de auto regressão $(A R)$ igual a 1 .

A estimação dos modelos seguiu as seguintes etapas: i) os modelos separados para cada um dos grupos etários $(<1,1-4,5-9$ e $\geq 10$ anos de idade) foram estimados para o Brasil como um todo, considerando como variáveis explicativas o "ano", o "trimestre", a "região" e a "vacina" (esta com cinco categorias), e como desfecho a taxa de incidência de DMC na idade específica; ii) os modelos foram estimados para cada uma das regiões do país; para assegurar poder estatístico, a variável "vacina" foi incluída com três categorias; iii) os modelos foram avaliados (detalhes abaixo); iv) os modelos foram repetidos utilizando como desfecho a taxa de incidência de DMC sem a redistribuição dos casos sem identificação do sorogrupo. Foi considerado nível de significância de 5\% (erro tipo I) nos modelos de regressão.

Os modelos de regressão estatística GLS foram avaliados considerando os testes de significância para a hipótese nula de homogeneidade da variância entre os painéis [para avaliar a presença de heterocedasticidade do erro padrão (error variance) dos painéis] e a hipótese nula de auto correlação entre os painéis. Além disso, para o modelo final estimado, foram avaliados os valores AIC e BIC (capacidade explicativa) considerando as opções com e sem heterocedasticidade do erro padrão dos 
painéis. Com base nesses testes foi tomada a decisão de adotar o modelo com as opções mais adequadas.

Para avaliar as estimativas do impacto populacional da vacina MenC foram preditos o número de casos de DMC esperados com e sem a intervenção da vacina, usando os modelos de regressão, para o período de 2011 a 2013, para o Brasil e regiões. O impacto foi calculado da seguinte maneira: Impacto=(EV-E) * $100 / \mathrm{E}$; onde $\mathrm{EV}=$ efeito com vacinação para um determinado ano; E=efeito sem vacinação para o mesmo ano.

As análises foram feitas com o auxilio dos softwares Microsoft Office Excel 2010 e STATA versão 10 (StataCorp. 2007).

\subsection{Terceiro Artigo}

População e período do estudo

Foram selecionadas crianças menores de cinco anos (idade elegível para vacinação) que foram registradas como casos confirmados de doença meningocócica (DM) ao Sistema de Informação de Agravos de Notificação (Sinan), no período de $1^{\circ}$ de janeiro de 2011 a 31 de dezembro de 2015 (data de inicio de sintomas), que tinham registro do sorogrupo causador da doença e da situação vacinal.

A idade elegível para vacinação foi calculada de acordo com a data de nascimento e o mês de inicio de vacinação no estado de residência da 
criança, como segue: i) inicialmente foi considerado o calendário nacional de implantação da vacina para avaliação da elegibilidade das crianças segundo suas coortes de nascimento; ii) posteriormente foi considerada a data de implantação da vacina em cada estado e excluídas as crianças que não eram elegíveis para a vacinação em seu estado de residência.

Foram excluídas as crianças sem informação sobre o status de vacinação (campo sobre vacinação em branco ou ignorado).

Tipo de estudo e critérios de seleção de casos e controles

Foi realizado um estudo caso-controle não pareado. Neste estudo os casos e controles apresentam a doença de interesse (neste caso, doença meningocócica), porém apenas os casos apresentam a doença causada pelo sorogrupo alvo da vacina sendo avaliada (sorogrupo C). Desta forma, casos foram todas as crianças elegíveis da população fonte cuja DM foi causada pelo sorogrupo C (DM_C). Os controles foram todas as demais crianças elegíveis da população fonte, ou seja, aquelas cuja DM foi causada por outro sorogrupo - não C - (DM_NC).

A variável de exposição considerada foi a confirmação ou não do status sobre vacinação com a MenC, registrado na notificação do Sinan. Todas as crianças que apresentavam confirmação (sim) de vacina MenC foram consideradas expostas à vacinação, independente da data da vacinação, exceto aquelas com data de vacinação menor que 15 dias da data do inicio de sintoma da doença. 
Fonte de dados

O banco de dados utilizado foi proveniente do Sistema de Informação de Agravos de Notificação (Sinan), no qual são registrados os casos de DM notificados ao sistema nacional de vigilância epidemiológica das meningites. O banco de dados do Sinan contém variáveis epidemiológicas, do sorogrupo identificado, bem como o status vacinal de cada caso.

Análise de dados

As características da população de estudo, casos e controles foram descritas segundo idade, sexo, raça/cor, forma clínica, região de residência e data de inicio de sintomas.

$\mathrm{Na}$ etapa analítica foram calculadas as razões de chances (OR) bruta e ajustada para a associação entre DM_C e vacinação e seus respectivos intervalos com 95\% de confiança (IC95\%), assim como a significância estatística, considerando probabilidade de erro tipo I de $5 \%(p<0,05)$.

A efetividade (E) da vacina foi calculada com segue: $E=(1-O R) \times 100$. Nesse caso, tem-se como pressuposto que a OR é um bom estimador do Risco Relativo (RR) (Orestein et al. 1988).

A estimação da OR ajustada foi feita por regressão logística, tendo como variáveis de ajuste a idade, sexo, raça/cor e região de residência. Cada variável foi avaliada separadamente nos modelos estimados. Sempre que o OR bruto sofreu mudança de $15 \%$ ou mais na sua magnitude quando 
ajustado, a variável avaliada foi considerada variável de confundimento e mantida no modelo final.

As análises foram feitas com o auxilio dos softwares Microsoft Office Excel 2010, SPSS versão 20 e STATA versão 10.

\subsection{Aspectos Éticos}

O projeto foi aprovado pelo Comitê de Ética em Pesquisa da Faculdade de Medicina da Universidade de Brasília sob Parecer nº 908.096. Este projeto utilizou apenas dados secundários não nominais de acesso publico. 


\section{RESULTADOS}

\subsection{Primeiro artigo}

Os resultados serão apresentados nesse subcapitulo em formato de artigo, e respondem ao primeiro objetivo especifico que trata da descrição dos casos de doença meningocócica segundo características de tempo, lugar, pessoa, e sorogrupos identificados. Este trabalho será submetido à revista Epidemiologia e Serviços de Saúde. 
Distribuição geográfica e temporal da doença meningocócica com ênfase na Neisseria meningitidis sorogrupo C. Brasil, 2001-2013

Camile de Moraes ${ }^{1,4}$, José Cássio de Moraes ${ }^{2}$, Elisabeth Carmen Duarte ${ }^{3}$

1. Doutoranda do Programa de Pós-Graduação em Medicina Tropical, Faculdade de Medicina, Universidade de Brasília, Brasília/DF; 2. Faculdade de Ciências Médicas da Santa Casa de São Paulo, São Paulo/SP; 3. Faculdade de Medicina, Universidade de Brasília, Brasília/DF; 4. Secretaria de Vigilância em Saúde, Ministério da Saúde, Brasília/DF.

\section{RESUMO}

A epidemiologia da doença meningocócica (DM) no Brasil é caracterizada por níveis endêmicos de doença, com a ocorrência de períodos epidêmicos. A partir dos anos 2000 ocorreu o aumento das taxas de incidência da DM sorogrupo $\mathrm{C}$ e a recorrência de surtos em diferentes localidades do país; estas características levaram à inclusão da vacina meningocócica $C$ conjugada (MenC) no Programa Nacional de Imunizações, em 2010. O objetivo do estudo foi caracterizar a epidemiologia da doença no Brasil com ênfase na doença meningocócica causada pelo sorogrupo C. Foi realizado um estudo descritivo utilizando os casos de doença meningocócica notificados ao sistema nacional de vigilância epidemiológica da meningite (2001-2013). Um total de 37.575 casos de DM foram registados durante o 
período de estudo. Os sorogrupos B (35,9\%) e C $(57,5 \%)$ foram identificados para a maioria dos casos de DM. Considerando a DM geral (todos os sorogrupos), entre 2001 e 2013 as taxas de incidência de mortalidade apresentaram redução, de 2,11 para 1,03 casos/100 mil habitantes e de 0,43 para 0,24 óbitos $/ 100$ mil habitantes, respectivamente. Este fato foi especialmente devido a DM causada pelo sorogrupo $B$, para a qual a incidência reduziu de 0,55 para 0,10 casos/100 mil habitantes, e a mortalidade de 0,07 para 0,02 óbitos/100 mil habitantes. Em contraponto as taxas de incidência e mortalidade da DM sorogrupo C elevaram-se entre 2001 e 2010, passando de 0,19 para 0,62 casos/100 mil habitantes e de 0,02 para 0,13 óbitos/100 mil habitantes, respectivamente. Em conclusão, a análise desta série histórica permitiu a caracterização epidemiológica de um período importante da DM no Brasil, onde ocorreu aumento expressivo da doença causada pelo sorogrupo C. O aprimoramento da vigilância da doença, em especial com ações voltadas para diagnostico laboratorial, assistência aos pacientes e avaliações das ações de imunização é de fundamental importância.

\section{INTRODUÇÃO}

A despeito das vacinas disponíveis, a doença meningocócica (DM) permanece como um importante problema de saúde publica em todo mundo. A Neisseria meningitidis é caracterizada em sorogrupos e seis deles (A, B, $\mathrm{C}, \mathrm{W}, \mathrm{X}, \mathrm{Y}$ ) são responsáveis por virtualmente todos os casos de doença 
invasiva (Halperin et al. 2012). Entretanto, importantes diferenças regionais nas taxas de incidência e na distribuição dos sorogrupos são observadas. Uma característica marcante da doença é sua ocorrência cíclica e a ocorrência de surtos e epidemias (Harrison et al. 2009).

A DM no Brasil é caracterizada por manter níveis endêmicos com a ocorrência eventual de períodos epidêmicos. A terceira e maior epidemia registrada no Brasil caracterizou-se pela ocorrência de duas ondas epidêmicas seguidas, a saber: uma com inicio em 1971 foi causada predominantemente pelo sorogrupo C e outra em 1974, foi causada pelo sorogrupo $A$, quando os picos de incidência chegaram a atingir 179 casos/100.000 habitantes no município de São Paulo (Moraes e Barata 2005). Durante a década de 1980, a incidência da doença permaneceu em níveis endêmicos. Até que, em 1996, epidemias atribuídas ao sorogrupo B foram observadas em vários locais do país (Safadi e Cintra 2010). A partir do final da década de 1990 os casos causados por esse sorogrupo vêm apresentando declínio no Brasil.

A partir dos anos 2000, observou-se aumento das taxas de incidência da DM sorogrupo C, principalmente entre crianças, bem como a recorrência de surtos em diferentes regiões do país (Iser et al. 2012; Gorla et al. 2012; Liphaus et al. 2013). Esses fatos levaram os gestores do Ministério da Saúde do Brasil a incluir a vacina meningocócica C conjugada (MenC) no calendário de vacinação da criança do Programa Nacional de Imunizações (PNI/MS), em 2010. O esquema recomendado, e que permanece até o 
momento, foi de duas doses (aos 3 e 5 meses de idade) e um reforço (entre 12 e 15 meses de idade). Excepcionalmente, no primeiro ano de implantação da vacina (2011), as crianças entre 12 e 23 meses de idade também receberam uma dose da vacina.

O objetivo do presente estudo é descrever as características da DM, dando ênfase a distribuição geográfica e temporal dos casos causados pelo sorogrupo C, no Brasil, no período de 2001 a 2013. Este estudo tem ainda como propósito, servir como linha de base para estudos futuros de efetividade e impacto da introdução da vacina MenC no Brasil em anos recentes.

\section{METODOLOGIA}

Tipo de estudo, população e período - Foi realizado um estudo descritivo, considerando a série temporal e a distribuição nas regiões dos casos confirmados de DM que ocorreram e foram notificadas ao Sistema de Informação de Agravos de Notificação (Sinan), no Brasil, entre 2001 e 2013.

Fonte de dados - As bases populacionais utilizadas foram: Sistema de Informação de Nascidos Vivos (Sinasc) e as estimativas populacionais do Instituto Brasileiro de Geografia e Estatística (IBGE). Os casos de DM incluídos no estudo foram os registrados no Sinan, oriundos do Sistema nacional de vigilância epidemiológica das meningites (SNVEM). No Brasil, todo caso de DM (suspeito ou confirmado) é de notificação compulsória e 
universal (oriundos de serviços públicos ou privados) e deve ser notificado às vigilâncias epidemiológicas municipais dentro de 24 horas, onde são incluídos no Sinan.

Definição de caso de DM confirmado adotada pelo SNVEM - Os casos confirmados são classificados como meningite meningocócica, meningococcemia, ou meningococcemia com meningite meningocócica (Brasil MS. 2014). Os critérios de diagnóstico considerados para confirmação de casos de DM são: cultura, detecção de DNA bacteriano por meio da reação em cadeia da polimerase - PCR, detecção de antígeno (aglutinação por látex e contra-imunoeletroforese), critério clínicoepidemiológico (quando é identificado contato próximo com caso confirmado por teste laboratorial), coloração de Gram, ou critério clínico (com presença de petéquias). O sorogrupo é determinado apenas para os casos de DM confirmados por cultura, PCR, detecção de antígeno e por critério clínicoepidemiológico. Quando o caso de DM é confirmado por coloração de Gram e por critério clínico, o sorogrupo não pode ser identificado (Brasil MS. 2014).

Variáveis de estudo - Idade, sexo, Unidade Federada de residência, data de primeiros sintomas, evolução do caso, exames realizados e sorogrupo. Para este estudo foi criada uma variável denominada como "outros" sorogrupos, que agregou os casos causados pelos sorogrupos A, X, 29E e NG.

Análise de dados - Para o cálculo das taxas de incidência e das taxas específicas de mortalidade foram utilizados como numerador os casos e os 
óbitos (respectivamente), todos confirmados de DM por qualquer sorogrupo e de DM por sorogrupo especifico. Como denominador, foi considerada a população do ano de referência. A taxa de letalidade foi calculada utilizando como numerador os óbitos de DM por qualquer sorogrupo e de DM por sorogrupo especifico e como denominador os casos de DM por qualquer sorogrupo e de DM por sorogrupo especifico. Esses indicadores foram analisados segundo ano de notificação, região de residência e idade do paciente. A análise foi feita com auxilio dos softwares Microsoft Office Excel 2010 e Epilnfo versão 7.

Aspectos Éticos - O estudo foi aprovado pelo Comitê de Ética em Pesquisa da Faculdade de Medicina da Universidade de Brasília sob Parecer oㅡ 908.096. O estudo utilizou apenas dados secundários não nominais de acesso publico.

\section{RESULTADOS}

No período de 2001 a 2013 foram registrados no Sinan um total de 37.575 casos confirmados de DM. A maioria dos casos era do sexo masculino (55,7\%). A mediana de idade dos casos de DM foi de sete anos, sendo que $25 \%$ dos casos tinham dois anos de idade ou menos ( $1^{\circ}$ quartil), e $25 \%$ tinham 19 anos de idade ou mais ( $3^{\circ}$ quartil).

De maneira geral a taxa de incidência da DM apresentou redução no período de análise, passando de 2,11 casos/100.000 habitantes, em 2001, 
para 1,03 casos/100.000 habitantes, em 2013. No entanto, observam-se dois momentos de elevação na série histórica desse indicador, o primeiro pontual no ano de 2004 e o segundo gradual no período de 2008 a 2010; para ambas as situações são observadas reduções nos anos subsequentes. A taxa de mortalidade também apresentou redução (Tabela 1).

A informação sobre o sorogrupo estava disponível para $44 \%$ dos casos $(n=16.540)$. Destes, $9.490 \quad(57,5 \%)$ foram classificados como sorogrupo C, 5.953 (35,9\%) como B, 748 (4,5\%) como W e 349 (2,1\%) como "outros" sorogrupos. A maioria desses casos $(94,7 \%)$ foi confirmada por técnicas laboratoriais [cultura (56,3\%), detecção de antígenos $(31,4 \%)$ ou Reação em Cadeia da Polimerase - PCR (7,0\%)]; e apenas 1,0\% por vinculo epidemiológico. Para 4,3\% dos casos, o critério de confirmação não estava registrado no Sinan. A proporção de casos com identificação do sorogrupo aumentou ao longo do período, de 36,0\% (2001) para 52,5\% (2013) (Tabela 1). 
Tabela 1 Número de casos e óbitos, taxas de incidência, mortalidade e letalidade de doença meningocócica total, a as causadas pelo sorogrupo C e sorogrupo B. Brasil, 2001 a 2013.

\begin{tabular}{|c|c|c|c|c|c|c|c|c|c|c|c|c|c|c|}
\hline Indicador & & 2001 & 2002 & 2003 & 2004 & 2005 & 2006 & 2007 & 2008 & 2009 & 2010 & 2011 & 2012 & 2013 \\
\hline \multirow{6}{*}{ № casos } & $\mathrm{DM}^{\mathrm{a}}$ & 3.709 & 3.444 & 3.068 & 3.329 & 3.020 & 2.845 & 2.515 & 2.677 & 2.816 & 2.892 & 2.698 & 2.493 & 2.069 \\
\hline & $\mathrm{DMC}^{\mathrm{b}}$ & 335 & 326 & 389 & 538 & 564 & 600 & 653 & 893 & 1034 & 1219 & 1113 & 1065 & 761 \\
\hline & $\mathrm{DMB}^{\mathrm{c}}$ & 964 & 856 & 697 & 657 & 572 & 444 & 310 & 285 & 233 & 215 & 256 & 254 & 210 \\
\hline & $\%$ & & & & & & & & & & & & & \\
\hline & Sorogrupos & 36,5 & 35,5 & 36,8 & 37,7 & 40,0 & 39,1 & 41,5 & 48,2 & 48,9 & 53,3 & 55,3 & 57,6 & 52,5 \\
\hline & DM & 761 & 647 & 623 & 677 & 639 & 591 & 540 & 583 & 619 & 643 & 601 & 566 & 482 \\
\hline \multirow[t]{2}{*}{ № óbitos } & DMC & 34 & 35 & 46 & 63 & 95 & 78 & 109 & 151 & 184 & 245 & 218 & 224 & 154 \\
\hline & DMB & 122 & 122 & 101 & 96 & 85 & 62 & 35 & 45 & 38 & 45 & 47 & 54 & 41 \\
\hline \multirow{3}{*}{$\begin{array}{l}\text { Tx. Incidência } \\
\text { (casos/100 mil } \\
\text { hab.) }\end{array}$} & $\mathrm{DM}$ & 2,11 & 1,93 & 1,70 & 1,82 & 1,63 & 1,52 & 1,33 & 1,40 & 1,45 & 1,48 & 1,37 & 1,25 & 1,03 \\
\hline & DMC & 0,19 & 0,18 & 0,22 & 0,29 & 0,30 & 0,32 & 0,34 & 0,47 & 0,53 & 0,62 & 0,56 & 0,53 & 0,38 \\
\hline & DMB & 0,55 & 0,48 & 0,39 & 0,36 & 0,31 & 0,24 & 0,16 & 0,15 & 0,12 & 0,11 & 0,13 & 0,13 & 0,10 \\
\hline
\end{tabular}




\begin{tabular}{|c|c|c|c|c|c|c|c|c|c|c|c|c|c|c|}
\hline Tx. Mortalidade & DM & 0,43 & 0,36 & 0,34 & 0,37 & 0,35 & 0,32 & 0,29 & 0,30 & 0,32 & 0,33 & 0,30 & 0,28 & 0,24 \\
\hline \multirow{2}{*}{$\begin{array}{l}\text { (óbitos/100 mil } \\
\text { hab.) }\end{array}$} & DMC & 0,02 & 0,02 & 0,03 & 0,03 & 0,05 & 0,04 & 0,06 & 0,08 & 0,10 & 0,13 & 0,11 & 0,11 & 0,08 \\
\hline & DMB & 0,07 & 0,07 & 0,06 & 0,05 & 0,05 & 0,03 & 0,02 & 0,02 & 0,02 & 0,02 & 0,02 & 0,03 & 0,02 \\
\hline \multirow{3}{*}{ Tx. Letalidade (\%) } & $\mathrm{DM}^{*}$ & 21,6 & 20,4 & 21,7 & 21,4 & 22,6 & 22,0 & 23,5 & 23,9 & 24,2 & 24,3 & 23,6 & 23,9 & 24,9 \\
\hline & $\mathrm{DMC}^{*}$ & 10,6 & 11,8 & 12,8 & 12,5 & 18,2 & 14,0 & 18,3 & 18,8 & 19,4 & 21,8 & 20,7 & 22,1 & 21,3 \\
\hline & $\mathrm{DMB}^{*}$ & 13,2 & 15,2 & 15,3 & 15,2 & 15,3 & 14,3 & 12,0 & 17,0 & 17,8 & 22,1 & 19,3 & 22,2 & 20,6 \\
\hline
\end{tabular}

DM: doença meningocócica; DMC: doença meningocócica sorogrupo C; DMB: doença meningocócica sorogrupo B. ${ }^{\star} A$ informação sobre evolução não estava disponível para 2.559 dos casos de DM, para 664 casos de DMC, e para 287 casos de DMB. 
No Brasil, no início da série histórica de análise, havia maior número de casos de DM por sorogrupo B do que por sorogrupo C. Ao longo do período houve aumento na taxa de incidência de DM por sorogrupo $\mathrm{C}$, enquanto que para o sorogrupo B ocorreu redução, resultando na inversão de circulação destes sorogrupos, em 2005. A incidência para o sorogrupo W permaneceu estável até 2006 (média de 0,02 casos/100.000 habitantes), quando dobrou sua incidência, assim permanecendo estável até 2013 (média de 0,04 casos/100.000 habitantes). Para a incidência da DM causada pelos "outros" sorogrupos também foi observado um discreto aumento a partir de 2010, o qual se deve especificamente ao sorogrupo Y (Figura 1).

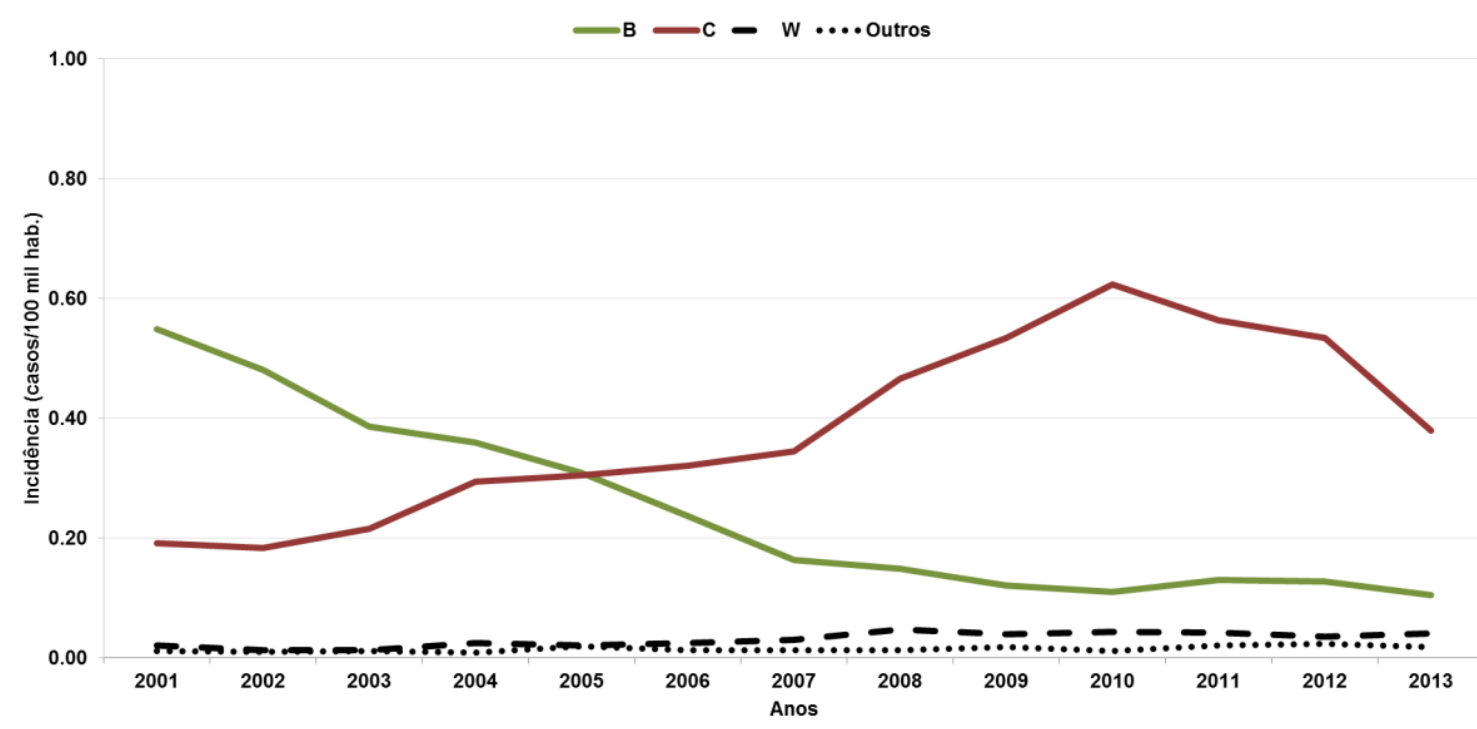

Figura 1 Taxa de incidência de doença meningocócica por sorogrupo. Brasil, 2001 a 2103. 
As taxas de identificação de sorogrupos, bem como a carga da doença diferem entre as regiões, embora a incidência do sorogrupo $C$ tenha elevado em todas elas. $\mathrm{O}$ aumento da incidência foi mais expressiva nas regiões Sudeste, Centro Oeste e Nordeste, sendo que no ano seguinte a introdução da vacina (2011), estas regiões já demonstravam redução da taxa do sorogrupo C. O padrão da incidência foi mais estável nas regiões Sul e Norte, com padrão cíclico mais discreto, e sem redução consistente após o ano de 2010 (Figura 2).

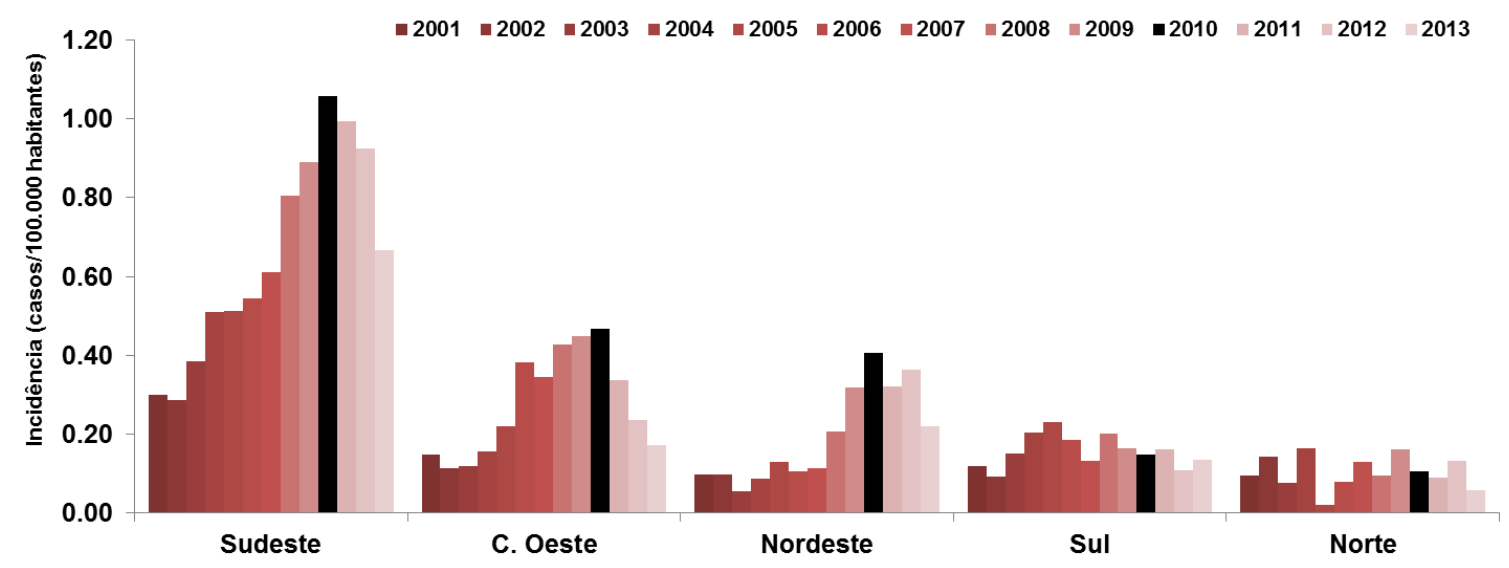

*2010: ano de introdução da vacina MenC.

Figura 2 Taxa de incidência de doença meningocócica sorogrupo $C$ por região. Brasil, 2001 a 2103. 
Em contraponto, todas as regiões apresentaram redução da incidência da DM do sorogrupo B. De maneira geral, a região Sul foi a que apresentou as taxas de incidência para este sorogrupo mais elevadas, principalmente nos primeiros anos da série. A partir de 2010 parece haver um aumento da incidência nas regiões Sudeste e Centro-Oeste (Figura 3).

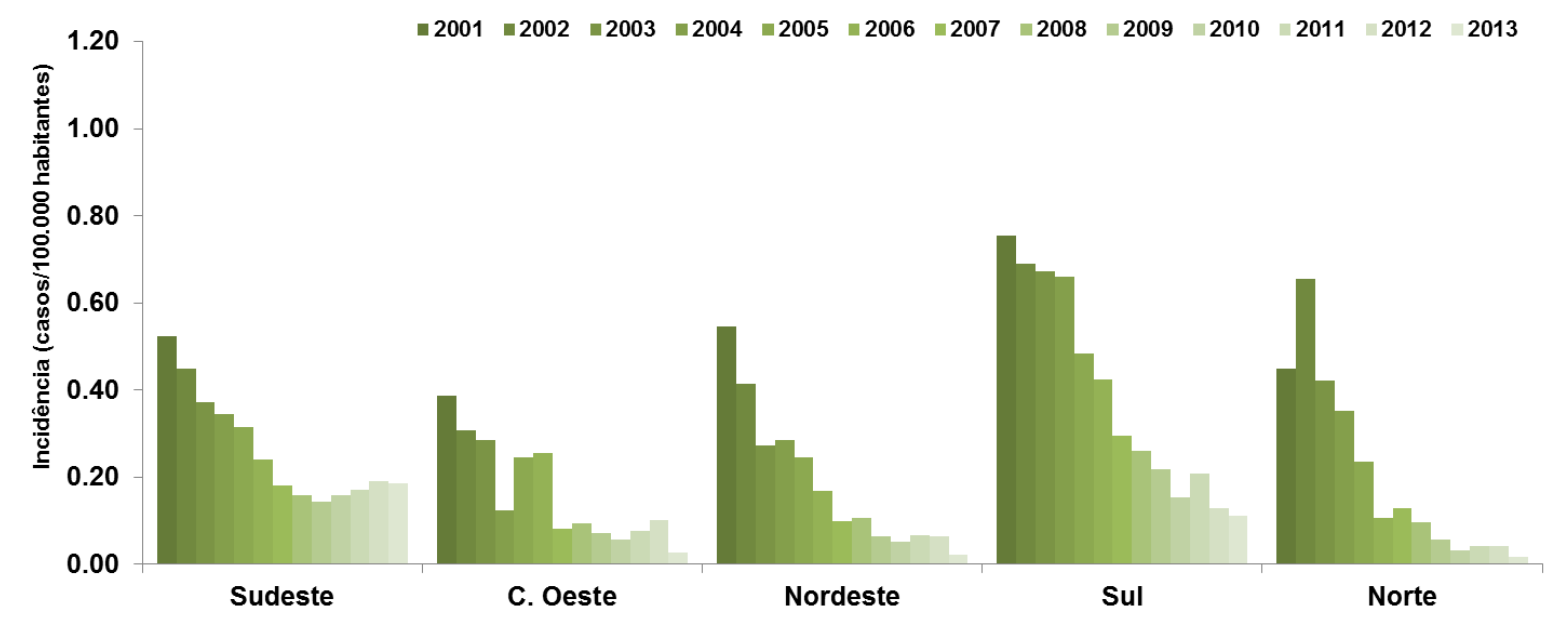

Figura 3 Taxa de incidência de doença meningocócica sorogrupo B por região. Brasil, 2001 a 2103.

Os momentos da inversão na circulação entre os sorogrupos B e C foram distintos segundo as regiões de residência: na Sudeste, esta inversão ocorreu entre os anos de 2003-2004, no Centro Oeste, entre 2005-2006, no Nordeste, entre 2007-2008, no Norte, entre 2008-2009, e na região Sul, mais tardiamente, entre 2012-2013. 
O aumento da incidência da doença meningocócica sorogrupo $C$ no período foi observado para os menores de cinco anos até 2010, e para os demais grupos de idade até 2012. Para os menores de um ano, aumentou $185 \%$, passando de 1,73 casos para 4,93 casos/100.000 hab., entre 2001 e 2010, respectivamente. Para crianças de 1 a 4 anos o aumento foi de $119 \%$. O aumento relativo mais elevado foi observado no grupo com mais de cinco anos, principalmente nos maiores de vinte anos de idade (540\%). No entanto, imediatamente no ano seguinte à introdução da vacina (2011), é possível observar redução da incidência da DM sorogrupo $C$ entre as crianças menores de um ano de idade, e - mais discretamente - entre as crianças de 1 a 4 anos de idade. Reduções das taxas de menor intensidade foram observadas para os outros grupos etários (Tabela 2).

A taxa de letalidade média da DM sorogrupo $\mathrm{C}$ considerando todo o período foi de 18,5\%. Esta taxa aumentou de 10,6\% para 21,3\%, entre 2001 e 2013, respectivamente. Este aumento foi observado para todas as faixas etárias consideradas no estudo, e os indivíduos >20 anos apresentaram as taxas mais elevadas em praticamente todos os anos (Tabela 2).

A mediana de idade dos casos de DM sorogrupo $\mathrm{C}$ foi de oito anos no período pré-introdução da vacina (2001-2010) e de 16 anos no período pósintrodução da vacina (2011-2013). A proporção de casos com mais de cinco anos de idade foi maior em todos os anos da série analisada, mas aumentou marcadamente com o passar do tempo (dados não apresentados em tabela). 
Tabela 2 Taxa de incidência e de letalidade da doença meningocócica sorogrupo C por faixa etária. Brasil, 2001 a 2013.

\begin{tabular}{|c|c|c|c|c|c|c|c|c|c|c|c|c|c|c|}
\hline \multirow{2}{*}{$\begin{array}{c}\text { Fx. Etária } \\
\text { (anos) }\end{array}$} & 2001 & 2002 & 2003 & 2004 & 2005 & 2006 & 2007 & 2008 & 2009 & 2010 & 2011 & 2012 & 2013 & \multirow{2}{*}{ Tendência } \\
\hline & \multicolumn{13}{|c|}{ Incidência (casos/100.000 habitantes) } & \\
\hline$<1$ & 1.73 & 1.14 & 2.27 & 2.74 & 2.73 & 3.29 & 3.04 & 4.05 & 4.06 & 4.93 & 1.92 & 1.27 & 1.48 & - \\
\hline 1 a 4 & 0.75 & 0.66 & 0.83 & 1.05 & 1.11 & 1.19 & 1.06 & 1.48 & 1.85 & 1.64 & 1.38 & 0.84 & 0.38 & 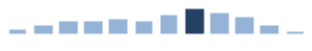 \\
\hline 5 a 9 & 0.30 & 0.30 & 0.27 & 0.49 & 0.48 & 0.51 & 0.56 & 0.74 & 0.82 & 0.98 & 0.92 & 1.10 & 0.68 & 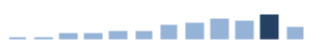 \\
\hline 10 a 14 & 0.21 & 0.21 & 0.21 & 0.35 & 0.38 & 0.38 & 0.48 & 0.55 & 0.78 & 0.90 & 0.97 & 0.84 & 0.57 & $---=-m=\square \square \square \square$ \\
\hline 15 a 19 & 0.18 & 0.17 & 0.16 & 0.23 & 0.21 & 0.28 & 0.34 & 0.49 & 0.59 & 0.80 & 0.89 & 0.76 & 0.69 & $------m \in \mathbb{\square}$ \\
\hline$>20$ & 0.05 & 0.07 & 0.08 & 0.11 & 0.12 & 0.12 & 0.15 & 0.22 & 0.24 & 0.32 & 0.31 & 0.35 & 0.26 & 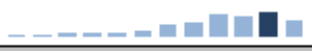 \\
\hline \multicolumn{15}{|c|}{ Letalidade (\%) } \\
\hline$<1$ & 11.8 & 6.5 & 12.7 & 8.1 & 28.2 & 13.3 & 20.2 & 19.2 & 13.3 & 26.8 & 14.5 & 28.6 & 17.5 & - - - \\
\hline 1 a 4 & 13.0 & 9.4 & 8.6 & 12.4 & 14.8 & 12.8 & 16.7 & 12.7 & 20.3 & 16.1 & 17.9 & 18.4 & 13.3 & 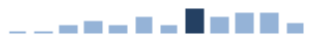 \\
\hline 5 a 9 & 12.2 & 6.7 & 14.0 & 8.6 & 8.8 & 10.6 & 15.4 & 16.5 & 15.6 & 21.3 & 18.8 & 12.6 & 23.6 & - \\
\hline 10 a 14 & 8.1 & 11.8 & 16.7 & 5.1 & 20.6 & 12.3 & 12.0 & 8.1 & 13.0 & 13.4 & 13.4 & 16.3 & 13.6 & 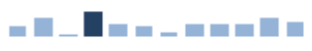 \\
\hline 15 a 19 & 6.3 & 9.7 & 11.1 & 7.5 & 17.1 & 8.5 & 14.3 & 20.0 & 26.0 & 23.1 & 22.1 & 20.3 & 19.0 & 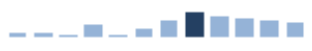 \\
\hline$>20$ & 7.8 & 21.1 & 16.5 & 23.5 & 21.4 & 21.0 & 24.1 & 27.2 & 23.1 & 26.1 & 26.2 & 28.5 & 25.0 & 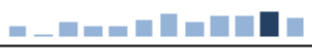 \\
\hline
\end{tabular}


Considerando a proporção de casos segundo a idade (em meses) das crianças $<1$ ano de idade, foi possível observar que no período anterior a vacinação a proporção de casos de DM do sorogrupo C se distribuía de maneira relativamente uniforme em todos os subgrupos de idades (Figura 4). Entretanto, no período posterior a vacinação ocorreu uma mudança bem acentuada, com as crianças acima de três meses de idade reduzindo marcadamente sua contribuição no total de casos, enquanto que as crianças com 0-3 meses de idade passam a representar $73 \%$ do total de casos (Figura 4).

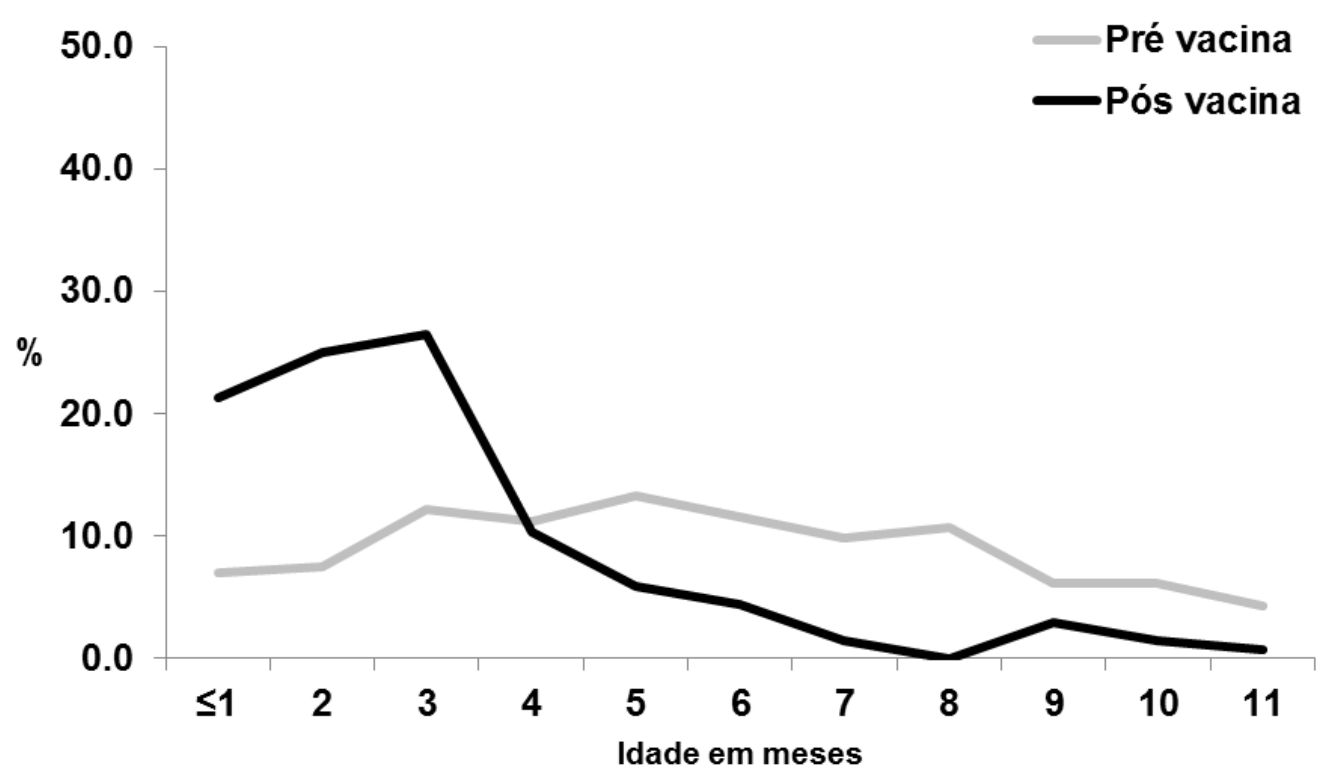

Figura 4 Distribuição proporcional dos casos de doença meningocócica do sorogrupo C nos períodos anterior (2001-2010) e posterior (2011-2013) a vacinação, segundo idade (0-11 meses). Brasil, 2001 a 2103. 
A forma clínica mais frequente registrada para os casos de DM do sorogrupo C foi a meningite $(48,5 \%)$, seguida por meningite com meningococcemia $(36,3 \%)$, e por meningococcemia $(15,2 \%)$. Para esta última forma a proporção dos casos de aumentou ao longo do período, de 6,9\% (2001) para 19,7\% (2013) (dados não apresentados em tabela).

\section{DISCUSSÃO}

Este estudo descreveu as características epidemiológicas da doença meningocócica no Brasil a partir dos casos registrados no Sinan por meio das notificações ao sistema de vigilância epidemiológica das meningites.

De maneira geral, no período de estudo (2001 a 2013) a doença meningocócica (DM) no Brasil pode ser caracterizada como endêmica, com taxas de incidência mais baixas do que as observadas na década de 1990 .

Para a DM geral foi observada queda nas taxas de incidência e mortalidade, muito provavelmente relacionada à redução constante das taxas do sorogrupo B observada no período de análise. A redução da DM sorogrupo B pode ser reflexo do período epidêmico deste sorogrupo observado na década de 1990 no Brasil, que foi marcado por apresentar taxas mais elevadas de incidência em grande parte das Unidades Federadas, com pico de incidência nos anos de 1995-1996. O sorogrupo B foi o mais frequentemente identificado nas cepas isoladas deste período (Lemos et al. 2006), embora o sorogrupo C também tenha aumentado em 
algumas cidades do país (Noronha et al. 1997; Cordeiro et al. 2007; Masuda et al. 2015).

Quanto à DM sorogrupo C, as taxas de incidência elevaram-se de maneira relevante no período, sendo compatível com momento epidêmico, conforme observado em períodos passados (Moraes e Barata 2005). Este aumento coincide com a identificação de uma nova cepa do sorogrupo $C$ pertencente a uma linhagem hipervirulenta (ST-103), que foi descrita pela primeira vez em São Paulo no início dos anos 2000 (Lemos et al. 2007), e depois se espalhou para outras regiões do país (Cardoso et al. 2012; Tauil et al. 2014). O aumento da circulação desta nova cepa no Brasil também resultou numa maior ocorrência de surtos em várias cidades (Iser et al. 2012; Gorla et al. 2012; Liphaus et al. 2013).

O aumento da incidência da DM sorogrupo $\mathrm{C}$ ocorreu em todas as faixas etárias, inclusive nas idades mais avançadas. Este achado pode estar relacionado com o fato de que é característica marcante de epidemias por DM o "deslocamento do risco" para as idades mais velhas, ou seja, para grupos etários que não costumam ser afetados nos períodos endêmicos. Em especial adolescentes e adultos passam a apresentar a doença refletindo o aumento de circulação do agente etiológico e provavelmente a maior patogenicidade das cepas (Moraes e Barata 2005).

A redução mais recente das taxas de incidência de DM sorogrupo $C$ observada para os menores de cinco anos, em 2011, levanta a hipótese de relevante efeito direto da vacina MenC imediatamente após sua introdução. 
Sustentando essa hipótese está o fato de que altas taxas de cobertura vacinal (>95\% - meta do PNI/MS) foram alcançadas, já em 2011, em quase todas as regiões, com exceção da região Nordeste, que atingiu a meta apenas em 2013, e da Norte, onde as coberturas vacinais permaneceram entre $80 \%-90 \%$ em todo o período (SI-PNI/MS). Estudos que tenham especificamente o objetivo de avaliar essa hipótese devem ser realizados.

A redução proporcional de casos observada em crianças entre três e 11 meses de idade após o inicio da vacinação, também indicam a hipótese de marcada proteção dessas crianças coincidente com a introdução da vacina. Por outro lado, como era de se esperar, entre as crianças menores de três meses (grupo que não é alvo da vacinação) não foi observado tal redução de casos. Os países que introduziram a vacina MenC em seus programas de vacinação observaram redução de casos de DM sorogrupo C também em crianças menores de três meses como consequência de um efeito protetor indireto, devido a vacinação de coortes que incluíam adolescentes e adultos jovens (Campbell et al. 2009). Os presentes resultados apontam para ausência desses efeitos indiretos nesse grupo etário no Brasil, o que merece ser mais bem estudado.

De maneira geral, a letalidade da DM se mostrou crescente e elevada (acima de 20\%) em todos os anos no período de estudo, sendo que estes valores são maiores do que os relatados em países desenvolvidos, bem como em países da América Latina (Halperin et al. 2012; Cohn et al. 2010; Smith et al. 2006; Safadi \& Cintra, 2010). A elevação expressiva da 
letalidade de DM sorogrupo $\mathrm{C}$ pode estar relacionada ao aumento dos casos de meningococcemia que também foi observado no período, e é caracterizada por um quadro clínico mais grave e de evolução mais rápida (Rosenstein et al. 2001). Taxas de letalidade mais elevadas geralmente ocorrem em surtos e estão associadas a linhagens de $N$. meningitidis mais virulentas, que apresentam risco aumentado de transmissão e podem causar quadros clínicos mais graves (Brooks et al. 2006). Diferentes cepas do sorogrupo C já foram associadas a taxas de letalidade mais elevadas em outros países (Smith et al. 2006; Jensen et al. 2003; Xu et al. 2012). A relação entre a virulência da cepa circulante no Brasil e a possibilidade de esta explicação contribuir para as elevadas taxas de letalidade deve ser mais bem explorada em estudos futuros. Outras possíveis explicações para alta letalidade incluem notificação diferencial para casos graves, acesso tardio a cuidados médicos e a qualidade da assistência prestada. Várias publicações apontam a influência da qualidade da assistência no desfecho de pacientes com DM, sobretudo em quadros graves, de evolução rápida, que requerem diagnóstico oportuno e manejo adequado para a prevenção do óbito (Souza et al. 2012; Gama et al. 1997; Masuda et al. 2015).

O aumento da proporção de DM com identificação do sorogrupo causador da doença observado neste estudo ao longo do período de análise reflete avanços nas ações de vigilância da doença. Em especial, deve ser destacado o aprimoramento do diagnóstico laboratorial das meningites bacterianas ocorrido no Brasil nos últimos anos (Brasil, MS 2014), incluindo 
a disponibilização e descentralização de técnicas de biologia molecular (reação em cadeia de polimerase em tempo real - PCR) para os laboratórios estaduais de saúde pública (Lacen) a partir de 2006. O Instituto Adolfo Lutz foi o primeiro Lacen no Brasil a implantar a técnica de PCR em tempo real como rotina diagnóstica, e o estudo da padronização da técnica em hospitais de São Paulo demonstrou um aumento expressivo na identificação dos principais agentes relacionados com meningite bacteriana ( $N$. meningitidis, S. pneumoniae, $H$. influenzae) em comparação aos métodos convencionalmente utilizados (Sacchi et al. 2011).

O perfil da DM no Brasil difere entre as regiões. O aumento da DM do sorogrupo $\mathrm{C}$ foi mais expressivo nas regiões Sudeste, Centro Oeste e Nordeste, enquanto que nas regiões Sul e Norte foi mais discreto. As razões que levam a este perfil de doença no Brasil precisam ser mais bem entendidas em estudos futuros.

A dinâmica populacional do meningococo é complexa e envolve uma variedade de mecanismos para mudanças antigênicas, particularmente em face da pressão seletiva devido a imunidade natural ou induzida pela vacina (Harrison et al. 2009). Para tanto, estudos fenotípicos e moleculares das cepas de $N$. meningitidis são essenciais para a compreensão dos eventos associados as mudanças epidemiológicas no tempo e nas diferentes regiões (Lemos et al. 2006; Safadi et al. 2015).

Os resultados deste artigo devem ser interpretados considerando algumas limitações. A primeira delas está relacionada ao uso de dados 
secundários, que podem apresentar subnotificações e inconsistências nas variáveis de interesse. Porém, devido à gravidade da doença e necessidade de tratamento específico, com internação hospitalar obrigatória, acredita-se ser desprezível a probabilidade de subnotificação de casos. No entanto, este fato também pode resultar em maior probabilidade de notificação de casos mais graves, e consequentemente resultar na superestimação das taxas de letalidade. Contudo, estudos têm demonstrado que dados provenientes do Sinan são suficientemente válidos para acompanhar mudanças nas tendências históricas da doença (Azevedo et al. 2013). A segunda limitação está relacionada com o percentual de casos de doença meningocócica sem a identificação do sorogrupo responsável pela doença, o que se acredita pode ter levado a subestimativas das taxas de incidência específicas por sorogrupo. Como as taxas de identificação do sorogrupo aumentaram ao longo do tempo, certas tendências temporais podem estar ligeiramente distorcidas como consequência da mudança diferencial de melhoria do registro do sorogrupo ao longo do período.

Embora tenha sido observado neste estudo que as taxas de incidência para os maiores de cinco anos tenham reduzido (2012/2013), esse grupo ainda contribui com número expressivo de casos de DM e sabese que tem papel relevante como portadores de meningococo (Christensen et al. 2010). Sendo assim, deve ser equacionada a relevância sobre vacinação de outros grupos etários, como por exemplo, os adolescentes, para que ocorresse uma redução mais expressiva da doença no país. 
Estudo recente realizado em Campinas/SP, que avaliou a prevalência de portadores de N. meningitidis em jovens estudantes (11-19 anos), demonstrou uma alta taxa de portadores do sorogrupo C (1,32\%) (de Moraes et al. 2015).

Por fim, a análise desta série histórica permitiu a caracterização epidemiológica de um período importante da DM no Brasil. O aprimoramento da vigilância da doença no Brasil é essencial, em especial com ações voltadas para diagnóstico laboratorial, assistência aos pacientes e avaliações das ações de imunização, tais como: i) melhoria do percentual de identificação diagnóstica, e monitoramento contínuo das características fenotípicas e genéticas das cepas de meningococo circulantes no país; ii) redução da taxa de letalidade, por meio da elaboração de protocolos clínicos que abordem o diagnóstico e tratamento precoces para estes pacientes; iii) acompanhamento das coberturas vacinais, e avaliação permanente da efetividade e do impacto da vacina sobre a epidemiologia da doença nos diferentes grupos etários.

\section{REFERÊNCIAS}

Azevedo LCP, Toscano CM, Bierrenbach AL. Bacterial meningitis in Brazil: baseline epidemiologic assessment of the decade prior to the introduction of pneumococcal and meningococcal vaccines. PLoS ONE. 2013; 8:e64524. 
Brasil. Ministério da Saúde. Secretaria de Vigilância em Saúde. Guia de $\begin{array}{llll}\text { Vigilância em } & \text { Saúde. }\end{array}$ http://portalsaude.saude.gov.br/images/pdf/2014/novembro/27/guiavigilancia-saude-linkado-27-11-14.pdf - Acessado em agosto 2016 Brasil. Ministério da Saúde. Secretaria de Vigilância em Saúde. Programa Nacional de Imunizações. Sistema de informação do Programa Nacional de Imunização.

Disponível

em: http://pni.datasus.gov.br/inf estatistica cobertura.asp - Acessado em agosto 2015

Brasil. Ministério do Planejamento, Orçamento e Gestão. Instituto Brasileiro de Geografia e Estatística. Diretoria de Pesquisas. Coordenação de População e Indicadores Sociais. Gerência de Estudos e Análises da Dinâmica Demográfica. Projeção da população do Brasil por sexo e idade para 0 período 2000-2060. Disponível em: http://www.ibge.gov.br/home/estatistica/populacao/projecao da populacao/2

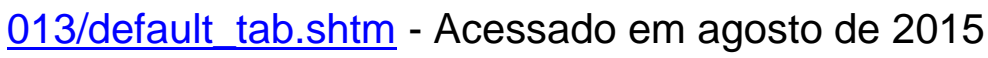

Brooks R, Woods CW, Benjamin DK, and Rosenstein NE. Increased CaseFatality Rate Associated with Outbreaks of Neisseria meningitidis Infection, Compared with Sporadic Meningococcal Disease, in the United States, 1994-2002. CID 2006; 43:49-54

Campbell H, Borrow R, Salisbury D, et al. Meningococcal C conjugate vaccine: the experience in England and Wales. Vaccine 2009; 27S:B20-B29. 
Cardoso CW, Pinto LLS, Reis MG, Flannery B, Reis JN. Impact of vaccination during an epidemic of serogroup $C$ meningococcal disease in Salvador, Brazil. Vaccine. 2012; 30: 5541-5546.

Christensen H, May M, Bowen L, et al. Meningococcal carriage by age: a systematic review and meta-analysis. Lancet Infect Dis 2010; 10:853-61.

Cohn AC, MacNeil JR, Harrison LH, Hatcher C, Theodore J et al. Changes in Neisseria meningitidis Disease Epidemiology in the United States, 19982007: Implications for Prevention of Meningococcal Disease. CID 2010;50:184-91.

Cordeiro SM, Neves AB, Ribeiro CT, Petersen ML, Gouveia EL et al. Hospital-based surveillance of meningococcal meningitis in Salvador, Brazil. Trans R Soc Trop Med Hyg 2007;101:1147-1153.

de Moraes JC, Kemp B, de Lemos APS, Gorla MCO, Marques EGL et al. Prevalence, Risk Factors and Molecular Characteristics of Meningococcal Carriage Among Brazilian Adolescents. Pediatr Infect Dis J 2015;34:11971202.

Gama SG, Marzochi KBF, Filho GBS. Caracterização epidemiológica da doença meningocócica na área metropolitana do Rio de Janeiro, Brasil, 1976 a 1994. Rev Saúde Pública 1997; 31:254-62.

Gorla MC, de Lemos AP, Quaresma M, Vilasboas R, Marques $O$ et al. Phenotypic and molecular characterization of serogroup C Neisseria 
meningitidis associated with an outbreak in Bahia, Brazil. Enferm Infecc Microbiol Clin 2012;30:56-9.

Halperin SA, Bettinger JA, Greenwood B, Harrison H, Jelfs J, Ladhani SN et al. The changing and dynamic epidemiology of meningococcal disease. Vaccine 2012;30: B26-36.

Harrison LH, Trotter CL, Ramsay ME. Global epidemiology of meningococcal disease. Vaccine 2009; 27S: B51-B63.

Iser BPM, Lima HCAV, de Moraes C, de Almeida RPA, Watanabe LT, Alves SLA et al. Outbreak of Neisseria meningitidis C in workers at a large foodprocessing plant in Brazil: challenges of controlling disease spread to the larger community. Epidemiol Infect 2012;140:906-915.

Jensen ES, Schønheyder HC, Lind I, Berthelsen L, Nørga B et al. Neisseria meningitidis phenotypic markers and septicaemia, disease progress and case-fatality rate of meningococcal disease: a 20-year population based historical follow-up study in a Danish county. J Med Microbiol 2003; 52:173179.

Lemos APS, Brandão AP, Gorla MCO, Paiva MV, Simonsen V, Melles CE. Phenotypic characterization of Neisseria meningitidis strains isolated from invasive disease in Brazil from 1990 to 2001. J Med Microbio 2006; 55: $751-$ 757. 
Lemos APS, Yara TY, Gorla MCO, et al. Clonal distribution of invasive Neisseria meningitides serogroup C strains circulating from 1976 to 2005 in Greater São Paulo, Brazil. J Clin Microbiol 2007;45:1266-1273.

Liphaus BL, Cappeletti-Gonçalves-Okai MI, Silva-Delemos AP, Gorla MC, Rodriguez-Fernandes $\mathrm{M}$ et al. Outbreak of Neisseria meningitidis $\mathrm{C}$ in a Brazilian oil refinery involving an adjacent community. Enferm Infecc Microbiol Clin. 2013 Feb;31(2):88-92.

Masuda ET, Carvalhanas TR, Fernandes RM, Casagrande ST, Okada OS et al. Mortalidade por doença meningocócica no Município de São Paulo, Brasil: aracterísticas e preditores. Cad Saúde Pública 2015; 31:405-416.

Moraes JC e Barata RB. A doença meningocócica em São Paulo. Brasil, no século XX: características epidemiológicas. Cad Saúde Pública 2005; $21: 1458-71$.

Noronha CP, Baran M, Nicolai CCA, Azevedo MB, Bernardes ATO, Monteiro GTR et al. Epidemiologia da doença meningocócica na cidade do Rio de Janeiro: modificações após vacinação contra os sorogrupos B e C. Cad. Saúde Pública 1997; 13: 295-303.

Rosenstein NE, Perkins BA, Stephens DS, Popovic T, Hughes JM. Meningococcal disease. N Engl J Med. 2001 May; 344(18):1378-88.

Sacchi CT, Fukasawa LO, Gonçalves MG, Salgado MM, Shutt KA et al. Incorporation of Real-Time PCR into Routine Public Health Surveillance of 
Culture Negative Bacterial Meningitis in São Paulo, Brazil. PLoS ONE 2011;6:e20675.

Safadi MAP, Cintra OAL. Epidemiology of meningococcal disease in Latin America: current situation and opportunities for prevention. Neurol Res 2010;32:263-71.

Smith I, Caugant DA, Høiby EA, Wentzel-Larsen T and Halstensen A. High case-fatality rates of meningococcal disease in Western Norway caused by serogroup C strains belonging to both sequence type (ST)-32 and ST-11 complexes, 1985-2002. Epidemiol. Infect 2006; 134:1195-1202.

de Souza SF, Costa MCN, Paim JS, da Natividade MS, Pereira SM et al. Bacterial meningitis and living conditions. Rev Soc Bras Med Trop 2012; 45:323-8.

Tauil MC, de Carvalho CSR, Vieira AC, Waldman EA. Meningococcal disease before and after the introduction of meningococcal serogroup $\mathrm{C}$ conjugate vaccine. Federal District, Brazil. Braz J Infect Dis 2014;18:379386.

Xu X-H, Ye Y, Hu LF, Jin Y-H, Jiang Q-Q et al. Emergence of serogroup C meningococcal disease associated with a high mortality rate in Hefei, China. BMC Infectious Diseases 2012,12:205. 


\subsection{Segundo artigo}

Os resultados serão apresentados nesse subcapitulo em formato de artigo, e respondem ao segundo objetivo especifico que trata da avaliação do impacto a vacina sobre a DM do sorogrupo C no Brasil e Regiões. Este trabalho foi submetido à revista cientifica Memórias do Instituto Oswaldo Cruz e encontra-se em revisão. 
Avaliação do impacto do programa de vacinação contra a doença meningocócica do sorogrupo C no Brasil e Regiões: estudo de base

$$
\text { populacional - 2001-2013 }
$$

Camile de Moraes ${ }^{1,4}$, José Cássio de Moraes ${ }^{2}$, Elisabeth Carmen Duarte ${ }^{3}$

1. Doutoranda do Programa de Pós-Graduação em Medicina Tropical, Faculdade de Medicina, Universidade de Brasília, Brasília/DF; 2. Faculdade de Ciências Médicas da Santa Casa de São Paulo, São Paulo/SP; 3. Faculdade de Medicina, Universidade de Brasília, Brasília/DF; 4. Secretaria de Vigilância em Saúde, Ministério da Saúde, Brasília/DF.

\section{RESUMO}

A vacina meningocócica $\mathrm{C}$ conjugada foi introduzida no Programa Nacional de Imunização do Brasil em 2010, para crianças menores de um ano de idade. O objetivo do estudo foi avaliar o impacto desta vacinação. Foi realizado um estudo observacional, ecológico misto, analítico, com análise de séries temporais baseada em dados de painéis utilizando os casos de doença meningocócica notificados ao sistema nacional de vigilância epidemiológica (2001-2013). Um total 37.538 casos de doença meningocócica (DM) foram registados durante o período de estudo, sendo que 19.997 foram atribuídos como DM sorogrupo C (DMC). As reduções nas incidências da DMC em crianças <1 ano (65,2\%; IC95\%: 20,5\%, 84,7\%) e 
de 1 a 4 anos de idade (46,9\%; IC $95 \%$ : 14,6\%, 79,1\%) foram observados nos três anos seguintes a introdução da vacina. O impacto estimado da vacinação na redução da incidência da DMC variou de 83,7\% (IC95\%: $51,1 \%, 100,0 \%)$ na região Centro-Oeste a 56,7\% (IC95\%: 37,4\%, 76,0\%) na região Nordeste. A vacinação contra DMC no Brasil demonstrou impacto na redução das taxas de incidência de crianças $<1$ ano de idade, em todas as regiões analisadas, bem como no grupo etário de 1 a 4 anos de idade. Mesmo assim, acreditamos que há espaço para melhorar a estratégia de vacinação adotado no Brasil.

\section{INTRODUÇÃO}

A doença meningocócica (DM) é considerada endêmica no Brasil, com registros de surtos esporádicos em municípios ou instituições. O meningococo é o principal agente etiológico da meningite bacteriana no país. Até 2005 , o sorogrupo B foi o isolado mais frequente nos casos de DM invasiva (67\%) em todos os grupos etários (PAHO 2007), desde então a circulação do sorogrupo $C$ aumentou e tornou-se o mais frequente entre os casos, sendo responsável por mais de 74\% dos isolados em 2010 (IbarzPavon et al. 2012).

A alta incidência de DM, de aproximadamente 1,6 casos/100.000 habitantes, com taxas mais elevadas entre crianças, principalmente lactentes, bem como a recorrência de surtos em diferentes regiões do país 
(Iser et al. 2012; Gorla et al. 2012; Liphaus et al. 2013), levaram à inclusão da vacina meningocócica $\mathrm{C}$ conjugada (MenC) no calendário de vacinação da criança do Programa Nacional de Imunizações (PNI/MS), em 2010. O esquema recomendado foi de duas doses (aos 3 e 5 meses de idade) e um reforço (entre 12 e 15 meses de idade). No primeiro ano de implantação da vacina, as crianças entre 12 e 23 meses de idade também receberam uma dose da vacina. Três regiões brasileiras atingiram a meta de cobertura vacinal (>95\%) em 2011. A região Nordeste atingiu este objetivo somente em 2013, e a região Norte apresentou cobertura vacinal entre $80 \%$ e $90 \%$ durante o período de estudo (Brasil SI-PNI).

As taxas de incidência de DM e a circulação de sorogrupos diferem entre as regiões brasileiras: o sorogrupo C é predominante na região Sudeste desde 2002-2003, na Centro-Oeste desde 2005-2006, no Nordeste desde 2007-2008, no Norte desde 2008-2009, e na região Sul mais recentemente, a partir de 2012-2013 (de Moraes 2016).

Embora alguns estudos tenham avaliado o impacto da introdução da vacina em alguns municípios brasileiros (Cardoso et al. 2012;. Tauil et al. 2014), nenhum outro estudo que tenha avaliado esta estratégia em âmbito nacional foi identificado até o momento. Portanto, o objetivo deste estudo foi avaliar o impacto da vacinação sob as taxas de incidência da doença meningocócica sorogrupo C no Brasil e nas regiões geográficas. 


\section{MATERIAL E MÉTODOS}

Tipo de estudo - Foi realizado um estudo observacional, ecológico misto (agregados no tempo e espaço) (Morgenstern H. 1995), analítico, com análise de séries temporais baseada em dados de painéis, ou seja, observações transversais em diferentes pontos no tempo (Hsiao C. 2007).

Fonte de dados - O banco de dados utilizado foi o Sistema de Informação de Agravos de Notificação (Sinan), no qual são registrados os casos de DM notificados ao sistema nacional de vigilância epidemiológica. No Brasil, a notificação dos casos de DM é compulsória (Brasil MS. 2014). As bases populacionais utilizadas foram: Sistema de Informação de Nascidos Vivos (Sinasc) e as estimativas populacionais do Instituto Brasileiro de Geografia e Estatística (IBGE).

População e período do estudo - Foram incluídos no estudo os casos confirmados de DM que ocorreram no Brasil entre 2001 e 2013 e foram notificados no Sinan. De acordo com o Guia de Vigilância em Saúde (Brasil MS. 2014), os casos notificados no Sinan são classificados como meningite meningocócica, meningococcemia, ou meningococcemia com meningite meningocócica. Os critérios de diagnóstico considerados para confirmação de casos de DM são: cultura; detecção de DNA bacteriano por meio da reação em cadeia da polimerase - PCR; detecção de antígeno; critério clínico-epidemiológico (para caso com contato próximo com caso confirmado por teste laboratorial); coloração de Gram; ou critério clínico (com presença de petéquias). O sorogrupo é determinado apenas para os casos de DM 
confirmados por cultura, PCR, detecção de antígeno e por critério clínicoepidemiológico. Quando o caso de DM é confirmado por coloração de Gram e por critério clínico, o sorogrupo não é identificado (Brasil MS. 2014).

Os casos de DM sem identificação de sorogrupo foram redistribuídos de acordo com a proporção de casos com sorogrupo identificado na região de residência, faixa etária e o trimestre de início dos sintomas.

A população do estudo foi composta por casos confirmados de doença meningocócica do sorogrupo $\mathrm{C}$, somados a fração de casos sem sorogrupo identificados que após a redistribuição proporcional foram atribuídos ao sorogrupo $\mathrm{C}$. Todas as análises foram realizadas utilizando as taxas de incidência de DMC com e sem a redistribuição dos casos com sorogrupo não identificado.

Variáveis de estudo - Variáveis dependentes: taxas de incidência trimestrais de DMC foram calculadas para cada ano, por grupo etário $(<1 ; 1-4 ; 5-9 ; \geq 10$ anos) e por região de residência. Variáveis independentes: i) Ano (tendência histórica): variável "ano" para o período 2001-2013; ii) Trimestre (sazonalidade): variável "mês" foi agregada em trimestres: janeiro-março (categoria $=0, \quad$ referência), abril-junho (categoria=1), julho-setembro (categoria=2) e outubro-dezembro (categoria=3); iii) Vacina (impacto da vacinação): a série temporal foi dividida em períodos de acordo com as etapas de implantação da vacinação, como se segue: 2001-2009 - sem rotina de vacinação (pré-implantação, período de referência=0); 2010 - ano de implantação (categoria=1); 2011-2013 - período pós implantação da 
vacina (categoria=2), sendo também classificado como categoria=2 (2011), 3 (2012) e 4 (2013); iv) Região de residência: Nordeste, Centro Oeste, Sudeste, Sul e Norte; v) Idade: <1 ano; 1-4 anos; 5-9 anos; $\geq 10$ anos de idade.

Análise de dados - Para a análise das séries temporais foi utilizado o modelo generalizado de mínimos quadrados ("Generalized Least Square" GLS) com componente de auto regressão (AR) igual a 1. A estimação dos modelos seguiu as seguintes etapas: i) os modelos separados para cada um dos grupos etários $(<1,1-4,5-9$ e $\geq 10$ anos de idade) foram estimados para - Brasil como um todo, considerando como variáveis explicativas o "ano", o "trimestre", a "região" e a "vacina" (esta com cinco categorias), e como desfecho a taxa de incidência de DMC na idade específica; ii) os modelos foram estimados para cada uma das regiões do país; para assegurar poder estatístico, a variável "vacina" foi incluída com três categorias; iii) os modelos foram avaliados (detalhes abaixo); iv) os modelos foram repetidos utilizando como desfecho a taxa de incidência de DMC sem a redistribuição dos casos sem identificação do sorogrupo. Foi considerado nível de significância de 5\% (erro tipo I) nos modelos de regressão. Os modelos de regressão estatística GLS foram avaliados considerando os testes de significância para a hipótese nula de homogeneidade da variância entre os painéis [para avaliar a presença de heterocedasticidade do erro padrão (error variance) dos painéis] e a hipótese nula de auto correlação entre os painéis. Além disso, para o modelo final estimado, foram avaliados os valores AIC e BIC 
(capacidade explicativa) considerando as opções com e sem heterocedasticidade do erro padrão dos painéis. Com base nesses testes foi tomada a decisão de adotar o modelo com as opções mais adequadas.

Para avaliar as estimativas do impacto populacional da vacina MenC foram preditos o número de casos de DMC esperados com e sem a intervenção da vacina, usando os modelos de regressão, para o período de 2011 a 2013, para o Brasil e regiões. O impacto foi calculado da seguinte maneira: Impacto $=(E V-E)$ * $100 / E$; onde $E V=$ efeito com vacinação para um determinado ano; E=efeito sem vacinação para o mesmo ano.

As análises foram feitas com o auxilio dos softwares Microsoft Office Excel 2010 e STATA versão 10 (StataCorp. 2007).

Aspectos Éticos - O estudo foi aprovado pelo Comitê de Ética em Pesquisa da Faculdade de Medicina da Universidade de Brasília sob Parecer $\mathrm{n}^{\circ}$ 908.096. O estudo utilizou apenas dados secundários não nominais de acesso publico.

\section{RESULTADOS}

Entre 2001 e 2013, um total de 37.538 casos confirmados de DM foi notificado no Sinan. Para 16.600 casos (44,2\%) o sorogrupo foi identificado, sendo $9.503(57,3 \%)$ como sorogrupo C, 5.999 (36,1\%) como sorogrupo $B$, e $1.098(6,6 \%)$ como outros sorogrupos. Para os outros 20.938 casos $(55,8 \%)$ confirmados de DM o sorogrupo era desconhecido. Estes casos, com 
sorogrupo não identificado, foram redistribuídos entre os sorogrupos conhecidos de acordo com a proporção de identificação na região de residência, faixa etária e trimestre de início dos sintomas, sendo que um total de $10.494(50,1 \%)$ casos de DM foi atribuído ao sorogrupo C. Assim, a população do estudo foi composta por 19.997 casos $(9.503+10.494)$ de DMC como demonstrado na Figura 1.

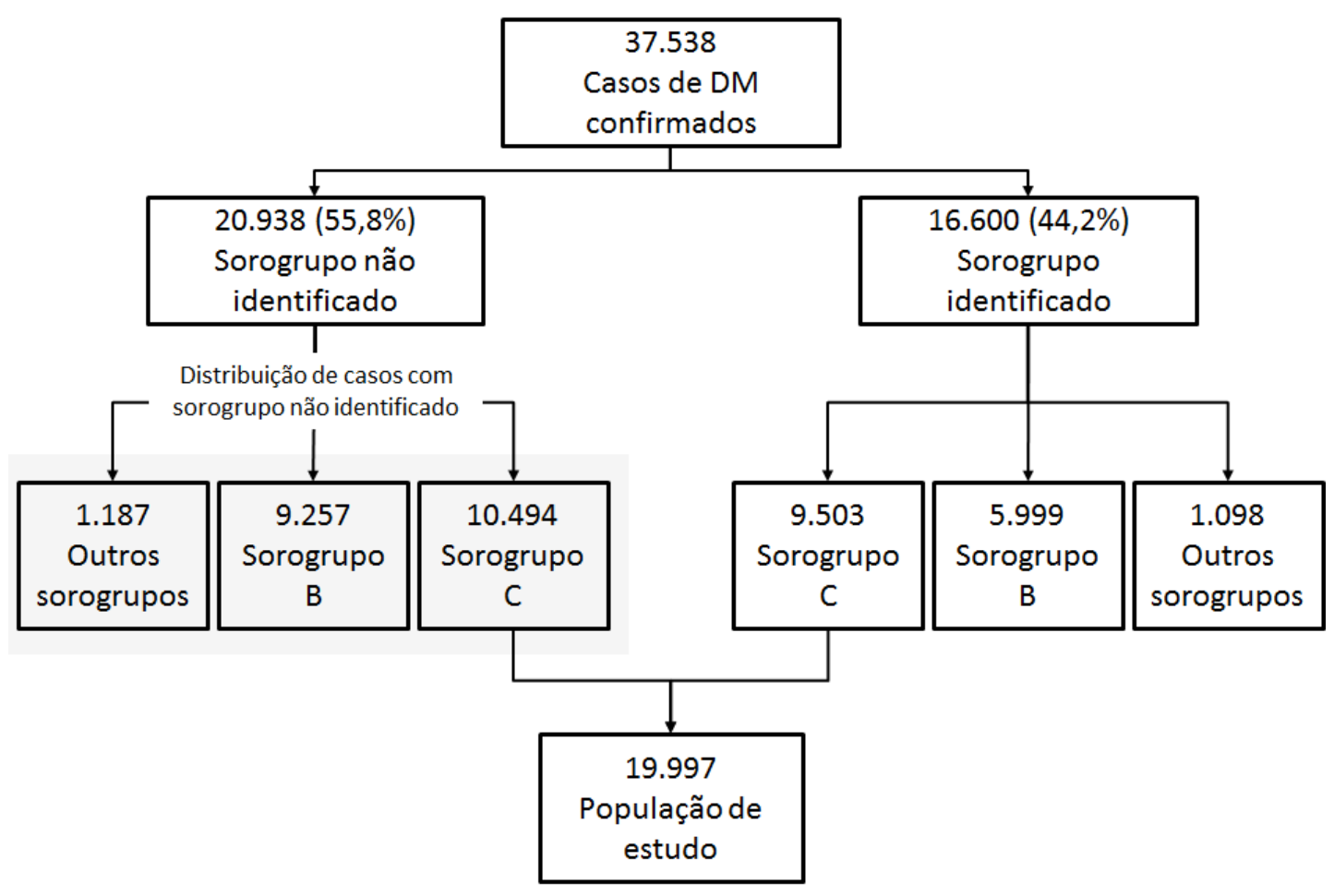

Nota: os casos sem sorogrupos identificados foram redistribuídos proporcionalmente segundo os sorogrupos identificados por idade, região de residência e trimestre.

Figura 1 Descrição dos casos confirmados de doença meningocócica por sorogrupo. Brasil, 2001-2013. 
As variações sazonais das taxas de incidência trimestrais, considerando os casos de DMC com $(n=19.997)$ e sem $(n=9.503)$ a redistribuição dos casos com sorogrupo desconhecido são praticamente idênticas (Figura 2). 


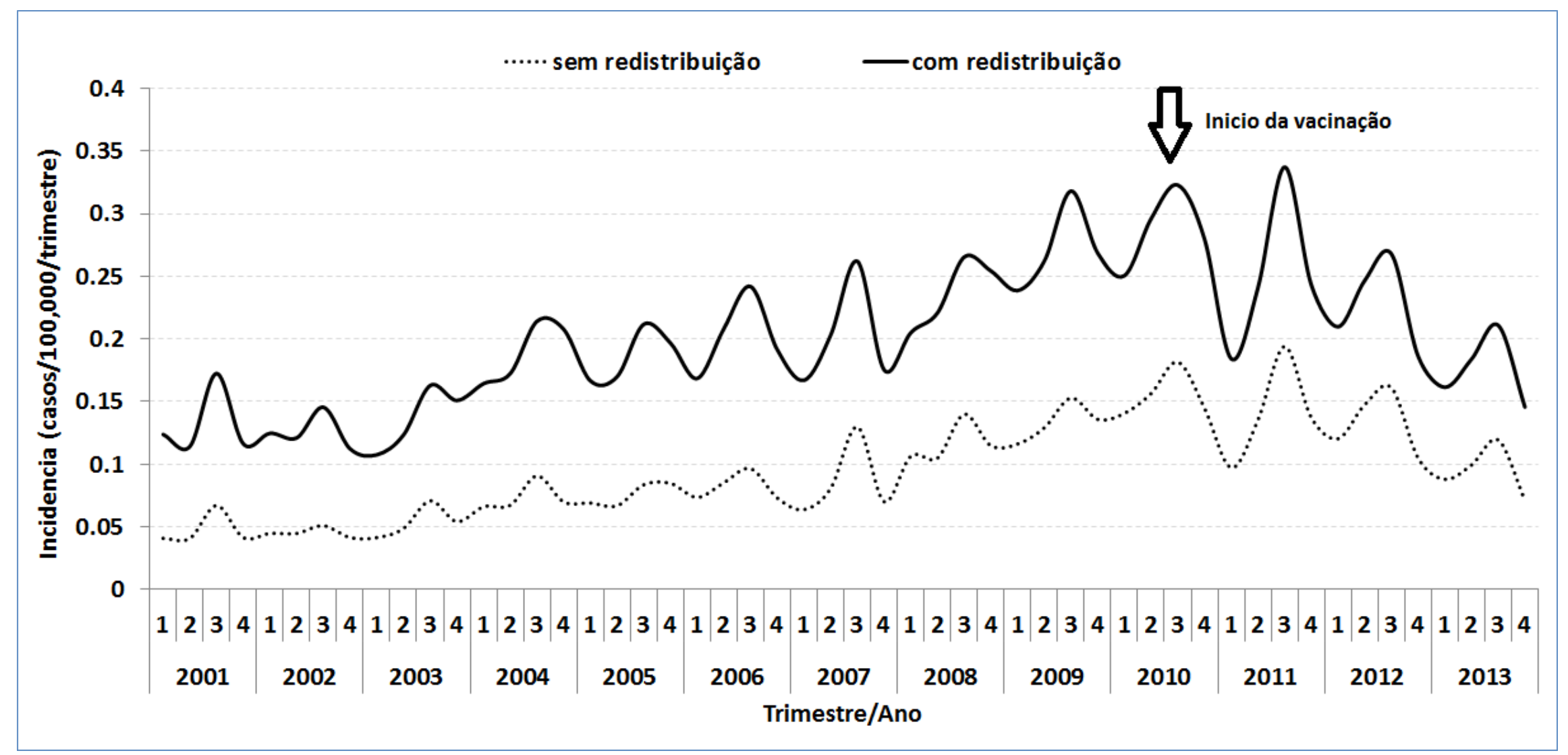

Figura 2 Taxas de incidência de doença meningocócica com e sem redistribuição de casos por trimestre e ano de inicio de sintomas. Brasil, 2001-2013. 
No Brasil, entre 2001 e 2009 (período pré-implantação da vacina), a taxa de incidência de DMC aumentou cerca de 100\%, variando de 0,53 (2001) para 1,09 casos/100.000 (2009). Este aumento ocorreu em todos os grupos etários, salientado que para os $<1$ ano este aumento foi de $120 \%$, de 3,98 (2001) para 8,78 casos/100.000 (2009); e para o grupo de 1-4 anos o aumento foi de $72 \%(2,26$ casos, em 2001, para 3,89 casos/100.000 em 2009) (Tabela 1).

As taxas de incidência de DMC aumentaram em todas as regiões geográficas entre 2001 e 2009. O maior aumento ocorreu na região Nordeste (162\%) (Tabela 1). 
Tabela 1 Taxa de incidência da doença meningocócica sorogrupo C por grupo etário e região de residência. Brasil, 2001-2013*.

\begin{tabular}{|c|c|c|c|c|c|c|c|c|c|c|c|c|c|c|c|}
\hline \multicolumn{16}{|c|}{ Taxa de incidência de Doença Meningocócica sorogrupo C (casos/100.000) } \\
\hline \multirow{2}{*}{ Região } & & & & & & & & & & & & & & & Linha de tendência \\
\hline & Faixa etária (anos) & 2001 & 2002 & 2003 & 2004 & 2005 & 2006 & 2007 & 2008 & 2009 & 2010 & 2011 & 2012 & 2013 & 2001-2013 \\
\hline \multirow{5}{*}{ Brasil } & $<1$ & 3.98 & 2.84 & 4.67 & 6.24 & 6.19 & 7.71 & 6.92 & 7.09 & 8.78 & 9.50 & 4.15 & 2.82 & 3.03 & \\
\hline & $1-4$ & 2.26 & 1.85 & 2.18 & 2.77 & 2.96 & 3.13 & 2.78 & 3.40 & 3.89 & 3.68 & 3.16 & 1.70 & 0.89 & \\
\hline & 5-9 & 0.95 & 1.06 & 0.90 & 1.50 & 1.41 & 1.61 & 1.61 & 1.71 & 2.00 & 2.03 & 1.87 & 2.05 & 1.42 & \\
\hline & $\geq 10$ & 0.23 & 0.25 & 0.26 & 0.37 & 0.36 & 0.38 & 0.43 & 0.54 & 0.62 & 0.71 & 0.70 & 0.71 & 0.58 & \\
\hline & Total & 0.53 & 0.50 & 0.54 & 0.76 & 0.75 & 0.81 & 0.81 & 0.95 & 1.09 & 1.15 & 1.01 & 0.91 & 0.70 & \\
\hline \multirow{5}{*}{ Norte } & $<1$ & 0 & 0 & 0 & 0.49 & 1.59 & 0 & 0 & 1.86 & 0 & 1.63 & 0 & 1.30 & 1.60 & \\
\hline & $1-4$ & 0.48 & 0.68 & 0.27 & 0.33 & 0.20 & 1.21 & 0.54 & 0 & 0.92 & 0.48 & 0.70 & 0.42 & 0.22 & \\
\hline & $5-9$ & 0.18 & 0.70 & 0.69 & 1.16 & 0 & 0.23 & 1.06 & 0.22 & 0.56 & 0 & 0.22 & 0.42 & 0.22 & \\
\hline & $\geq 10$ & 0.32 & 0.22 & 0.17 & 0.35 & 0.03 & 0.20 & 0.27 & 0.38 & 0.47 & 0.29 & 0.20 & 0.29 & 0.39 & \\
\hline & Total & 0.31 & 0.33 & 0.24 & 0.45 & 0.07 & 0.30 & 0.38 & 0.35 & 0.51 & 0.30 & 0.24 & 0.30 & 0.38 & \\
\hline \multirow{5}{*}{ Nordeste } & $<1$ & 0.00 & 0.26 & 1.69 & 1.47 & 2.09 & 3.14 & 2.37 & 2.62 & 4.90 & 3.11 & 2.64 & 1.32 & 2.55 & \\
\hline & $1-4$ & 0.93 & 0.41 & 0.52 & 0.57 & 0.93 & 0.58 & 0.90 & 1.18 & 1.95 & 0.91 & 1.09 & 0.94 & 0.50 & \\
\hline & 5-9 & 0.63 & 0.80 & 0.41 & 0.32 & 0.68 & 0.71 & 0.87 & 0.64 & 1.45 & 1.06 & 1.01 & 1.19 & 0.53 & \\
\hline & $\geq 10$ & 0.17 & 0.22 & 0.11 & 0.22 & 0.25 & 0.26 & 0.28 & 0.35 & 0.48 & 0.61 & 0.50 & 0.58 & 0.41 & \\
\hline & Total & 0.29 & 0.30 & 0.20 & 0.28 & 0.38 & 0.38 & 0.42 & 0.48 & 0.76 & 0.71 & 0.62 & 0.67 & 0.46 & \\
\hline \multirow{5}{*}{$\begin{array}{c}\text { Centro } \\
\text { Oeste }\end{array}$} & $<1$ & 4.40 & 0.00 & 3.02 & 4.88 & 5.66 & 7.22 & 8.05 & 7.64 & 9.08 & 4.53 & 2.65 & 2.39 & 1.49 & \\
\hline & $1-4$ & 1.51 & 1.62 & 0.33 & 0.72 & 2.64 & 3.53 & 2.81 & 3.30 & 3.63 & 3.62 & 2.13 & 0.81 & 0.66 & \\
\hline & 5-9 & 0.42 & 0.20 & 0.37 & 0.74 & 0.18 & 0.55 & 0.98 & 0.59 & 1.38 & 1.21 & 1.10 & 0.88 & 0.41 & \\
\hline & $\geq 10$ & 0.20 & 0.12 & 0.17 & 0.21 & 0.18 & 0.35 & 0.31 & 0.41 & 0.46 & 0.59 & 0.45 & 0.39 & 0.44 & \\
\hline & Total & 0.41 & 0.25 & 0.26 & 0.38 & 0.46 & 0.72 & 0.67 & 0.74 & 0.89 & 0.90 & 0.65 & 0.48 & 0.47 & \\
\hline \multirow{5}{*}{ Sudeste } & $<1$ & 8.48 & 6.59 & 9.17 & 12.10 & 11.06 & 14.93 & 13.72 & 12.86 & 15.65 & 18.97 & 7.62 & 5.16 & 4.19 & \\
\hline & $1-4$ & 4.25 & 3.59 & 4.60 & 5.87 & 5.83 & 6.17 & 5.32 & 6.97 & 7.27 & 7.90 & 6.41 & 3.38 & 1.64 & \\
\hline & $5-9$ & 1.75 & 1.85 & 1.56 & 2.75 & 2.86 & 2.75 & 2.79 & 3.48 & 3.56 & 3.96 & 3.61 & 4.10 & 3.09 & \\
\hline & $\geq 10$ & 0.26 & 0.34 & 0.41 & 0.57 & 0.54 & 0.56 & 0.67 & 0.82 & 0.92 & 1.05 & 1.13 & 1.10 & 0.88 & \\
\hline & Total & 0.81 & 0.80 & 0.94 & 1.29 & 1.25 & 1.32 & 1.33 & 1.59 & 1.71 & 1.92 & 1.70 & 1.51 & 1.13 & \\
\hline \multirow{5}{*}{ Sul } & $<1$ & 2.24 & 1.51 & 2.77 & 5.00 & 5.26 & 3.42 & 2.05 & 4.55 & 4.20 & 4.85 & 1.32 & 0.44 & 2.79 & \\
\hline & $1-4$ & 1.40 & 1.22 & 1.55 & 2.14 & 1.96 & 1.93 & 1.90 & 1.43 & 1.53 & 1.11 & 1.56 & 0.35 & 0.41 & \\
\hline & $5-9$ & 0.29 & 0.12 & 0.60 & 1.24 & 0.60 & 1.99 & 0.62 & 0.83 & 0.23 & 0.83 & 0.69 & 0.47 & 0.26 & \\
\hline & $\geq 10$ & 0.20 & 0.14 & 0.18 & 0.16 & 0.25 & 0.19 & 0.17 & 0.22 & 0.19 & 0.19 & 0.19 & 0.17 & 0.18 & \\
\hline & Total & 0.32 & 0.24 & 0.35 & 0.46 & 0.47 & 0.50 & 0.34 & 0.40 & 0.32 & 0.35 & 0.32 & 0.20 & 0.23 & \\
\hline
\end{tabular}

${ }^{*}$ O sombreado indica o período pós vacinação. 
$\mathrm{Na}$ analise da série temporal não foi possível incluir a região Norte devido ao grande número de trimestres sem casos, e para os trimestres que tinham registro de casos, na maioria deles o sorogrupo era desconhecido. Esta situação não permitiu que os casos de DM sem sorogrupo fossem redistribuídos para a maioria dos trimestres.

Houve uma tendência histórica de aumento da DMC em todos os grupos etários durante o período de 2001-2013, após o controle da tendência sazonal e implantação da vacina (Tabela 2). As únicas exceções foram na região Sudeste (grupo etário de 1-4 anos) e da região Sul (para os maiores de um ano de idade). O modelo estimou um aumento médio anual de 0,14 casos/100.000/trimestre/ano para os menores de um ano. Este aumento foi maior nas regiões Centro-Oeste e Sudeste.

Com relação à sazonalidade, foi observado um aumento estatisticamente significativo (após o controle da tendência histórica e implantação da vacina) entre os meses de julho e setembro para o Brasil e em todas os grupos etários (Tabela 2).

O efeito da vacinação nas taxas de incidência trimestrais médias da DMC foi ajustada pela tendência histórica, tendência sazonal e regiões geográficas. O modelo estimou reduções estatisticamente significativas que incrementam conforme os anos de implantação da vacina (2011, 2012 e 2013). Por outro lado, o efeito da vacinação diminuiu com o aumento da idade da população do estudo (Tabela 2; Figura 3). 
Tabela 2 Associação entre taxa de incidência de doença meningocócica sorogrupo $\mathrm{C}$ e variáveis* por grupo de idade. Brasil e Regiões, 2001-1013.

\begin{tabular}{|c|c|c|c|c|c|c|c|c|c|c|c|c|}
\hline \multirow{2}{*}{ Variáveis } & \multicolumn{3}{|c|}{$<1$ ano } & \multicolumn{3}{|c|}{ 1-4 anos } & \multicolumn{3}{|c|}{ 5-9 anos } & \multicolumn{3}{|c|}{$\geq 10$ anos } \\
\hline & Coef. & IC $95 \%$ & $\boldsymbol{P}$ & Coef. & IC $95 \%$ & $\boldsymbol{P}$ & Coef. & IC $95 \%$ & $\boldsymbol{P}$ & Coef. & IC $95 \%$ & $\boldsymbol{P}$ \\
\hline \multicolumn{13}{|l|}{ BRASIL } \\
\hline \multicolumn{13}{|c|}{ Vacina: pré-implantação (2001-2009; Ref.) } \\
\hline Implantação (2010) & -0.21 & $(-0.64,0.22)$ & 0.334 & -0.09 & $(-0.20,0.03)$ & 0.136 & 0.01 & $(-0.09,0.11)$ & 0.873 & 0.02 & $(-0.003,0.04)$ & 0.094 \\
\hline Pós-implantação (2011) & -1.13 & $(-1.59,-0.67)$ & 0.000 & -0.27 & $(-0.39,-0.15)$ & 0.000 & -0.06 & $(-0.17,0.04)$ & 0.251 & -0.003 & $(-0.03,0.02)$ & 0.803 \\
\hline Pós-implantação (2012) & -1.58 & $(-2.07,-1.09)$ & 0.000 & -0.64 & $(-0.77,-0.51)$ & 0.000 & -0.05 & $(-0.16,0.06)$ & 0.366 & -0.01 & $(-0.04,0.02)$ & 0.448 \\
\hline Pós-implantação (2013) & -1.49 & $(-2.00,-0.97)$ & 0.000 & -0.84 & $(-0.98,-0.70)$ & 0.000 & -0.22 & $(-0.34,-0.10)$ & 0.000 & -0.04 & $(-0.07,-0.005)$ & 0.024 \\
\hline Ano (2001-2013) & 0.14 & $(0.09,0.18)$ & 0.000 & 0.05 & $(0.04,0.07)$ & 0.000 & 0.02 & $(0.01,0.04)$ & 0.000 & 0.01 & $(0.01,0.01)$ & 0.000 \\
\hline \multicolumn{13}{|l|}{ Trimestre (Jan.-Mar.; Ref.) } \\
\hline 3 (Jul.-Set.) & 0.40 & $(0.14,0.66)$ & 0.003 & 0.15 & $(0.10,0.21)$ & 0.000 & 0.08 & $(0.03,0.13)$ & 0.002 & 0.04 & $(0.03,0.05)$ & 0.000 \\
\hline 4 (Out.-Dez.) & 0.08 & $(-0.18,0.33)$ & 0.560 & 0.00 & $(-0.05,0.06)$ & 0.881 & 0.01 & $(-0.03,0.06)$ & 0.555 & 0.01 & $(0.004,0.02)$ & 0.005 \\
\hline \multicolumn{13}{|l|}{ Região (Nordeste; ref.) } \\
\hline Centro Oeste & 0.63 & $(0.30,0.96)$ & 0.000 & 0.30 & $(0.14,0.46)$ & 0.000 & -0.03 & $(-0.09,0.04)$ & 0.411 & 0.00 & $(-0.02,0.02)$ & 0.769 \\
\hline Sudeste & 2.16 & $(1.87,2.44)$ & 0.000 & 1.10 & $(0.96,1.25)$ & 0.000 & 0.53 & $(0.46,0.60)$ & 0.000 & 0.09 & $(0.07,0.11)$ & 0.000 \\
\hline Sul & 0.24 & $(-0.004,0.48)$ & 0.054 & 0.14 & $(0.02,0.25)$ & 0.018 & -0.03 & $(-0.09,0.03)$ & 0.341 & -0.04 & $(-0.05,-0.02)$ & 0.000 \\
\hline \multicolumn{13}{|l|}{ NORDESTE } \\
\hline \multicolumn{13}{|c|}{ Pré-implantação (2001-2009; Ref.) } \\
\hline Implantação (2010) & -0.31 & $(-0.63,0.004)$ & 0.053 & -0.13 & $(-0.30,0.03)$ & 0.111 & -0.01 & $(-0.15,0.13)$ & 0.881 & 0.05 & $(0.02,0.08)$ & 0.003 \\
\hline Ano (2001-2013) & 0.12 & $(0.09,0.15)$ & 0.000 & 0.03 & $(0.01,0.04)$ & 0.003 & 0.02 & $(0.0004,0.03)$ & 0.044 & 0.01 & $(0.004,0.01)$ & 0.000 \\
\hline \multicolumn{13}{|l|}{ Trimestre (Jan.-Mar.; Ref.) } \\
\hline 2 (Abr.-Jun.) & -0.14 & $(-0.44,0.15)$ & 0.340 & -0.08 & $(-0.17,0.01)$ & 0.084 & -0.03 & $(-0.10,0.03)$ & 0.341 & 0.00 & $(-0.01,0.02)$ & 0.636 \\
\hline 3 (Jul.-Set.) & 0.13 & $(-0.11,0.37)$ & 0.283 & -0.03 & $(-0.13,0.06)$ & 0.477 & 0.00 & $(-0.08,0.07)$ & 0.930 & 0.02 & $(0.01,0.04)$ & 0.006 \\
\hline 4 (Out.-Dez.) & 0.10 & $(-0.19,0.40)$ & 0.486 & -0.08 & $(-0.17,0.02)$ & 0.110 & -0.03 & $(-0.09,0.04)$ & 0.426 & 0.00 & $(-0.01,0.02)$ & 0.694 \\
\hline
\end{tabular}

${ }^{*}$ As associações foram estimadas com base no modelo de regressão GLS considerando como variável dependente as taxas de incidência trimestrais de doença meningocócica sorogrupo $\mathrm{C}$ para cada ano. 
Tabela 2 Associação entre taxa de incidência de doença meningocócica sorogrupo C e variáveis* por grupo de idade. Brasil e Regiões, 2001-1013. - continuação.

\begin{tabular}{|c|c|c|c|c|c|c|c|c|c|c|c|c|}
\hline \multirow{2}{*}{ Variáveis } & \multicolumn{3}{|c|}{$<1$ ano } & \multicolumn{3}{|c|}{ 1-4 anos } & \multicolumn{3}{|c|}{$5-9$ anos } & \multicolumn{3}{|c|}{$\geq 10$ anos } \\
\hline & Coef. & IC 95\% & $P$ & Coef. & IC 95\% & $\boldsymbol{P}$ & Coef. & IC 95\% & $\boldsymbol{P}$ & Coef. & IC $95 \%$ & $P$ \\
\hline \multicolumn{13}{|l|}{ CENTRO OESTE } \\
\hline \multicolumn{13}{|c|}{ Pré-implantação (2001-2009; Ref.) } \\
\hline Implantação (2010) & -1.27 & $(-2.29,-0.24)$ & 0.016 & -0.05 & $(-0.47,0.37)$ & 0.801 & 0.04 & $(-0.14,0.22)$ & 0.632 & 0.03 & $(-0.02,0.08)$ & 0.241 \\
\hline Ano (2001-2013) & 0.21 & $(0.11,0.32)$ & 0.000 & 0.08 & $(0.04,0.12)$ & 0.000 & 0.02 & $(0.003,0.04)$ & 0.023 & 0.01 & $(0.004,0.02)$ & 0.001 \\
\hline \multicolumn{13}{|l|}{ Trimestre (Jan.-Mar.; Ref.) } \\
\hline 2 (Abr.-Jun.) & 0.20 & $(-0.61,1.01)$ & 0.628 & -0.09 & $(-0.35,0.17)$ & 0.499 & -0.05 & $(-0.16,0.06)$ & 0.398 & 0.01 & $(-0.02,0.03)$ & 0.711 \\
\hline 3 (Jul.-Set.) & 0.11 & $(-0.62,0.84)$ & 0.759 & 0.22 & $(-0.05,0.48)$ & 0.104 & 0.05 & $(-0.07,0.16)$ & 0.423 & 0.04 & $(0.01,0.07)$ & 0.014 \\
\hline \multicolumn{13}{|l|}{ SUDESTE } \\
\hline \multicolumn{13}{|c|}{ Pré-implantação (2001-2009; Ref.) } \\
\hline Implantação (2010) & 0.70 & $(-0.16,1.56)$ & 0.108 & -0.04 & $(-0.53,0.46)$ & 0.883 & 0.08 & $(-0.13,0.28)$ & 0.469 & 0.02 & $(-0.03,0.07)$ & 0.374 \\
\hline Pós-implantação (2011-2013) & -3.08 & $(-3.87,-2.29)$ & 0.000 & -0.86 & $(-1.44,-0.27)$ & 0.004 & -0.15 & $(-0.35,0.05)$ & 0.154 & -0.02 & $(-0.08,0.03)$ & 0.424 \\
\hline Ano (2001-2013) & 0.23 & $(0.14,0.32)$ & 0.000 & 0.06 & $(-0.01,0.13)$ & 0.096 & 0.06 & $(0.03,0.08)$ & 0.000 & 0.02 & $(0.01,0.02)$ & 0.000 \\
\hline \multicolumn{13}{|l|}{ Trimestre (Jan.-Mar.; Ref.) } \\
\hline 2 (Abr.-Jun.) & -0.19 & $(-0.69,0.30)$ & 0.451 & 0.27 & $(0.11,0.42)$ & 0.001 & 0.15 & $(0.06,0.25)$ & 0.002 & 0.05 & $(0.03,0.06)$ & 0.000 \\
\hline 3 (Jul.-Set.) & 0.88 & $(0.37,1.40)$ & 0.001 & 0.44 & $(0.27,0.62)$ & 0.000 & 0.30 & $(0.19,0.40)$ & 0.000 & 0.08 & $(0.06,0.10)$ & 0.000 \\
\hline 4 (Out.-Dez.) & 0.04 & $(-0.45,0.54)$ & 0.865 & 0.15 & $(-0.01,0.31)$ & 0.059 & 0.15 & $(0.06,0.25)$ & 0.002 & 0.04 & $(0.02,0.06)$ & 0.000 \\
\hline Implantação (2010) & 0.05 & $(-0.52,0.62)$ & 0.863 & -0.15 & $(-0.42,0.12)$ & 0.274 & 0.01 & $(-0.19,0.21)$ & 0.945 & 0.00 & $(-0.03,0.02)$ & 0.718 \\
\hline Pós-implantação (2011-2013) & -0.96 & $(-1.46,-0.45)$ & 0.000 & -0.24 & $(-0.48,0.00)$ & 0.052 & -0.11 & $(-0.29,0.08)$ & 0.269 & -0.01 & $(-0.03,0.01)$ & 0.514 \\
\hline Ano (2001-2013) & 0.06 & $(0.00,0.12)$ & 0.036 & 0.00 & $(-0.03,0.03)$ & 0.876 & 0.01 & $(-0.01,0.03)$ & 0.517 & 0.00 & $(-0.002,0.003)$ & 0.509 \\
\hline \multicolumn{13}{|l|}{ Trimestre (Jan.-Mar.; Ref.) } \\
\hline 2 (Abr.-Jun.) & -0.02 & $(-0.57,0.52)$ & 0.930 & 0.03 & $(-0.17,0.22)$ & 0.798 & 0.05 & $(-0.05,0.15)$ & 0.360 & 0.01 & $(-0.01,0.02)$ & 0.355 \\
\hline 3 (Jul.-Set.) & 0.77 & $(0.34,1.21)$ & 0.000 & 0.14 & $(-0.05,0.32)$ & 0.140 & 0.13 & $(0.02,0.24)$ & 0.023 & 0.02 & $(0.01,0.04)$ & 0.002 \\
\hline 4 (Out.-Dez.) & 0.21 & $(-0.33,0.75)$ & 0.452 & 0.16 & $(-0.04,0.35)$ & 0.113 & 0.06 & $(-0.04,0.16)$ & 0.258 & 0.01 & $(-0.01,0.03)$ & 0.173 \\
\hline
\end{tabular}

*As associações foram estimadas com base no modelo de regressão GLS considerando como variável dependente as taxas de incidência trimestrais de doença meningocócica sorogrupo $\mathrm{C}$ para cada ano. 
Figura 3 Reduções médias das taxas de incidência de doença meningocócica sorogrupo C* por faixa etária após a introdução da vacina. Brasil, 2010 a 2013.
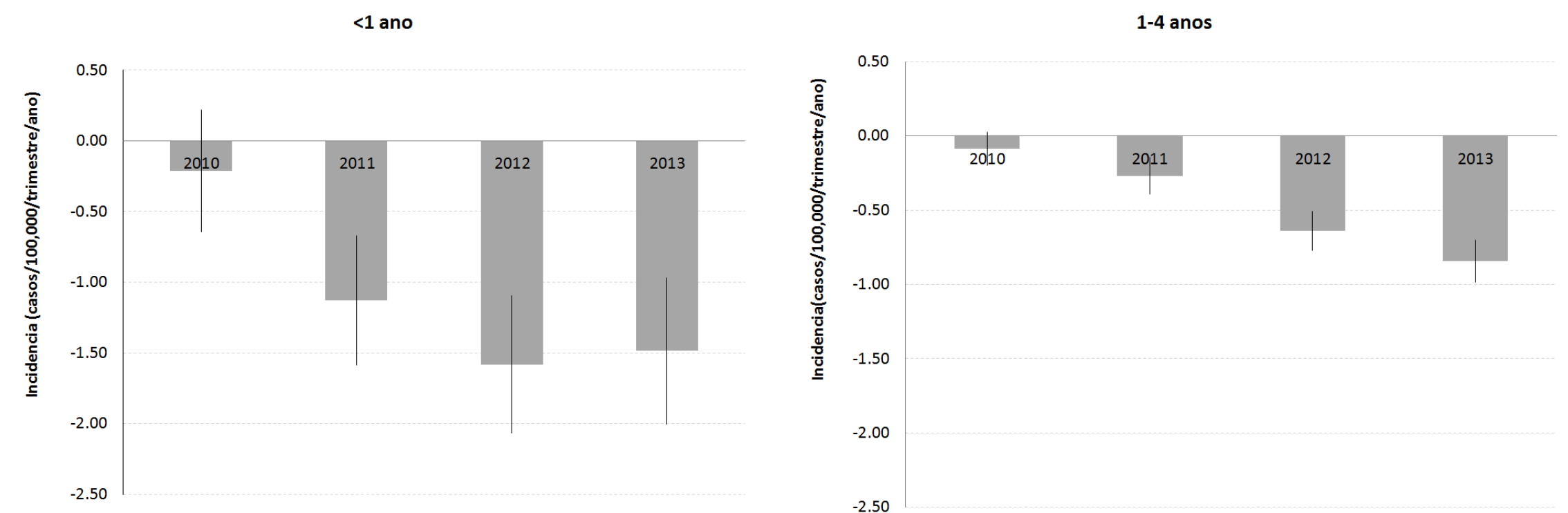

*As reduções médias foram estimadas com base nos modelos de regressão GLS considerando-se como variável dependente as taxas de incidência trimestrais de cada ano, e ajustadas pela tendência histórica e sazonalidade. 
Figura 3 Reduções médias das taxas de incidência de doença meningocócica sorogrupo C* por faixa etária após a introdução da vacina. Brasil, 2010 a 2013. - continuação
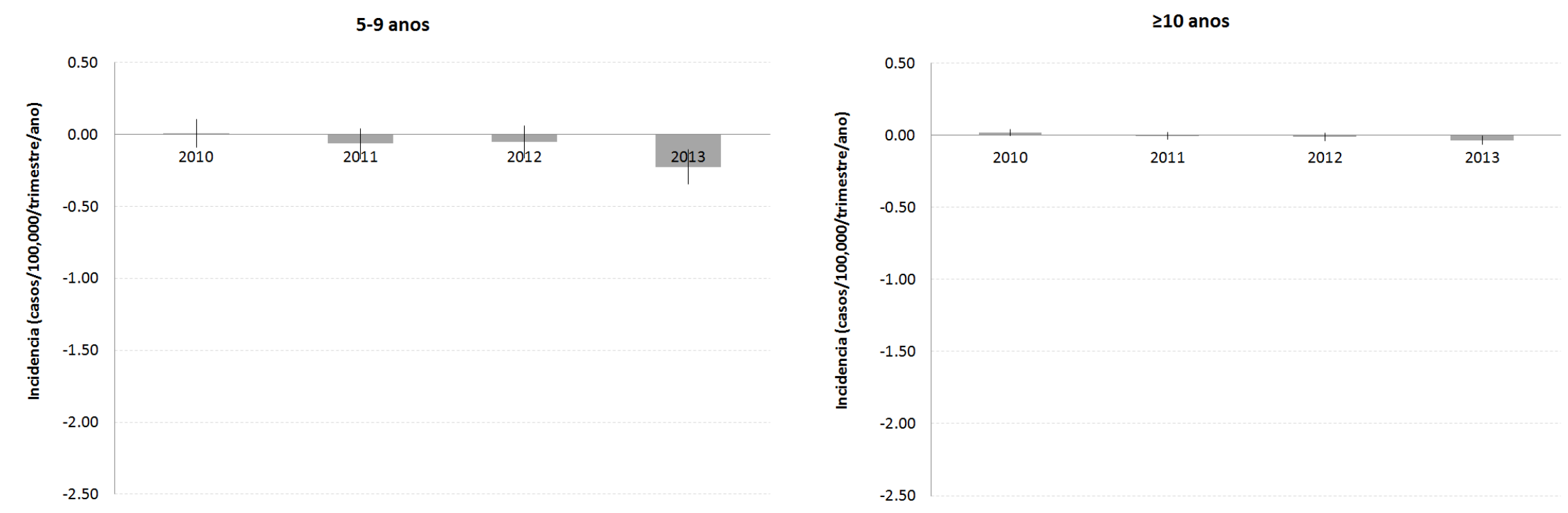

*As reduções médias foram estimadas com base nos modelos de regressão GLS considerando-se como variável dependente as taxas de incidência trimestrais de cada ano, e ajustadas pela tendência histórica e sazonalidade. 
Para o grupo de menores de um ano foi observada redução das taxas de incidência nos três anos após a introdução da vacina MenC $(P<0,001)$. Essa redução ocorreu de forma gradual, com a taxa de incidência de DMC reduzindo em média $1,13 \quad$ (2011), $1,58 \quad$ (2012), e $\quad 1,49$ casos/100.000/trimestre/ano (2013). Em relação ao grupo de 1-4 anos, também ocorreu um gradiente de redução de 0,27 (2011), 0,64 (2012) e 0,84 casos/100.000/trimestre/ano em (2013) $(P<0,001)$. Com relação aos grupos de 5-9 e $\geq 10$ anos a redução foi de $0,22(P<0,001)$ e de 0,04 casos/100.000/trimestre/ano $(P=0,024)$, respectivamente, apenas para o ano de 2013 (Tabela 2; Figura 3).

As quatro regiões avaliadas apresentaram redução na taxa de incidência de DMC, estatisticamente significativa, para os grupos etários de $<1$ ano e de 1-4 anos, com exceção da região Sul para o grupo de 1-4 anos. Os maiores impactos foram encontrados nas regiões Sudeste e CentroOeste: para os <1 ano de idade, as reduções foram 3,08 e 2,33 casos/100.000/trimestre/ano, enquanto que para o grupo de 1-4 anos foram 0,86 e 0,82 casos/100.000/trimestre/ano, respectivamente. Nas regiões Nordeste e Sul as reduções foram menores: 0,82 e 0,96 casos/100.000/trimestre/ano para os $<1$ ano de idade, e 0,20 e 0,24 casos/100.000/trimestre/ano para o grupo de 1-4 anos, respectivamente (Tabela 2).

A estimação dos mesmos modelos de séries temporais considerando as taxas de incidência de DMC sem a redistribuição de casos com sorogrupo 
desconhecido produziram resultados praticamente idênticos, exceto por subestimarem de maneira sistemática os coeficientes estimados.

Na Tabela 3 estão apresentados os resultados do impacto da vacina MenC em termos de redução percentual de casos de DMC, derivados dos modelos de regressão. No Brasil, no período de 2011 a 2013, a redução dos casos para as crianças $<1$ ano e de $1-4$ anos de idade, foi de $65,2 \%$ e $46,9 \%$, respectivamente. Com relação às regiões geográficas, a redução de caso para as crianças $<1$ ano de idade, foi maior na região Centro-Oeste, e menor na Nordeste (Tabela 3). 
Tabela 3 Percentual de redução de casos estimado pelo modelo de regressão para os menores de um ano e para o grupo de um a quatro anos de idade no Brasil e regiões nos três anos seguintes a introdução da vacina MenC.

\begin{tabular}{|c|c|c|c|c|}
\hline & \multicolumn{2}{|c|}{$<1$ ano } & \multicolumn{2}{|c|}{ 1-4 anos } \\
\hline & $\begin{array}{c}\text { Variação } \\
\text { nos casos } \\
\text { de DMC }\end{array}$ & IC 95\% & $\begin{array}{c}\text { Variação } \\
\text { nos casos } \\
\text { de DMC }\end{array}$ & IC 95\% \\
\hline \multicolumn{5}{|l|}{ Brasil } \\
\hline 2010 & 1,5 & $(-19,6$ a 22,5$)$ & $-4,2$ & $(-23,2$ a 14,8$)$ \\
\hline 2011 & $-54,6$ & $(-75,3$ a $-33,8)$ & $-21,8$ & $(-40,8$ a $-2,8)$ \\
\hline 2012 & $-70,9$ & $(-91,7$ a $-50,2)$ & $-57,6$ & $(-76,8$ a $-38,4)$ \\
\hline 2013 & $-70,7$ & $(-91,6$ a $-49,8)$ & $-74,5$ & $(-92,7$ a $-56,2)$ \\
\hline 2011-2013 & $-65,7$ & $(-86,5 \mathrm{a}-44,9)$ & $-51,8$ & $(-70,6$ a $-33,0)$ \\
\hline \multicolumn{5}{|l|}{ Nordeste } \\
\hline 2010 & $-28,2$ & $(-52,5$ a $-3,9)$ & $-44,8$ & $(-90,9$ a 1,2$)$ \\
\hline 2011-2013 & $-56,7$ & $(-76,0$ a $-37,4)$ & $-55,0$ & $(-97,2 \mathrm{a}-12,9)$ \\
\hline \multicolumn{5}{|l|}{ Centro Oeste } \\
\hline 2010 & $-55,0$ & $(-97,0$ a $-13,1)$ & $-9,4$ & $(-46,5$ a 27,8$)$ \\
\hline $2011-2013$ & $-83,7$ & $(-100,0$ a $-51,1)$ & $-73,4$ & $(-100,0$ a $-39,1)$ \\
\hline \multicolumn{5}{|l|}{ Sudeste } \\
\hline 2010 & 13,5 & $(-2,7$ a 29,7$)$ & 4,5 & $(-6,8$ a 15,8$)$ \\
\hline 2011-2013 & $-65,4$ & $(-82,2 \mathrm{a}-12,2)$ & $-42,9$ & $(-72,3$ a $-13,5)$ \\
\hline \multicolumn{5}{|l|}{ Sul } \\
\hline 2010 & 4,2 & $(-34,7$ a 43,0$)$ & $-32,6$ & $(-75,5$ a 10,3$)$ \\
\hline 2011-2013 & $-60,1$ & $(-91,7$ a $-28,5)$ & $-44,0$ & $(-88,4$ a 0,4$)$ \\
\hline
\end{tabular}




\section{DISCUSSÃO}

Este é o primeiro estudo a avaliar o impacto da introdução da vacina MenC no Brasil considerando os dados nacionais, os diferenciais regionais e por idade.

A estimação do impacto da vacinação requer ajuste das tendências temporais e sazonais. O método escolhido levou esses fatores em consideração, uma vez que se tivessem sido ignorados poderiam influenciar negativamente a validade das estimativas do impacto da vacinação. De modo geral, houve uma tendência histórica de aumento da DMC em todos os grupos etários ao longo do período 2001-2013, especialmente nas regiões Centro-Oeste e Sudeste. O estudo estimou um aumento médio de 0,14 casos/100.000/trimestre/ano para o grupo etário de $<1$ ano de idade. Esses achados refletem a introdução de uma cepa do sorogrupo $C$ pertencente a uma linhagem hipervirulenta (ST-103), que foi descrita pela primeira vez em São Paulo, na região Sudeste no inicio dos anos 2.000 (Lemos et al. 2007), e depois se espalhou para outras regiões (Cardoso et al. 2012; Tauil et al. 2014). Também foi observado predomínio sazonal da doença nos meses de inverno, julho a setembro. Esta é uma característica conhecida da DM no Brasil, que também ocorre em outros países (Halperin et al. 2012).

A redução da taxa de incidência de DMC no Brasil ocorre de forma consistente com a implantação da vacina MenC. Foi observada uma redução significativa no número de casos estimados após a introdução da vacinação 
(2011, 2012 e 2013) em crianças $<1$ e de $1-4$ anos de idade. No que diz respeito aos grupos etários de 5-9 e $\geq 10$ anos de idade, também foi observada uma redução estatisticamente significativa na taxa de incidência da DMC no ano de 2013, embora a pequena magnitude desse efeito deva ser considerada com cautela. Além disso, o estudo identificou a região geográfica como sendo uma variável modificadora do impacto da vacina MenC no Brasil. Nas regiões Centro-Oeste e Sudeste, os impactos foram mais precoces e mais relevantes do que nas outras regiões.

O impacto relevante encontrado na redução da DMC no Brasil para crianças < 1 ano de idade no período 2011-2013 (65,7\%; IC95\%: 44,9 a 86,5) demonstra o efeito direto da vacinação na população-alvo. No Reino Unido e na Espanha, o impacto da vacina MenC na incidência da doença em crianças $<1$ ano de idade foi de $77,5 \%$ e $85 \%$, respectivamente (Balmer et al. 2002;. Larrauri et al. 2005).

Para as crianças de 1-4 anos de idade a redução dos casos estimados devido à vacinação foi de $51,8 \%$ (IC $95 \%$ : 33,0 a 70,6 ), sendo este valor inferior à redução estimada para 0 grupo $<1$ ano de idade. Isso pode ser justificado devido ao fato de este grupo incluir crianças que não tenham sido vacinadas. A redução atribuída à vacinação nessa faixa etária em outros países foi de aproximadamente 85\% (Balmer et al. 2002;. Larrauri et al. 2005).

O impacto reduzido para o ano 2013, para os grupos etários de 5-9 anos $(P<0,001)$ e $\geq 10$ anos de idade $(P=0,024)$, pode ser consequência do 
deslocamento da coorte de imunizados no decorrer do tempo (em particular crianças de 5-6 anos de idade). A hipótese de ocorrência de imunidade de rebanho também pode ser considerada.

É controversa a discussão da influencia da vacinação de crianças mais jovens na disponibilidade, ainda que baixa, do estado de portador de meningococo, e seu potencial impacto indireto na redução da doença em grupos de crianças mais velhas. É importante ressaltar que a prevalência de portadores de meningococo, descrito em um estudo de meta-análise (Christensen et al. 2010), tendeu a ser maior na adolescência e início da idade adulta (pico de $23,7 \%$ aos 19 anos de idade), do que entre as crianças (4,5\% em recém-nascidos e $7,7 \%$ aos 10 anos de idade). Estudos que avaliem adequadamente esta hipótese devem ser realizados.

De maneira geral, os resultados deste estudo foram semelhantes aos descritos na literatura (Balmer et al. 2002;. Larrauri et al. 2005;. Mooney et al. 2004; Bettinger et al. 2009). As pequenas diferenças observadas no impacto podem ser justificadas, pelo menos em parte, devido às opções metodológicas utilizadas na analise, as especificidades da epidemiologia da doença, e o tipo de esquema vacinal utilizado em cada país. No que diz respeito ao método, é importante ressaltar que a estimativa do impacto foi oriunda de um estudo ecológico, em que as populações de crianças do período pré-vacinação foram comparadas com as crianças do período pósvacinação (sendo estas últimas vacinadas ou não; e entre as vacinadas, podendo apresentar ainda diferenças nos tempos decorridos desde a 
vacinação e no número de doses recebidas). Além disso, como o modelo escolhido para a estimação do impacto foi o de séries temporais ajustadas, é de se esperar que a estimação dos parâmetros seja mais conservadora que aquelas obtidas a partir de análises não ajustadas.

Com relação aos grupos etários alvos da vacinação, o objetivo do Brasil foi imunizar diretamente crianças $<2$ anos, principalmente os lactentes, grupo este com maior risco de contrair doença meningocócica no país. Diferente de outros países, no Brasil não é observado pico de incidência da doença entre adolescentes ou adultos jovens. Esta condição é verificada apenas em situações de surtos, quando são observadas altas taxas de ataque entre estes grupos (Cardoso et al. 2012; Iser et al. 2012; Gorla et al. 2012). Praticamente todos os países (Bettinger et al. 2009; Trotter et al. 2004, 2007; Garrido-Estepa et al. 2014) que implantaram a vacina MenC em seus programas de imunização optaram por realizar campanhas catch-up para adolescentes, o que pareceu ter sido crucial para gerar níveis elevados de imunidade de rebanho (Ramsay et al. 2001, 2003;. Kinlin et al. 2009). As vacinas conjugadas têm a capacidade de reduzir a prevalência de portadores, resultando na redução do risco de adquirir a doença, mesmo para aqueles indivíduos não vacinados (Maiden et al. 2008; Campbell et al. 2010). Com base nos dados deste estudo, aparentemente, não foi possível observar redução consistente de DMC em outros grupos etários não alvo da vacinação após introdução da vacina MenC. Um exemplo disso é o observado no numero de casos de DMC em crianças 
menores de três meses de idade, no Brasil, onde não houve redução após a introdução da vacina (de Moraes 2016). No Reino Unido, para esta faixa etária, houve redução no numero de casos de doença, atribuída ao efeito protetor indireto da vacina (Campbell et al. 2009). Esses achados devem ser considerados para discussão sobre a inclusão da vacina MenC para outras faixas etárias no Brasil.

Importantes variações subnacionais são descritas quando consideradas as análises do impacto da vacinação nas diferentes regiões. Além disso, observa-se impacto crescente desta intervenção ao longo do período de análise. O Brasil é um país continental, com diferenças importantes na implantação das políticas de saúde, tal como o programa de imunização, como consequência do desenvolvimento regional e de um sistema de saúde descentralizado. As análises subnacionais são úteis para formular hipóteses que podem explicar o menor impacto da vacina em algumas regiões brasileiras. Estas hipóteses podem estar relacionadas às coberturas vacinais, a qualidade da vigilância da doença, bem como a carga da DM que pode ser influenciada pela densidade populacional e presença de aglomerados urbanos.

De maneira geral, a implantação da vacina MenC no Brasil ocorreu entre março e novembro de 2010, e altas coberturas vacinais foram alcançadas nos meses seguintes a implantação em praticamente todas as regiões do país. Com exceção da região Nordeste, que atingiu a meta preconizada pelo PNI/MS (cobertura vacinal >95\%) apenas em 2013 (Brasil 
SI-PNI). Este fato, eventualmente, poderia explicar o menor impacto da intervenção observada naquela região. A região Sudeste apresenta consistentemente as maiores taxas de incidência de DMC, tanto no período anterior como posterior a introdução da vacina. Além disso, nessa região, assim como na Centro-Oeste, ocorreu uma forte tendência de crescimento desta taxa no período que antecedeu a implantação da vacina, o que possivelmente pode ter influenciado o resultado, refletindo no impacto mais elevado observado para estas regiões. O impacto mediano encontrado na região Sul pode estar relacionado com as baixas taxas de incidência de DMC, devido aumento tardio da circulação do sorogrupo C, que ocorreu apenas entre 2012-2013, diferente do observado nas demais regiões.

Os resultados do estudo devem ser interpretados considerando algumas limitações. A primeira delas é inerente ao uso de fontes secundárias de dados, que inclui a possibilidade de subnotificação, algum grau de inconsistência no registro das variáveis de interesse e classificação de casos. Contudo, estudos têm demonstrado que dados provenientes do Sinan são suficientemente válidos para acompanhar mudanças nas tendências históricas da doença (Azevedo et al. 2013). Outra limitação é a percentagem elevada de casos de DM sem identificação do sorogrupo na base de dados utilizada neste estudo. Essa limitação foi minimizada pela redistribuição proporcional destes casos assumindo a mesma distribuição dos sorogrupos identificados dos casos de DM confirmados por laboratório, de acordo com a região de residência, grupo de idade e trimestre de início 
de sintomas dos casos (Miller et al. 2002). Se estes casos (com sorogrupo não identificado) não tivessem sido redistribuídos e sim excluídos da análise, isto poderia levar à subestimativa importante da taxa de incidência, aumentar o erro aleatório das estimativas (e a amplitude do intervalo de confiança) e introduzir viés de seleção, uma vez que a identificação de sorogrupos melhorou ao longo do período de análise. Outra limitação pode estar relacionada a não exclusão das crianças menores de três meses dos cálculos das taxas de incidência de DMC nas análises de impacto da vacina, estas crianças não foram alvo da vacinação e foram responsáveis por 14$18 \%$ dos casos de DMC no grupo etário de $<1$ ano. Como no Brasil, não foram incluídos adolescentes e adultos na estratégia de vacinação, não é esperado a ocorrência de imunidade de rebanho em faixas etárias não vacinadas como observado em outros países (Ramsay et al. 2003; Maiden et al. 2008). De fato, os dados nacionais indicam que os casos em crianças menores de três meses não diminuíram após a introdução da vacina (de Moraes 2016). Portanto, a não exclusão destas crianças dos cálculos pode ter influenciado os resultados em termos de impactos subestimados. Finalmente, a natureza ecológica deste estudo limita a generalização de seus resultados para o nível individual, não permitindo que seus resultados sejam, por exemplo, comparáveis aos de estudos individuados.

Em conclusão, a vacinação contra DMC no Brasil apresentou impacto na população-alvo (crianças $<1$ ano de idade) para todas as regiões analisadas (embora em diferentes magnitudes) e na coorte de 1-4 anos de 
idade. Ainda assim, acreditamos que exista espaço para aprimoramento da estratégia de vacinação adotada no Brasil. A vacinação de outros grupos etários, como os adolescentes, poderia contribuir para um impacto mais relevante, incluindo um possível efeito indireto sobre os grupos não vacinados. Nossos resultados também apontam para a necessidade de desenvolver estudos para melhor compreensão das diferenças regionais sobre o impacto da vacina. Além disso, o monitoramento das coberturas vacinais e o aprimoramento contínuo do sistema de vigilância da DM são fundamentais para melhorar o impacto da vacina e consequentemente diminuir a carga da doença no Brasil.

\section{REFERÊNCIAS}

Azevedo LCP, Toscano CM, Bierrenbach AL. Bacterial meningitis in Brazil: baseline epidemiologic assessment of the decade prior to the introduction of pneumococcal and meningococcal vaccines. PLoS ONE. 2013; 8(6): e64524. doi:10.1371/journal.pone.0064524

Balmer $\mathrm{P}$, Borrow R, Miller E.Impact of meningococcal $\mathrm{C}$ conjugate vaccine in the UK.J Med Microbiol 2002;51(9):717-22.

Bettinger JA, Scheifele DW, Le Saux N, Halperin SA, Vaudry W, Tsang R, et al. The impact of childhood meningococcal serogroup $C$ conjugate vaccine programs in Canada. Pediatr Infect Dis J. 2009; 28: 220-224. 
Brasil. Ministério do Planejamento, Orçamento e Gestão. Instituto Brasileiro de Geografia e Estatística. Diretoria de Pesquisas. Coordenação de População e Indicadores Sociais. Gerência de Estudos e Análises da Dinâmica Demográfica. Projeção da população do Brasil por sexo e idade para período 2000-2060. Disponível em: http://www.ibge.gov.br/home/estatistica/populacao/projecao da populacao/2 013/default tab.shtm - Acessado em agosto de 2015

Brasil. Ministério da Saúde. Secretaria de Vigilância em Saúde. Programa Nacional de Imunizações. Calendário Nacional de Imunização. Disponível em: http://portalsaude.saude.gov.br/index.php/o-ministerio/principal/leiamais-o-ministerio/197-secretaria-svs/13600-calendario-nacional-devacinacao - Acessado em agosto 2015

Brasil. Ministério da Saúde. Secretaria de Vigilância em Saúde. Sistema de Informação de Agravos de Notificação. Brasil, 2001-2006. Disponível em: http://dtr2004.saude.gov.br/sinanweb/tabnet/dh?sinan/meningite/bases/meni nbr.def - Acessado em agosto 2015

Brasil. Ministério da Saúde. Secretaria de Vigilância em Saúde. Sistema de Informação de Agravos de Notificação. Brasil, 2007-2013. Disponível em: http://dtr2004.saude.gov.br/sinanweb/tabnet/dh?sinannet/meningite/bases/m eninbrnet.def - Acessado em agosto 2015

Brasil. Ministério da Saúde. Portaria no. 1271, Junho, 2014. Diário Oficial da União, Brasília, DF, Seção I, № 108, pag. 67-69. Disponível em: 
http://bvsms.saude.gov.br/bvs/saudelegis/gm/2014/prt1271 $06 \quad 06$ 2014.htm I - Acessado em agosto 2015

Brasil. Ministério da Saúde. Secretaria de Vigilância em Saúde. Sistema de Informação de Nascidos Vivos. Disponível em: http://tabnet.datasus.gov.br/cgi/deftohtm.exe?sinasc/cnv/nvuf.def - Acessado em agosto 2015

Brasil. Ministério da Saúde. Secretaria de Vigilância em Saúde. Programa Nacional de Imunizações. Sistema de informação do Programa Nacional de Imunização.

Disponível

em: http://pni.datasus.gov.br/inf estatistica cobertura.asp - Acessado em agosto 2015

Brasil. Ministério da Saúde. Secretaria de Vigilância em Saúde. Guia de $\begin{array}{llll}\text { Vigilância em } & \text { Saúde. } & \text { Disponível }\end{array}$ http://portalsaude.saude.gov.br/images/pdf/2014/novembro/27/guiavigilancia-saude-linkado-27-11-14.pdf - Acessado em agosto 2016 Campbell H, Borrow R, Salisbury D, et al. Meningococcal C conjugate vaccine: the experience in England and Wales. Vaccine 2009;27S:B20-B29.

Campbell $\mathrm{H}$, Andrews N, Borrow R, et al. Updated postlicensure surveillance of the meningococcal $\mathrm{C}$ conjugate vaccine in England and Wales: effectiveness, validation of serological correlates of protection, and modeling predictions of the duration of herd immunity. Clin Vaccine Immunol2010;17:840-847. 
Cardoso CW, Pinto LLS, Reis MG, et al. Impact of vaccination during an epidemic of serogroup C meningococcal disease in Salvador, Brazil.Vaccine 2012;30:5541-5546.

Christensen H, May M, Bowen L, et al. Meningococcal carriage by age: a systematic review and meta-analysis. Lancet Infect Dis 2010;10:853-61.

Garrido-Estepa M, León-Gómez I, Herruzo R, Cano R. Changes in meningococcal $\mathrm{C}$ epidemiology and vaccine effectiveness after vaccine introduction and schedule modification. Vaccine 2014; 32: 2604-2609.

Gorla MC, de Lemos AP, Quaresma M, et al. Phenotypic and molecular characterization of serogroup C Neisseria meningitidis associated with an outbreak in Bahia, Brazil. Enferm Infecc Microbiol Clin 2012;30(2):56-9.

Halperin SA, Bettinger JA, Greenwood B, et al.The changing and dynamic epidemiology of meningococcal disease.Vaccine 2012;30:B26-36.

Hsiao, C. Panel data analysis-advantages and challenges.TEST 2007; 16(1):1-22.

Ibarz-Pavon AB, Lemos AP, Gorla MC, et al. Laboratory-Based Surveillance of Neisseria meningitidis isolatesfrom Disease Cases in Latin American and Caribbean Countries, SIREVA II 2006-2010. PLoS ONE 2012;7(8):e44102.

Iser BPM, Lima HCAV, De Moraes C, et al. Outbreak of Neisseria meningitidis $\mathrm{C}$ in workers at a largefood-processing plant in Brazil: 
challenges of controlling diseasespread to the larger community. Epidemiol Infect 2012;140:906-915.

Kinlin LM, Jamieson F, Brown EM, et al. Rapid identification of herd effects with the introduction of serogroup $\mathrm{C}$ meningococcal conjugate vaccine in Ontario, Canada, 2000-2006. Vaccine 2009;27:1735-1740.

Larrauri A, Cano R, Garcia $M$, et al.Impact and effectiveness of meningococcal C conjugate vaccine following its introduction in Spain. Vaccine2005;23:4097-4100.

Lemos APS, Yara TY, Gorla MCO, et al. Clonal distribution of invasive Neisseria meningitides serogroup C strains circulating from 1976 to 2005 in Greater São Paulo, Brazil. J ClinMicrobiol 2007;45:1266-1273.

Liphaus BL, Cappeletti-Gonçalves-Okai MI, Silva-Delemos AP, et al. Outbreak of Neisseria meningitidis $C$ in a Brazilian oil refinery involving an adjacent community. Enferm Infecc Microbiol Clin. 2013 Feb;31(2):88-92.

Maiden MCJ, Ibarz-Pavón $A B$, Urwin $R$, et al. Impact of meningococcal serogroup $\mathrm{C}$ conjugate vaccines on carriage and herd immunity. $\mathrm{J}$ Infect Dis 2008;197:737-743.

Miller E, Salisbury D, Ramsay M. Planning, registration, and implementation of an immunization campaign against meningococcal serogroup $\mathrm{C}$ disease in the UK: a success story. Vaccine 2002;20:S58-S67. 
Mooney JD, Christie P, Robertson C, et al. The impact of meningococcal serogroup C conjugate vaccine in Scotland.Clin Infect Dis 2004;39(3):349356.

Moraes, Camile de. Doença meningocócica no Brasil: descrição de casos, evidência da efetividade e do impacto da vacina meningocócica $C$ conjugada, 2001-2013. Brasília/DF: UnB, 2016. Tese. Programa de Pósgraduação em Medicina Tropical, Faculdade de Medicina, Universidade de Brasilia. Brasília/DF, 2016.

Morgenstern $\mathrm{H}$. Ecologic studies in epidemiology: concepts, principles, and methods. Annu Rev Public Health 1995;16:61-81

Pan American Health Organization.Informe regional de SIREVA II: datos por país y por grupos de edad sobre las características de los aislmientos de Streptococcus pneumoniae, Haemophilus influenzae y Neisseria meningitidis, em procesos invasores, 2000-2005. Documentos Técnicos, Tecnologías Esenciales de Salud. THS/EV. 2007/002, Washington, DC: Pan American HealthOrganization, 2007. http://www.paho.org/Spanish/AD/THS/EV/LABS-Sireva.pdf accessed August 2015

Ramsay ME, Andrews N, Kaczmarski EB, et al. Efficacy of meningococcal serogroup $\mathrm{C}$ conjugate vaccine in teenagers and toddlers in England. Lancet 2001;357:195-196. 
Ramsay $\mathrm{ME}$, Andrews $\mathrm{NJ}$, Trotter $\mathrm{CL}$, et al. Herd immunity from meningococcal serogroup C conjugate vaccination in England: database analysis. BMJ 2003;326:365-366.

Sáfadi MA, O'Ryan M, Valenzuela Bravo MT, et al. The current situation of meningococcal disease in Latin America and updated Global Meningococcal Initiative (GMI) recommendations. Vaccine 2015;33(48):6529-36.

StataCorp. 2007.Stata Statistical Software: Release 10. College Station, TX: StataCorp LP.

Tauil MC, de Carvalho CSR, Vieira AC, et al. Meningococcal disease before and after the introduction of meningococcal serogroup $C$ conjugate vaccine. Federal District, Brazil. Braz J Infect Dis 2014;18(4):379-386.

Trotter CL, Andrews NJ, Kaczmarski EB, et al. Effectiveness of meningococcal serogroup $\mathrm{C}$ conjugate vaccine 4 years after introduction. Lancet 2004;364:365-67.

Trotter CL, Ramsay ME. Vaccination against meningococcal disease in Europe: review and recommendations for the use of conjugate vaccines. FEMS Microbiol Rev 2007;31:101-107. 


\subsection{Terceiro artigo}

Os resultados serão apresentados nesse subcapitulo em formato de artigo, e respondem ao terceiro objetivo especifico que trata da estimação da efetividade da vacina sobre a DM sorogrupo $\mathrm{C}$ em menores de cinco anos. Este trabalho será submetido à revista cientifica Vaccine. 
Efetividade da vacina meningocócica conjugada $\mathrm{C}$ contra doença meningocócica do sorogrupo $\mathrm{C}$ em menores de cinco anos de idade no Brasil, 2011-2015

Camile de Moraes ${ }^{1,4}$, Elisabeth Carmen Duarte ${ }^{2}$, Gustavo Adolfo Sierra Romero², José Cássio de Moraes ${ }^{3}$

1. Programa de Pós-Graduação em Medicina Tropical, Faculdade de Medicina, Universidade de Brasília, Brasília/DF; 2. Núcleo de Medicina Tropical, Faculdade de Medicina, Universidade de Brasília, Brasília/DF; 3. Faculdade de Ciências Médicas da Santa Casa de São Paulo, São Paulo/SP; 4. Secretaria de Vigilância em Saúde, Ministério da Saúde, Brasília/DF.

\section{RESUMO}

A vacina meningocócica $\mathrm{C}$ conjugada (MenC) foi incluída no calendário de vacinação da criança do Programa Nacional de Imunizações do Brasil (PNI/MS) a partir de 2010. A decisão para introdução da vacina MenC foi baseada na situação epidemiológica da doença, devido ao aumento das taxas de incidência do sorogrupo $\mathrm{C}$ e dos surtos em diferentes cidades brasileiras. Para estimar a efetividade da vacina foi realizado um estudo 
caso-controle não pareado em crianças menores de cinco anos que foram notificadas como casos confirmados de doença meningocócica (DM) ao sistema de vigilância das meningites entre 2011 e 2015. Foram incluídas no estudo 467 crianças com DM confirmada, sendo 151 classificadas como casos (DM sorogrupo C), e 316 como controles (DM causada por outros sorogrupos). A efetividade da vacina MenC para os menores de cinco anos como um todo foi de $89,3 \%$ (IC95\%: 83,3 a 93,$1 ; p<0,001$ ), e para os menores de um ano de idade foi de 93,0\% (IC95\%: 85,4 a 96,6; $p<0,001$ ). Os resultados deste estudo trazem evidências de que a vacina MenC apresenta uma alta efetividade no contexto brasileiro, embora haja necessidade de avaliar continuamente a efetividade da vacina MenC para verificar a proteção em longo prazo.

INTRODUÇÃO

A vacina meningocócica C conjugada (MenC) foi incluída no calendário de vacinação da criança do Programa Nacional de Imunizações do Brasil (PNI/MS) a partir de 2010 e sua implantação ocorreu de maneira progressiva e heterogênea nas diferentes Unidades Federadas. O esquema utilizado foi de duas doses aplicadas aos três e cinco meses e um reforço entre os 12 e 15 meses de idade. Crianças entre 12 e 23 meses de idade receberam uma dose da vacina durante o período de um ano contado a partir do inicio da vacinação. A decisão para introdução da vacina MenC foi baseada na situação epidemiológica da doença, caracterizada pelo aumento 
das taxas de incidência da doença meningocócica causada pelo sorogrupo C, principalmente em crianças, bem como pela recorrência de surtos em diferentes cidades brasileiras (Iser et al. 2012; Gorla et al. 2012; Liphaus et al. 2013), bem como no estudo de custo-efetividade realizado pelo Ministério da Saúde (Brasil, 2010).

A Neisseria meningitidis sorogrupo C começou a circular no Brasil com mais intensidade no início dos anos 2000, com predomínio de cepas do complexo clonal ST-103 (Lemos et al. 2007). Em 2010, 75\% dos isolados de casos de doença invasiva pertenciam ao sorogrupo C (Ibarz-Pavon et al. 2012). Apesar de acometer indivíduos de todas as faixas etárias, aproximadamente $40-50 \%$ dos casos registrados na era pré-vacina ocorriam em crianças menores de cinco anos de idade, sendo que os maiores coeficientes de incidência da doença causada pelo sorogrupo $C$ eram observados em menores de um ano, chegando a 4,9 casos/100.000 habitantes em 2010 (de Moraes 2016).

Diante do exposto, o objetivo deste estudo foi avaliar a efetividade da vacina MenC em crianças menores de cinco anos no Brasil, cinco anos após a sua introdução.

\section{METODOLOGIA}

População e período do estudo - Foram selecionadas crianças menores de cinco anos (idade elegível para vacinação) que foram registradas como 
casos confirmados de doença meningocócica (DM) ao Sistema de Informação de Agravos de Notificação (Sinan), no período de $1^{\circ}$ de janeiro de 2011 a 31 de dezembro de 2015 (data de inicio de sintomas), que tinham registro do sorogrupo causador da doença e da situação vacinal. A idade elegível para vacinação foi calculada de acordo com a data de nascimento e o mês de inicio de vacinação no estado de residência da criança, como segue: i) inicialmente foi considerado o calendário nacional de implantação da vacina para avaliação da elegibilidade das crianças segundo suas coortes de nascimento; ii) posteriormente foi considerada a data de implantação da vacina em cada estado e excluídas as crianças que não eram elegíveis para a vacinação em seu estado de residência. Foram excluídas as crianças sem informação sobre o status de vacinação (campo sobre vacinação em branco ou ignorado).

Tipo de estudo e critérios de seleção de casos e controles - Foi realizado um estudo caso-controle não pareado. Neste estudo os casos e controles apresentam a doença de interesse (neste caso, doença meningocócica), porém apenas os casos apresentam a doença causada pelo sorogrupo alvo da vacina sendo avaliada (sorogrupo C). Desta forma, casos foram todas as crianças elegíveis da população fonte cuja DM foi causada pelo sorogrupo C (DM_C). Controles foram todas as demais crianças elegíveis da população fonte, ou seja, aquelas cuja DM foi causada por outro sorogrupo - não C (DM_NC). A variável de exposição considerada foi a confirmação ou não do status sobre vacinação com a MenC, registrado na notificação do Sinan. 
Todas as crianças que apresentavam confirmação (sim) de vacina MenC foram consideradas expostas à vacinação, independente da data da vacinação, exceto aquelas com data de vacinação menor que 15 dias da data do inicio de sintoma da doença.

Fonte de dados - O banco de dados utilizado foi proveniente do Sistema de Informação de Agravos de Notificação (Sinan), no qual são registrados os casos de DM notificados ao sistema nacional de vigilância epidemiológica das meningites. $O$ banco de dados do Sinan contém variáveis epidemiológicas, do sorogrupo identificado, bem como o status vacinal de cada caso.

Análise de dados - As características da população de estudo, casos e controles foram descritas segundo idade, sexo, raça/cor, forma clínica, região de residência e data de inicio de sintomas. Na etapa analítica foram calculadas as razões de chances (OR) bruta e ajustada para a associação entre DM_C e vacinação e seus respectivos intervalos com $95 \%$ de confiança (IC95\%), assim como a significância estatística, considerando probabilidade de erro tipo I de $5 \%(p<0,05)$. A efetividade $(E)$ da vacina foi calculada com segue: $E=(1-O R) \times 100$. Nesse caso, tem-se como pressuposto que a OR é um bom estimador do Risco Relativo (RR). (Orestein et al. 1988). A estimação da OR ajustada foi feita por regressão logística, tendo como variáveis de ajuste a idade, sexo, raça/cor e região de residência. Cada variável foi avaliada separadamente nos modelos estimados. Sempre que o OR bruto sofreu mudança de $15 \%$ ou mais na sua 
magnitude quando ajustado, a variável avaliada foi considerada variável de confundimento e mantida no modelo final.

As análises foram feitas com o auxilio dos softwares Microsoft Office Excel 2010, SPSS versão 20 e STATA versão 10.

Aspectos Éticos - O estudo foi aprovado pelo Comitê de Ética em Pesquisa da Faculdade de Medicina da Universidade de Brasília sob Parecer oㅡ 908.096. O estudo utilizou apenas dados secundários não nominais de acesso publico.

\section{RESULTADOS}

Entre os anos de 2011 e 2015, o total de crianças em idade elegível para vacinação com a MenC, que estavam notificadas no Sinan como casos confirmados de DM, foi de 2.119. Destas, 840 (39,6\%) tinham a informação registrada sobre o sorogrupo causador da doença; e destas, 467 (55,5\%) tinham o registro sobre o status vacinal da MenC, e então foram incluídas no estudo. Das 467 crianças com DM, 151 foram acometidas pelo sorogrupo C, sendo classificadas como casos; e 316 foram acometidas por outros sorogrupos e foram classificadas como controles (Figura 1). Os sorogrupos identificados entre as 316 crianças classificadas como controles foram: B (76,3\%), W (18,3\%) e Y (5,4\%). 


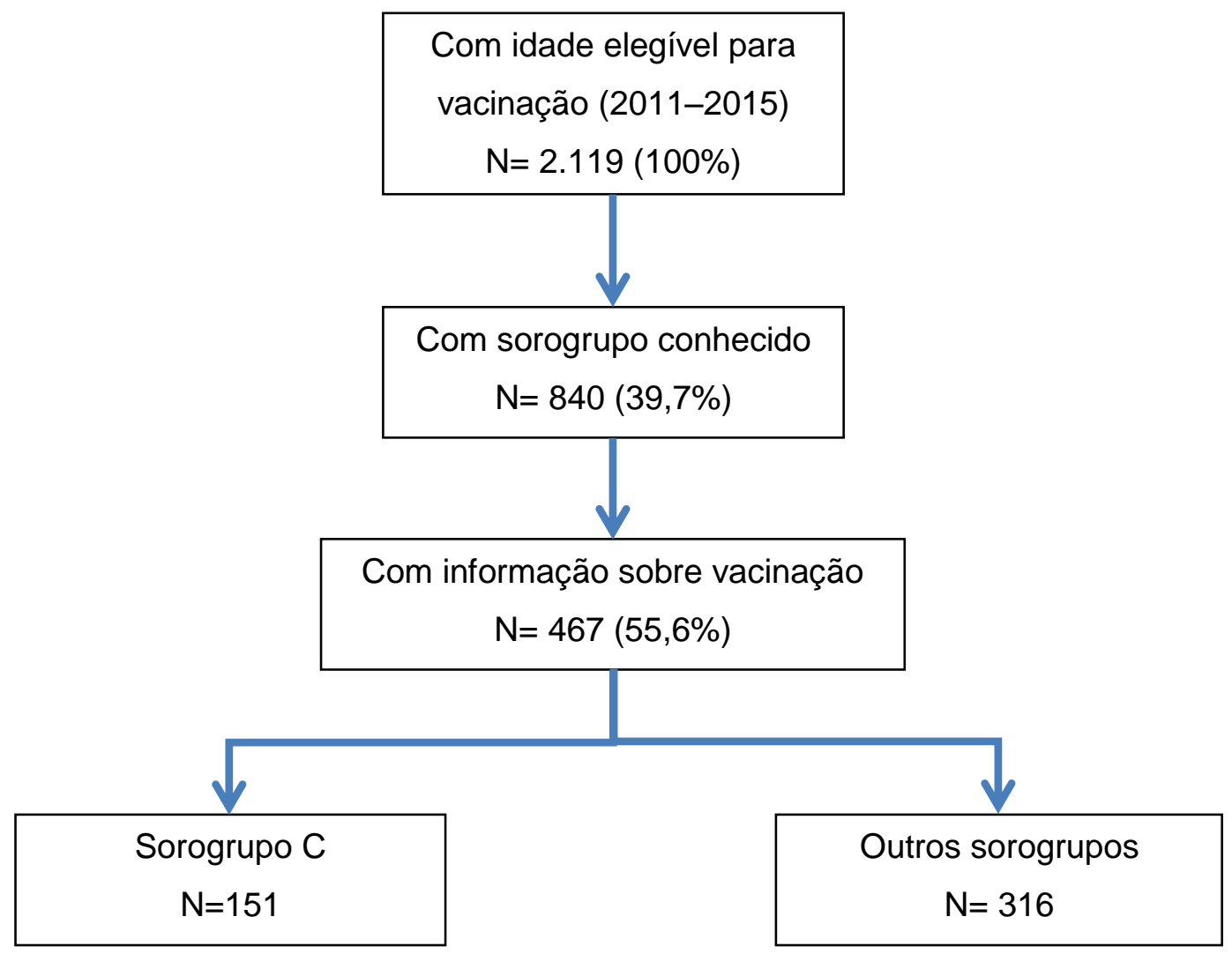

Figura 1. Fluxograma de seleção dos casos de Doença Meningocócica (DM) para o estudo (casos=casos confirmados do sorogrupo C; controles=casos confirmados de outros sorogrupos). 
Das crianças incluídas no estudo, 44,2\% ( $n=206)$ eram menores de um ano de idade; $57,4 \%(n=268)$ eram do sexo masculino; 50,3\% ( $n=235)$ eram da raça/cor branca. A meningite foi a forma clinica registrada com maior frequência $(50,8 \%)$. A taxa de letalidade foi de $17,1 \%$, para $12(2,6 \%)$ crianças, não foi registrada a evolução. A maioria das crianças residia na região Sudeste $(68,3 \%)$, seguido da Sul $(17,6 \%)$. O número de crianças menores de cinco anos que foram notificadas com DM reduziu com o passar do tempo, de 109 em 2011, para 85 em 2015, resultando em um decréscimo de 22,0\%. Em comparação aos controles, os casos foram mais frequentes nas idades: menor de um ano, de dois e de quatro anos de idade; residentes das regiões Sudeste, Nordeste, Centro Oeste e Norte, e nos anos de 2011 e 2013 (Tabela 1). 
Tabela 1: Características demográficas e clinicas da população de estudo. Brasil, 2011 a 2015.

\begin{tabular}{|c|c|c|c|c|}
\hline & & \multicolumn{3}{|c|}{ n (\%) } \\
\hline & & $\begin{array}{l}\text { Casos } \\
(n=151)\end{array}$ & $\begin{array}{c}\text { Controles } \\
(n=316)\end{array}$ & $\begin{array}{c}\text { Total } \\
(n=467)\end{array}$ \\
\hline \multirow{5}{*}{$\begin{array}{l}\text { Idade } \\
\text { (anos) }\end{array}$} & $<1$ & $68(45,0)$ & $138(43,7)$ & $206(44,2)$ \\
\hline & 1 & $20(13,2)$ & $78(24,7)$ & $98(20,1)$ \\
\hline & 2 & $29(19,2)$ & $38(12,0)$ & $67(14,3)$ \\
\hline & 3 & $17(11,3)$ & $42(13,3)$ & $59(12,6)$ \\
\hline & 4 & $17(11,3)$ & $20(6,3)$ & $37(7,9)$ \\
\hline \multirow[t]{2}{*}{ Sexo } & Masculino & $91(60,3)$ & $177(56,0)$ & $268(57,4)$ \\
\hline & Branca & $64(42,4)$ & $171(54,1)$ & $235(50,3)$ \\
\hline \multirow[t]{3}{*}{ Raça/Cor } & Parda & $55(36,4)$ & $89(27,8)$ & $143(30,6)$ \\
\hline & Preta & $9(6,0)$ & $16(5,1)$ & $25(5,3)$ \\
\hline & Ignorada & $23(15,2)$ & $41(13,0)$ & $64(13,7)$ \\
\hline Forma & Meningite & $80(53,0)$ & $157(49,7)$ & $237(50,8)$ \\
\hline \multirow[t]{2}{*}{ Clinica } & Meningococcemia & $20(13,2)$ & $49(15,5)$ & $69(14,8)$ \\
\hline & Ambas as formas & $51(33,8)$ & $110(34,8)$ & $161(34,4)$ \\
\hline \multirow{3}{*}{ Evolução } & Cura & $124(82,1)$ & $251(79,4)$ & $375(80,3)$ \\
\hline & Óbito & $25(16,6)$ & $55(17,4)$ & $80(17,1)$ \\
\hline & Ignorado & $2(1,3)$ & $10(3,2)$ & $12(2,6)$ \\
\hline \multirow{5}{*}{ Região } & Centro Oeste & $9(5,9)$ & $14(4,4)$ & $23(4,9)$ \\
\hline & Nordeste & $16(10,6)$ & $13(4,1)$ & $29(6,2)$ \\
\hline & Norte & $8(5,3)$ & $6(1,9)$ & $14(3,0)$ \\
\hline & Sudeste & $106(70,2)$ & $213(67,4)$ & $319(68,3)$ \\
\hline & Sul & $12(8,0)$ & $70(22,2)$ & $82(17,6)$ \\
\hline \multirow{5}{*}{ Ano } & 2011 & $45(29,8)$ & $64(20,2)$ & $109(23,3)$ \\
\hline & 2012 & $28(18,6)$ & $67(21,2)$ & $95(20,4)$ \\
\hline & 2013 & $34(22,5)$ & $60(19,0)$ & $94(20,1)$ \\
\hline & 2014 & $24(15,9)$ & $60(19,0)$ & $84(18,0)$ \\
\hline & 2015 & $20(13,2)$ & $65(20,6)$ & $85(18,2)$ \\
\hline
\end{tabular}


Quanto ao status da vacinação, 68,5\% (n=320) das crianças estudadas receberam pelo menos uma dose da vacina MenC. Destas, 106 $(33,1 \%)$ crianças tinham registro de uma dose, $121(37,8 \%)$ de duas doses e $92(28,8 \%)$ de três doses; para uma criança não havia o registro do número de doses recebidas.

Para estimar a efetividade, 20 crianças foram consideradas não vacinadas por terem recebido a primeira dose da vacina com intervalo menor que 15 dias do inicio dos sintomas da doença.

As proporções de vacinados entre casos e controles foram 30,5\% $(n=46)$ e $80,4 \% \quad(n=254)$, respectivamente. A proporção de vacinados aumentou com o passar do tempo tanto nos casos quanto nos controles.

A OR ajustada por região de residência foi utilizada para os grupos de crianças de um e dois anos, e para o de três e quatro anos de idade, assim como para o ano de 2011. Já a OR ajustada por idade foi utilizada para os anos de 2013 e 2015. E para o ano de 2012 a OR foi ajustada por região de residência e idade. Para as crianças menores de um ano e para o ano de 2014 nenhuma variável analisada foi considerada de confundimento segundo a decisão metodológica.

A efetividade da vacina MenC para os menores de cinco anos como um todo foi de 89,3\% (IC95\%: 83,3 a 93,1; $\mathrm{p}<0,001)$. Considerando a estratificação por grupos etários, a efetividade foi de: 93,0\% (IC95\%: 85,4 a 96,6; $p<0,001$ ) para os menores de um ano de idade; de $89,5 \%$ (IC95\%: 
74,4 a 95,7; $p<0,001$ ) para as crianças de 1 e 2 anos de idade; e de $85,0 \%$ (IC95\%: 58,7 a 94,6; $p<0,001$ ) para as crianças de 3 e 4 anos. Para o grupo de 1 a 4 anos a efetividade foi de $87,0 \%$ (IC95\%: 76,5 a 92,9; $p<0,001$ ) (Tabela 2).

A efetividade da vacina MenC foi variável entre os anos, se mantendo estável entre 2011-2012 [96,4\% (IC95\%:87,8 a 98,5; P<0,001) e 96,5\% (IC95\%: 80,3 a 99,4; <0,001), respectivamente], reduzindo nos anos de 2013 [89,9\% (IC95\%:61,1 a 97,4; 0,001)] e 2014 [83,1\% (IC95\%: 51,6 a 94,1; 0,001)], e aumentando novamente no ano de 2015 [92,9\% (IC95\%: 68,0 a 98,4; 0,001)] (Tabela 3). 
Tabela 2. Efetividade da vacina meningocócica C conjugada por grupo de idade. Brasil, 2011 a 2015.

\begin{tabular}{|c|c|c|c|c|c|}
\hline Idade (anos) & $\begin{array}{l}\text { Casos } \\
\text { n (\%) }\end{array}$ & $\begin{array}{c}\text { Controles } \\
\text { n (\%) }\end{array}$ & $\begin{array}{c}\text { OR } \\
\text { (IC95\%) }\end{array}$ & $\begin{array}{c}\text { Efetividade \% (1-OR) } \\
\text { (IC95\%) }\end{array}$ & Valor de $p$ \\
\hline$<1(\mathrm{n}=206)$ & $68(45,0)$ & $138(43,7)$ & & & \\
\hline Não Vacinados & $56(82,4)$ & $34(24,6)$ & 1,0 (REF) & -- & -- \\
\hline Vacinados & $12(17,6)$ & $104(75,4)$ & $0,070(0,034-0,146)^{\star}$ & $93,0(85,4$ a 96,6$)$ & $<0,001$ \\
\hline 1 e $2(n=165)$ & $49(32,5)$ & $116(36,7)$ & & & \\
\hline Não Vacinados & $26(53,1)$ & $15(12,9)$ & 1,0 (REF) & -- & -- \\
\hline \multirow[t]{2}{*}{ Vacinados } & $23(46,9)$ & $101(87,1)$ & $0,131(0,060-0,287)^{\star}$ & $86,9(71,3$ a 94,0$)$ & $<0,001$ \\
\hline & & & $0,105(0,043-0,256)^{\star *}$ & $89,5(74,4$ a 95,7$)$ & $<0,001$ \\
\hline 3 e $4(n=96)$ & $34(22,7)$ & $62(19,6)$ & & & \\
\hline Não Vacinados & $23(67,7)$ & $13(21,0)$ & 1,0 (REF) & -- & -- \\
\hline \multirow[t]{2}{*}{ Vacinados } & $11(32,3)$ & $49(79,0)$ & $0,127(0,049-0,326)^{\star}$ & $87,3(67,4$ a 95,1$)$ & $<0,001$ \\
\hline & & & $0,150(0,054-0,413)^{\star *}$ & $85,0(58,7$ a 94,6$)$ & $<0,001$ \\
\hline 1 a $4(n=261)$ & $83(54,9)$ & $178(56,3)$ & & & \\
\hline Não Vacinados & $49(59,0)$ & $28(15,7)$ & 1,0 (REF) & -- & -- \\
\hline Vacinados & $34(41,0)$ & $150(84,3)$ & $0,130(0,071-0,235)^{*}$ & $87,0(76,5$ a 92,9$)$ & $<0,001$ \\
\hline$<5(\mathrm{n}=467)$ & $151(100,0)$ & $316(100,0)$ & & & \\
\hline Não Vacinados & $105(69,5)$ & $62(19,6)$ & 1,0 (REF) & -- & -- \\
\hline Vacinados & $46(30,5)$ & $254(80,4)$ & $0,107(0,069-0,167)^{\star}$ & $89,3(83,3 \text { a } 93,1)^{*}$ & $<0,001$ \\
\hline
\end{tabular}

${ }^{*}$ OR bruta; ${ }^{* *}$ OR ajustada por região de residência. 
Tabela 3. Efetividade da vacina meningocócica $\mathrm{C}$ conjugada em menores de cinco anos de idade por ano. Brasil, 2011 a 2015.

\begin{tabular}{|c|c|c|c|c|c|}
\hline Ano & $\begin{array}{l}\text { Casos } \\
\text { n (\%) }\end{array}$ & $\begin{array}{c}\text { Controles } \\
\text { n (\%) }\end{array}$ & $\begin{array}{c}\text { OR } \\
\text { (IC95\%) }\end{array}$ & $\begin{array}{l}\text { Efetividade \% (1-OR) } \\
\text { (IC95\%) }\end{array}$ & Valor de $p$ \\
\hline $2011(n=109)$ & 45 & 64 & & & \\
\hline Não Vacinados & $41(91,1)$ & $21(32,8)$ & $1,0(\mathrm{REF})$ & -- & -- \\
\hline Vacinados & $4(8,9)$ & $43(67,2)$ & $\begin{array}{c}0,048(0,015-0,151)^{\star} \\
0,036(0,011-0,122)^{\star \star}\end{array}$ & $\begin{array}{l}95,2(84,9 \text { a } 98,5) \\
96,4(87,8 \text { a } 98,5)\end{array}$ & $\begin{array}{l}<0,001 \\
<0,001\end{array}$ \\
\hline $2012(n=95)$ & 28 & 67 & & & \\
\hline Não Vacinados & $21(75,0)$ & $13(19,4)$ & $1,0(\mathrm{REF})$ & -- & -- \\
\hline Vacinados & $7(25,0)$ & $54(80,6)$ & $\begin{array}{c}0,080(0,028-0,229)^{\star} \\
0,035(0,006-0,197)^{\star \star \star}\end{array}$ & $\begin{array}{l}92,0(77,1 \text { a } 97,2) \\
96,5(80,3 \text { a } 99,4)\end{array}$ & $\begin{array}{l}<0,001 \\
<0,001\end{array}$ \\
\hline $2013(n=94)$ & 34 & 60 & & & \\
\hline Não Vacinados & $22(64,7)$ & $14(23,3)$ & $1,0(\mathrm{REF})$ & -- & -- \\
\hline Vacinados & $12(35,3)$ & $46(76,7)$ & $\begin{array}{c}0,166(0,066-0,418)^{\star} \\
0,101(0,026-0,389)^{\star * \star *}\end{array}$ & $\begin{array}{l}83,4(58,2 \text { a } 93,4) \\
89,9(61,1 \text { a } 97,4)\end{array}$ & $\begin{array}{c}<0,001 \\
0,001\end{array}$ \\
\hline $2014(n=84)$ & 24 & 60 & & & \\
\hline Não Vacinados & $13(54,2)$ & $10(16,7)$ & $1,0(\mathrm{REF})$ & -- & -- \\
\hline Vacinados & $11(45,8)$ & $50(83,3)$ & $0,169(0,059-0,484)^{*}$ & $83,1(51,6$ a 94,1$)$ & 0,001 \\
\hline $2015(n=85)$ & 20 & 65 & & & \\
\hline Não Vacinados & $8(40,0)$ & $4(6,2)$ & $1,0(\mathrm{REF})$ & -- & -- \\
\hline Vacinados & $12(60,0)$ & $61(93,8)$ & $\begin{array}{c}0,098(0,025-0,380)^{*} \\
0,071(0,016-0,320)^{\star \star \star *}\end{array}$ & $\begin{array}{l}90,2(62,0 \text { a } 97,5) \\
92,9(68,0 \text { a } 98,4)\end{array}$ & $\begin{array}{l}0,001 \\
0,001\end{array}$ \\
\hline
\end{tabular}

${ }^{*}$ OR bruta; ${ }^{* *}$ OR ajustada por região de residência; ${ }^{* * *}$ OR ajustada por região de residência e idade; ${ }^{* * *}$ OR ajustada por idade. 


\section{DISCUSSÃO}

Este é o primeiro estudo que estimou a efetividade da vacina MenC contra DM do sorogrupo $\mathrm{C}$ em menores de cinco anos de idade no Brasil.

Os resultados deste estudo trazem evidências de que a vacina MenC apresenta uma alta efetividade no contexto brasileiro. Por exemplo, para crianças menores de cinco anos e menores de um ano de idade, a efetividade estimada foi de $89,3 \%$ (IC95\%: 83,3 a 93,1) e de $93,0 \%$ (IC95\%: 85,4 a 96,6), respectivamente. Estes achados reforçam a relevância da implantação da vacina MenC para o controle da doença em crianças no país, que se reflete na redução das taxas de incidência e mortalidade nos grupos alvo da vacinação, logo após sua introdução (de Moraes 2016).

O Brasil é o primeiro país a introduzir a vacina MenC onde a maioria das cepas isoladas, tanto de doença invasiva quanto de portadores assintomáticos, pertence ao complexo clonal ST-103 (Lemos et al. 2007; Ibarz-Pavon et al. 2012; de Moraes et al. 2015). A cepa que circulava com maior frequência na maioria dos países da Europa e América do Norte, que introduziram a vacina MenC em seus calendários de vacinação, pertencia ao complexo clonal ST-11 (Harrison et al. 2009; Halperin et. al. 2012). Desta forma, os estudos de efetividade da vacina MenC no contexto brasileiro são particularmente relevantes.

Os resultados aqui demonstrados são consistentes com resultados obtidos em Salvador (BA, Brasil), no Reino Unido e Espanha. Anterior à introdução da vacina no PNI/MS do Brasil, o município de Salvador, terceira 
mais populosa capital brasileira localizada na região Nordeste, enfrentou uma epidemia de doença meningocócica causada pelo sorogrupo $C$ que culminou em uma campanha de vacinação para crianças menores de cinco anos e para indivíduos de 10 a 24 anos de idade. O estudo caso-controle realizado naquela capital estimou 98\% (IC95\%: 89.8-100.0) de efetividade da vacina para os grupos alvos da vacinação (Cardoso et al. 2015). Os estudos realizados no Reino Unido e na Espanha, alguns anos após a introdução da vacina, demonstraram que efetividade foi de 66\% (IC95\%: 686) e 95.2\% (IC95\%: 91.2-97.3) para crianças imunizadas na rotina, respectivamente (Trotter et al. 2004; Laurrari et al. 2005). Estes estudos também demonstraram a redução de efetividade da vacina MenC com o passar do tempo de vacinação (Trotter et al. 2004; Laurrari et al. 2005). Com base nessas evidências, esses países mudaram o esquema vacinal utilizado incluindo uma dose de reforço após um ano de idade (Trotter \& Ramsay 2007).

Nossos resultados demonstram um gradiente de queda de efetividade da vacina com aumento da idade da criança: $93,0 \%$ (IC95\%: 85,4 a 96,6) para os menores de um ano de idade; $89,5 \%$ (IC95\%: 74,4 a 95,7) para as crianças de 1 e 2 anos de idade; e 85,0\% (IC95\%: 58,7 a 94,6) para as crianças de 3 e 4 anos. Considerando que o grupo alvo de vacinação no Brasil é o de menores de um ano de idade, os grupos mais avançados de idade incluem crianças com mais tempo de vacinação, enquanto que os grupos mais jovens (p.ex. os menores de um ano de idade) estão 
certamente, em média, com menos tempo de vacinação. Porém vale lembrar que existe grande sobreposição dos intervalos de confiança estimados (indicando que as diferenças observadas nos valores aparentemente podem ser produto do acaso).

Com relação ao período de estudo, a efetividade da vacina MenC permaneceu estável em 2011 e 2012 (em torno de 96,5\%), reduziu em 2013 e 2014 (<90\%), e voltou a aumentar em 2015 (92,9\%). Novamente deve ser ressaltado que todos os intervalos de confiança dessas estimativas de efetividade se sobrepõem marcadamente, dando evidencias de que essas variações sejam completamente atribuíveis ao acaso. Em particular no ano de 2015 o numero de casos e controles não vacinados foi muito pequeno, produzindo estimativas instáveis, devido a erro aleatório.

A despeito da dose de reforço recomendada no primeiro ano de idade, as falhas vacinais relacionadas à redução da proteção após um ano da vacinação continuam sendo um dos principais problemas (Garrido-Estepa et al. 2014). Estudos recentes têm demonstrado ainda que crianças vacinadas em idades mais jovens apresentam queda mais rápida de anticorpos protetores (anticorpos bactericidas séricos - SBA) do que aqueles indivíduos vacinados em idades mais avançadas, mantendo assim a persistência destes anticorpos por maior tempo (Snape et al. 2008; Borrow et al. 2013). Neste contexto, a vacinação de adolescentes em esquemas catch up, tem sido um auxilio adicional na manutenção de baixas taxas de incidência da doença do sorogrupo $C$ devido redução das taxas de 
portadores nestes grupos, como observado no Reino Unido, e em outros países (Borrow et al. 2013).

Em síntese, as evidências indicam que a resposta imune proporcionada pelas vacinas MenC tem relação diretamente proporcional com a idade (quanto maior a idade de aplicação da vacina mais persistente serão as taxas de anticorpos protetores) e tem relação inversamente proporcional com o tempo de vacinação da criança (a medida que o tempo da vacinação avança, menor será a efetividade da vacina). Em ambos os sentidos, a indicação de uma dose de reforço para crianças maiores, bem como a vacinação de adolescentes parece ser vantajosa para manutenção da efetividade da vacina e alcance de uma maior redução das taxas de incidência, como consequência de proteção indireta de indivíduos não vacinados.

Algumas limitações deste estudo merecem atenção. Aquelas relacionadas ao uso de fontes de dados secundários incluem a possibilidade de desvios na padronização da definição de casos, do protocolo (de boas práticas) da vacinação, bem como na aferição de variáveis relevantes, entre outros fatores. No entanto, vale lembrar que o Sinan tem sido avaliado de maneira sistemática e a sua sensibilidade para acompanhar tendências tem sido demonstrada (Azevedo et al. 2013). Além disso, os erros de informação implicados com o uso dessa base de dados são erros provavelmente não diferenciais (não associados ao status de vacinação da criança), o que resultaria em viés de informação em direção à hipótese nula, ou seja, na 
direção de subestimar a efetividade da vacina. No entanto, merece atenção o uso de variáveis com altos percentuais de informações ausentes $(60 \%$ de casos com sorogrupos não identificados; $44 \%$ de casos sem preenchimento da variável sobre condição vacinal). Os casos sem essas informações foram excluídos da análise. Essas exclusões podem ter gerado (em certo grau) viés de seleção, uma vez que essas crianças podem ser diferentes daquelas incluídas no estudo (por exemplo, em relação ao nível socioeconômico). É difícil prever se esse erro alterou ou não os resultados do estudo de maneira substancial. Contudo, vale lembrar que este é um estudo caso-controle, onde a representatividade populacional não é fundamental como a que se espera em outros delineamentos de estudo observacionais. Ademais, o elevado número de sujeitos incluídos no estudo, os resultados consistentes obtidos e na direção esperada, assim como as características coerentes do conjunto de crianças estudadas fazem supor que a representatividade de casos e de controles tenha sido preservada. Outro fator que merece reflexão é o delineamento do estudo, onde controles são crianças também doentes por DM de sorogrupo não alvo da vacinação. Esta opção metodológica assemelha casos e controles quanto ao risco de adoecer certificando que controles venham da mesma base populacional dos casos, o que é desejável em um estudo caso-controle. Como consequência, pode ter sido gerado, em certo grau, um super pareamento em relação à variável de exposição (vacinação) já que casos e controles tornaram-se mais semelhantes do que controles oriundos da população. Novamente, o resultado desse viés seria em direção à hipótese nula, ou seja, de 
subestimativa da efetividade. Outro ponto com relação ao delineamento é que o status de "vacinado" de casos e controles foi aferido sem considerar o número de doses recebidas. Essa forma de aferir pode ter gerado certa heterogeneidade na classificação de vacinados (incluindo crianças com 1, 2 ou 3 - reforço - doses) o que pode ter produzido erro de informação (provavelmente não diferencial, já que não é influenciado pelo status de ter ou não DM por sorogrupo C). Este, por sua vez, novamente, concorre para a hipótese nula, subestimando a efetividade da vacinação.

Finalmente, os resultados apresentados neste estudo demonstraram alta efetividade da vacina nos menores de cinco anos, em especial na população alvo da vacinação. Com base no observado em outros países, há necessidade de avaliação continua da efetividade para verificar a proteção da vacina a longo prazo.

\section{REFERENCIAS}

Azevedo LCP, Toscano CM, Bierrenbach AL. Bacterial meningitis in Brazil: baseline epidemiologic assessment of the decade prior to the introduction of pneumococcal and meningococcal vaccines. PLoS ONE 2013; 8:e64524.

Borrow R, Abad R, Trotter C, van der Klis FRM, Vazquez JA. Effectiveness of meningococcal serogroup C vaccine programmes. Vaccine 2013; 31 : $4477-4486$. 
Cardoso CW, Ribeiro GS, Reis MG, Flannery B, Reis JN. Effectiveness of meningococcal C conjugate vaccine in Salvador, Brazil: a case-control study. PLoS ONE 2015; 10: e0123734.

Garrido-Estepa M, León-Gómez I, Herruzo R, Cano R. Changes in meningococcal $\mathrm{C}$ epidemiology and vaccine effectiveness after vaccine introduction and schedule modification. Vaccine 2014; 32: 2604-2609.

Gorla MC, de Lemos AP, Quaresma M, Vilasboas R, Marques O et al. Phenotypic and molecular characterization of serogroup C Neisseria meningitidis associated with an outbreak in Bahia, Brazil. Enferm Infecc Microbiol Clin 2012;30:56-9.

Halperin SA, Bettinger JA, Greenwood B, Harrison H, Jelfs J, Ladhani SN et al. The changing and dynamic epidemiology of meningococcal disease. Vaccine 2012;30: B26-36.

Harrison LH, Trotter CL, Ramsay ME. Global epidemiology of meningococcal disease. Vaccine 2009; 27S: B51-B63.

Iser BPM, Lima HCAV, de Moraes C, de Almeida RPA, Watanabe LT, Alves SLA et al. Outbreak of Neisseria meningitidis $\mathrm{C}$ in workers at a large foodprocessing plant in Brazil: challenges of controlling disease spread to the larger community. Epidemiol Infect 2012;140:906-915.

Lemos APS, Yara TY, Gorla MCO, et al. Clonal distribution of invasive Neisseria meningitides serogroup C strains circulating from 1976 to 2005 in Greater São Paulo, Brazil. J Clin Microbiol 2007;45:1266-1273. 
Liphaus BL, Cappeletti-Gonçalves-Okai MI, Silva-Delemos AP, Gorla MC, Rodriguez-Fernandes $\mathrm{M}$ et al. Outbreak of Neisseria meningitidis $\mathrm{C}$ in a Brazilian oil refinery involving an adjacent community. Enferm Infecc Microbiol Clin. 2013 Feb;31(2):88-92.

Orenstein W, Bernier RH and Hinman AR. Assessing vaccine efficacy in the field: further observations. Epidemiol Rev 1988; 10:212-241.

Snape MD, Kelly DF, Lewis S, Banner C, Kibwana L et al. Seroprotection against serogroup $\mathrm{C}$ meningococcal disease in adolescents in the United Kingdom: observational study. BMJ 2008;336:1487-91.

Trotter CL, Ramsay ME. Vaccination against meningococcal disease in Europe: review and recommendations for the use of conjugate vaccines. FEMS Microbiol Rev. 2007; 31: 101-107. 


\section{CONSIDERAÇÕES FINAIS}

De maneira geral, no período de estudo (2001 a 2013) a DM no Brasil pode ser caracterizada como endêmica, com taxas de incidência mais baixas do que as observadas na década de 1990. As taxas da DM total (considerando todos os sorogrupos) apresentaram tendência de redução, fato relacionado a redução as taxas do sorogrupo $B$, enquanto que as taxas da DM do sorogrupo C aumentaram. Além disso, foi observado aumento expressivo da taxa de letalidade do sorogrupo C.

O aprimoramento da vigilância da doença no Brasil é essencial e para isso ações voltadas para melhoria do diagnóstico laboratorial, para o consequente aumento do percentual de identificação etiológica são particularmente importantes para acompanhamento epidemiológico mais acurado da doença. A elaboração de protocolos clínicos que abordem o diagnóstico e tratamento precoces, bem como a capacitação de profissionais de saúde no manejo adequado dos pacientes, pode auxiliar na redução da taxa de letalidade.

Para conter o avanço da doença, em 2010, foi adotada como medida de intervenção a vacina MenC, que teve como objetivo imunizar as crianças menores de dois anos de idade, em especial os lactentes. A avaliação desta intervenção foi realizada nesta tese por meio de dois estudos observacionais, um com o objetivo de avaliar o impacto da vacina sob as 
taxas de incidência da DM sorogrupo $C$ e outro de avaliar a efetividade da vacina em crianças menores de cinco anos de idade.

Os resultados apontam relevante impacto direto da vacina MenC logo após a sua introdução, com redução importante das taxas de incidência de DM sorogrupo $\mathrm{C}$ em crianças menores de um ano de idade (grupo alvo da vacinação) e entre crianças menores de cinco anos. Estes resultados foram coerentes com os achados de alta efetividade da vacina MenC observada para estes grupos de crianças.

O perfil da DM no Brasil difere entre as regiões, e os resultados apontaram para diferentes estimativas de impacto da vacina entre elas. Frente a isto é recomendável que avaliações futuras sejam realizadas considerando este diferencial. As menores estimativas de impacto observadas nas regiões Nordeste e Sul merecem atenção, porém estas regiões apresentavam menores taxas de incidência de DM sorogrupo $\mathrm{C}$ e portanto reduções mais discretas no período pós-vacinação. Para a região Nordeste as coberturas vacinais abaixo da meta preconizada pelo PNI/MS (>95\%), nos anos de 2011 e 2012, também pode ter influenciado este achado.

Com respeito a validade externa do estudo, vale lembrar a exclusão da região Norte das analises devido ao pequeno número de casos na avaliação de impacto da vacinação, o que indica a necessidade de aprofundamento em estudos futuros e limita a capacidade de generalização de nossos resultados para essa região. 
Com respeito a validade interna dos resultados, vale lembrar as limitações inerentes a estudos que usam dados secundários, em particular, a proporção de casos cujos sorogrupos eram indeterminados, e a consequente necessidade de redistribuição destes casos; e certa proporção de casos e controle com status vacinal não informado no estudo de efetividade da vacina. No entanto, o Sinan tem sido considerado um sistema de informação robusto com grande captação de casos em todo o território nacional. Ademais, os dois delineamentos metodológicos utilizados permitiram demonstrar a utilidade desse sistema de informação na geração de estudos analíticos com objetivo avaliativo, e os resultados encontrados foram consistentes e reforçam a tese de adequação dos dados analisados. Evidentemente estudos futuros com dados primários, particularmente com o objetivo de monitorar a resposta da vacina a longo prazo, poderão completar nossos resultados.

A despeito dos bons resultados sobre a vacina MenC aqui observados, é necessário que sejam consideradas e discutidas algumas estratégias complementares para ampliar a proteção contra a DM no país. Entre elas estaria a avaliação sobre a vacinação de adolescentes, que tem como objetivo a manutenção e redução das taxas de incidência, por meio do impacto indireto alcançado com a vacinação destes indivíduos. Outro ponto diz respeito a avaliação continuada da efetividade da vacina a longo prazo, a ser considerada como ação de vigilância. Este acompanhamento se faz necessário devido ao fato da efetividade da vacina reduzir à medida que o 
tempo de vacinação avança. Fato este relacionado com a resposta imune de indivíduos vacinados em idades mais precoces como é o esquema utilizado no Brasil (nestes indivíduos os títulos de anticorpos bactericidas circulantes reduzem com o passar do tempo), trazendo à tona a necessidade de discussão sobre a implantação de dose de reforço para estas crianças. 


\section{REFERENCIAS BIBLIOGRAFICAS}

American Academy of Pediatrics. Committee on Infectious Diseases. Recommendations for Serogroup B Meningococcal Vaccine for Persons 10 Years and Older. Pediatrics. 2016; 138(3):e20161890.

Auckland C, Gray S, Borrow R, Andrews N, Goldblatt D et al. Clinical and immunologic risk factors for meningococcal $\mathrm{C}$ conjugate vaccine failure in the United Kingdom. J Infect Dis 2006; 194:1745-52.

Azevedo LCP, Toscano CM, Bierrenbach AL. Bacterial meningitis in Brazil: baseline epidemiologic assessment of the decade prior to the introduction of pneumococcal and meningococcal vaccines. PLoS ONE. 2013; 8(6):e64524.

Balmer $\mathrm{P}$, Borrow R, Miller E.Impact of meningococcal $\mathrm{C}$ conjugate vaccine in the UK. J Med Microbiol. 2002; 51(9):717-22.

Barroso DE. Doença Meningocócica In: Medicina Tropical - Abordagem atual das doenças infecciosas e parasitárias. Batista RS, Gomes AP, Igreja RP, Huggins DW. Ed. Cultura Médica, 521-549, 2000.

Bettinger JA, Scheifele DW, Le Saux N, Halperin SA, Vaudry W, Tsang R, et al. The impact of childhood meningococcal serogroup $C$ conjugate vaccine programs in Canada. Pediatr Infect Dis J. 2009; 28: 220-224. 
Borrow R, Abad R, Trotter C, van der Klis FRM, Vazquez JA. Effectiveness of meningococcal serogroup C vaccine programmes. Vaccine 2013; $31: 4477-4486$.

Brasil. Ministério da Saúde. Nota técnica. Introdução da vacina meningocócica C (conjugada) no calendário de vacinação da criança. 2010.

Brasil. Ministério da Saúde. Secretaria de Vigilância em Saúde. Departamento de Análise de Situação em Saúde. Saúde Brasil 2012: uma análise da situação de saúde e dos 40 anos do Programa Nacional de Imunizações. 1. Ed. rev. - Brasília: Editora do Ministério da Saúde, 2014. 536 p.: il.

Brasil. Ministério da Saúde. Secretaria de Vigilância em Saúde. Vigilância de A a Z. Meningites. Situação Epidemiológica - Dados. Disponível em: < http://portalsaude.saude.gov.br/images/pdf/2016/outubro/33/tabela-20002015 meningite.pdf > Acesso em: agosto 2016.

Brasil. Ministério da Saúde. Secretaria de Vigilância em Saúde. Sistema de Informação de Agravos de Notificação. Disponível em: $<$ http://dtr2004.saude.gov.br/sinanweb/tabnet/dh?sinan/meningite/bases/men inbr.def> Acesso em: agosto 2015. 
Brasil. Ministério da Saúde. Secretaria de Vigilância em Saúde. Sistema de Informação de Nascidos Vivos. Disponível em: $<$ http://tabnet.datasus.gov.br/cgi/deftohtm.exe?sinasc/cnv/nvuf.def $>$ Acesso em: agosto 2015.

Brasil. Ministério da Saúde. Secretaria de Vigilância em Saúde. Programa Nacional de Imunizações. Sistema de informação do Programa Nacional de Imunização.

Disponível

em:

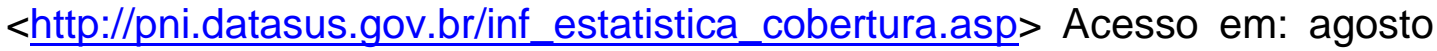
2015.

Brasil. Ministério da Saúde. Secretaria de Vigilância em Saúde. Guia de Vigilância em Saúde. Disponível em: $<$ http://portalsaude.saude.gov.br/images/pdf/2014/novembro/27/guiavigilancia-saude-linkado-27-11-14.pdf> Acesso em: agosto 2016.

Brasil. Ministério do Planejamento, Orçamento e Gestão. Instituto Brasileiro de Geografia e Estatística. Diretoria de Pesquisas. Coordenação de População e Indicadores Sociais. Gerência de Estudos e Análises da Dinâmica Demográfica. Projeção da população do Brasil por sexo e idade para 0 período 2000-2060. Disponível em: $<$ http://www.ibge.gov.br/home/estatistica/populacao/projecao da populacao/ 2013/default tab.shtm> Acesso em: agosto de 2015 . 
Brooks R, Woods CW, Benjamin DK, and Rosenstein NE. Increased CaseFatality Rate Associated with Outbreaks of Neisseria meningitidis Infection, Compared with Sporadic Meningococcal Disease, in the United States, 1994-2002. CID 2006; 43:49-54

Campbell H, Borrow R, Salisbury D, Miller E. Meningococcal C conjugate vaccine: the experience in England and Wales. Vaccine. 2009; 27S:B20B29.

Campbell H, Andrews N, Borrow R, Trotter C, Miller E. Updated postlicensure surveillance of the meningococcal $C$ conjugate vaccine in England and Wales: effectiveness, validation of serological correlates of protection, and modeling predictions of the duration of herd immunity. Clin Vaccine Immunol. 2010; 17:840-847.

Cano R, Larrauri A, Mateo S, Alcalá B, Salcedo C, Vázquez JA. Impact of the meningococcal C conjugate vaccine in Spain: an epidemiological and microbiological decision. Euro Surveill. 2004; 9:11-5.

Cardoso CW, Pinto LLS, Reis MG, Flannery B, Reis JN. Impact of vaccination during an epidemic of serogroup $C$ meningococcal disease in Salvador, Brazil. Vaccine. 2012; 30:5541-5546. 
Cardoso CW, Ribeiro GS, Reis MG, Flannery B, Reis JN. Effectiveness of meningococcal C conjugate vaccine in Salvador, Brazil: a case-control study. PLoS ONE. 2015; 10(4):e0123734.

Caugant DA. Genetics and evolution of Neisseria meningitidis: Importance for the epidemiology of meningococcal disease. Infect Gen Evol. 2008: 558565.

Caugant DA, Maiden MCJ. Meningococcal carriage and disease - Population biology and evolution. Vaccine. 2009; 27S:B64-B70.

Christensen H, May M, Bowen L, Hickman M, Trotter CL. Meningococcal carriage by age: a systematic review and meta-analysis. Lancet Infect Dis. 2010; 10: 853-61.

Collard J-M, Issaka B, Zaneidou M, Hugonnet S, Nicolas P, Taha M-K, et al. Epidemiological changes in meningococcal meningitis in Niger from 2008 to 2011 and the impact of vaccination. BMC Infect Dis. 2013; 13:576.

Cohn AC, MacNeil JR, Harrison LH, Hatcher C, Theodore $\mathrm{J}$ et al. Changes in Neisseria meningitidis Disease Epidemiology in the United States, 19982007: Implications for Prevention of Meningococcal Disease. CID 2010; $50: 184-91$. 
Cordeiro SM, Neves AB, Ribeiro CT, Petersen ML, Gouveia EL et al. Hospital-based surveillance of meningococcal meningitis in Salvador, Brazil. Trans R Soc Trop Med Hyg. 2007; 101:1147-1153.

de Moraes JC, Kemp B, de Lemos APS, Gorla MCO, Marques EGL et al. Prevalence, Risk Factors and Molecular Characteristics of Meningococcal Carriage Among Brazilian Adolescents. Pediatr Infect Dis J. 2015; 34:11971202.

de Souza SF, Costa MCN, Paim JS, da Natividade MS, Pereira SM et al. Bacterial meningitis and living conditions. Rev Soc Bras Med Trop. 2012; 45:323-8.

Gama SG, Marzochi KBF, Filho GBS. Caracterização epidemiológica da doença meningocócica na área metropolitana do Rio de Janeiro, Brasil, 1976 a 1994. Rev Saúde Pública. 1997; 31:254-62.

Garrido-Estepa M, León-Gómez I, Herruzo R, Cano R. Changes in meningococcal C epidemiology and vaccine effectiveness after vaccine introduction and schedule modification. Vaccine. 2014; 32:2604-2609.

Gorla MC, de Lemos AP, Quaresma M, Vilasboas R, Marques O et al. Phenotypic and molecular characterization of serogroup C Neisseria 
meningitidis associated with an outbreak in Bahia, Brazil. Enferm Infecc Microbiol Clin. 2012; 30:56-9.

Greenwood B. Editorial: 100 years of epidemic meningitis in West Africahas anything changed? Trop Med Int Health. 2006; 11:773-80.

Halperin SA; Bettinger JA; Greenwood B, Harrison H, Jelfs J, Ladhani SN et al. The changing and dynamic epidemiology of meningococcal disease. Vaccine; 2012; 30 Suppl 2:B26-36.

Harrison LH, Trotter CL, Ramsay ME. Global epidemiology of meningococcal disease. Vaccine. 2009; 27S:B51-B63.

Harrison OB, Claus $\mathrm{H}$, Jiang $\mathrm{Y}$, Bennett JS, Bratcher HB, Jolley KA, et al. Description and nomenclature of Neisseria meningitidis capsule locus. Emerg Infect Dis. 2013; 19(4):566-573.

Hsiao, C. Panel data analysis-advantages and challenges. TEST. 2007; 16(1):1-22.

Ibarz-Pavon AB, Lemos AP, Gorla MC, et al. Laboratory-Based Surveillance of Neisseria meningitidis isolates from Disease Cases in Latin American and Caribbean Countries, SIREVA II 2006-2010. PLoS ONE. 2012; 7(8):e44102. 
Iser BPM, Lima HCAV, de Moraes C, de Almeida RPA, Watanabe LT, Alves SLA et al. Outbreak of Neisseria meningitidis $C$ in workers at a large foodprocessing plant in Brazil: challenges of controlling disease spread to the larger community. Epidemiol Infect. 2012; 140:906-915.

Jensen ES, Schønheyder HC, Lind I, Berthelsen L, Nørga B et al. Neisseria meningitidis phenotypic markers and septicaemia, disease progress and case-fatality rate of meningococcal disease: a 20-year population based historical follow-up study in a Danish county. J Med Microbiol. 2003; 52:173179.

Kinlin LM, Jamieson F, Brown EM, Brown S, Rawte P, Dolman S, et al. Rapid identification of herd effects with the introduction of serogroup $C$ meningococcal conjugate vaccine in Ontario, Canada, 2000-2006. Vaccine. $2009 ; 27: 1735-1740$.

Larrauri A, Cano R, Garcia M, de Mateo S. Impact and effectiveness of meningococcal C conjugate vaccine following its introduction in Spain. Vaccine. 2005; 23:4097-4100.

Lemos APS, Brandão AP, Gorla MCO, Paiva MV, Simonsen V, Melles CE. Phenotypic characterization of Neisseria meningitidis strains isolated from invasive disease in Brazil from 1990 to 2001. J Med Microbio. 2006; 55:751757. 
Lemos APS, Yara TY, Gorla MCO, de Paiva MV, de Souza AL, Gonçalves MIC, et al. Clonal distribution of invasive Neisseria meningitides serogroup C strains circulating from 1976 to 2005 in Greater São Paulo, Brazil. J Clin Microbiol. 2007; 45:1266-1273.

Liphaus BL, Cappeletti-Gonçalves-Okai MI, Silva-Delemos AP, Gorla MC, Rodriguez-Fernandes $\mathrm{M}$ et al. Outbreak of Neisseria meningitidis $\mathrm{C}$ in a Brazilian oil refinery involving an adjacent community. Enferm Infecc Microbiol Clin. 2013; 31(2):88-92.

MacNeil JR, Medah I, Koussoubé D, Novak RT, Cohn AC, Diomandé FVK et al. Neisseria meningitidis Serogroup W, Burkina Faso, 2012. Emerging Infectious Diseases. 2014; 20 (3):394-99.

Maiden MCJ, Bygraves JA, Feil E, Morelli G, Russell JE, Urwin R, et al. Multilocus sequence typing: a portable approach to the identification of clones within populations of pathogenic microorganisms. Proc Natl Acad Sci USA. 1998; 95:3140-3145.

Maiden MCJ, Ibarz-Pavón AB, Urwin R, Gray SJ, Andrews NJ, Clarke SC, et al. Impact of meningococcal serogroup $C$ conjugate vaccines on carriage and herd immunity. J Infect Dis. 2008; 197:737-43. 
Maiden MCJ, Frosch M. Can we, should we, eradicate the meningococcus? Vaccine. 2012; 30S:B52- B56.

Maiden MCJ, Harrison OB. Population and functional genomics of Neisseria revealed with gene-by-gene approaches. J Clin Microbiol. 2016; 54:19491955.

Masuda ET, Carvalhanas TR, Fernandes RM, Casagrande ST, Okada OS et al. Mortalidade por doença meningocócica no Município de São Paulo, Brasil: características e preditores. Cad Saúde Pública. 2015; 31:405-416.

Miller E, Salisbury D, Ramsay M. Planning, registration, and implementation of an immunisation campaign against meningococcal serogroup $\mathrm{C}$ disease in the UK: a success story. Vaccine. 2002; 20:S58-S67.

Mooney JD, Christie P, Robertson C, et al. The impact of meningococcal serogroup C conjugate vaccine in Scotland. Clin Infect Dis. 2004; 39(3):349356.

Moraes JC, Barata RB. A doença meningocócica em São Paulo. Brasil, no século XX: características epidemiológicas. Cad Saúde Pública. 2005; $21: 1458-71$. 
Morgenstern H. Ecologic studies in epidemiology: concepts, principles, and methods. Annu Rev Public Health. 1995; 16:61-81.

Noronha CP, Baran M, Nicolai CCA, Azevedo MB, Bernardes ATO, Monteiro GTR et al. Epidemiologia da doença meningocócica na cidade do Rio de Janeiro: modificações após vacinação contra os sorogrupos B e C. Cad. Saúde Pública. 1997; 13:295-303.

Orenstein WA, Bernier RH, Hinman AR. Assessing vaccine efficacy in the field. Further observations. Epidemiol Rev. 1988; 10:212-41.

Pan American Health Organization. Informe regional de SIREVA II: datos por país y por grupos de edad sobre las características de los aislmientos de Streptococcus pneumoniae, Haemophilus influenzae y Neisseria meningitidis, em procesos invasores, 2000-2005. Documentos Técnicos, Tecnologías Esenciales de Salud. THS/EV. 2007/002, Washington, DC: Pan American Health Organization, 2007. Disponível em: $<$ http://www.paho.org/Spanish/AD/THS/EV/LABS-Sireva.pdf> Acesso em: Agosto de 2015.

Pelton SI. The Global Evolution of Meningococcal Epidemiology Following the Introduction of Meningococcal Vaccines. J Adolesc Health. 2016; 59:S3S11. 
Perrett KP, Winter AP, Kibwana E, Jin C, John TM, Yu LM, et al. Antibody persistence after serogroup C meningococcal conjugate immunization of United Kingdom primary-school children in 1999-2000 and response to a booster: a phase 4 clinical trial. Clin Infect Dis. 2010; 50:1601-10.

Ramsay ME, Andrews N, Kaczmarski EB, Miller E. Efficacy of meningococcal serogroup $\mathrm{C}$ conjugate vaccine in teenagers and toddlers in England. Lancet. $2001 ; 357: 195-196$.

Ramsay ME, Andrews NJ, Trotter CL, Kaczmarski EB, Miller E. Herd immunity from meningococcal serogroup $\mathrm{C}$ conjugate vaccination in England: database analysis. BMJ. 2003; 326:365-366.

Rosenstein NE, Perkins BA, Stephens DS, Popovic T, Hughes JM. Meningococcal disease. N Engl J Med. 2001; 344(18):1378-88.

Sacchi CT, Fukasawa LO, Gonçalves MG, Salgado MM, Shutt KA et al. Incorporation of Real-Time PCR into Routine Public Health Surveillance of Culture Negative Bacterial Meningitis in São Paulo, Brazil. PLoS ONE. 2011;6:e20675.

Sáfadi MA, Barros AP. Meningococcal conjugate vaccines: efficacy and new combinations. J Pediatr (Rio J). 2006; 82:S35-44. 
Safadi MAP, Cintra OAL. Epidemiology of meningococcal disease in Latin America: current situation and opportunities for prevention. Neurol Res. 2010; 32:263-71.

Sáfadi MAP, Berezin EN, Oselka GW. Neisseria meningitidis, meningococcal disease, conjugate meningococcal vaccines. J Pediatr (Rio J). 2012; 88(3):195-202.

Sáfadi MAP, Gonzalez S, Jakel A, Wieffer H, Moreno C, Vyse A. The epidemiology of meningococcal disease in Latin America 1945-2010: an unpredictable and changing landscape. Epidemiol Infect. 2013; 141:447-458.

Sáfadi MA, O'Ryan M, Valenzuela Bravo MT, et al. The current situation of meningococcal disease in Latin America and updated Global Meningococcal Initiative (GMI) recommendations. Vaccine 2015; 33(48):6529-36.

Smith I, Caugant DA, Høiby EA, Wentzel-Larsen T and Halstensen A. High case-fatality rates of meningococcal disease in Western Norway caused by serogroup C strains belonging to both sequence type (ST)-32 and ST-11 complexes, 1985-2002. Epidemiol. Infect 2006; 134:1195-1202.

Snape MD, Kelly DF, Lewis S, Banner C, Kibwana L, Moore CE, et al. Seroprotection against serogroup $\mathrm{C}$ meningococcal disease in adolescents in the United Kingdom: observational study. BMJ. 2008; 336:1487-91. 
StataCorp. 2007.Stata Statistical Software: Release 10. College Station, TX: StataCorp LP.

Stephens DS, Greenwood B, Brandtzaeg P. Epidemic meningitis, meningococcaemia, and Neisseria meningitidis. Lancet. 2007; 369:2196210.

Stephens DS. Biology and pathogenesis of the evolutionarily successful, obligate human bacterium Neisseria meningitidis. Vaccine. 2009; 27S:B71B77.

Tan LKK, Carlone GM, and Borrow R. Advances in the Development of Vaccines against Neisseria meningitidis. N Engl J Med. 2010; 362:1511-20.

Tauil MC, de Carvalho CSR, Vieira AC, Waldman EA. Meningococcal disease before and after the introduction of meningococcal serogroup $\mathrm{C}$ conjugate vaccine. Federal District, Brazil. Braz J Infect Dis. 2014; 18:379_ 386.

Trotter CL, Andrews NJ, Kaczmarski EB, Miller E, Ramsay ME. Effectiveness of meningococcal serogroup $\mathrm{C}$ conjugate vaccine 4 years after introduction. Lancet. 2004; 364:365-67. 
Trotter CL, Ramsay ME. Vaccination against meningococcal disease in Europe: review and recommendations for the use of conjugate vaccines. FEMS Microbiol Rev. 2007; 31:101-107.

World Health Organization. Meningococcal vaccines: WHO position paper, November 2011. Weekly Epidemiological Record. 2011; 86:521-540.

World Health Organization. WHO, 2013. Meningococcal disease: 2013 epidemic season in the African Meningitis Belt. Disponível em: $<$ http://www.who.int/csr/don/2013 0606 menin/en/> Acesso em: 15.06.2015.

World Health Organization. WHO, 2015. Rapidly growing outbreak of meningococcal disease in Niger. Disponível em: $<$ http://www.who.int/csr/don/15-may-2015-niger/en/> Acesso em: 15.06.2015.

Xu X-H, Ye Y, Hu LF, Jin Y-H, Jiang Q-Q et al. Emergence of serogroup C meningococcal disease associated with a high mortality rate in Hefei, China. BMC Infectious Diseases. 2012;12:205. 